


\section{GEORGIA \\ COUNTRY GENDER ASSESSMENT}

DECEMBER 2018 
(C) 2018 Asian Development Bank

6 ADB Avenue, Mandaluyong City, 1550 Metro Manila, Philippines

Tel +632632 4444; Fax +6326362444

www.adb.org

Some rights reserved. Published in 2018.

ISBN 978-92-9261-472-0 (print), 978-92-9261-473-7 (electronic)

Publication Stock No. TCS189794-2

DOI: http://dx.doi.org/10.22617/TCS189794-2

The views expressed in this publication are those of the authors and do not necessarily reflect the views and policies of the Asian Development Bank (ADB) or its Board of Governors or the governments they represent.

$\mathrm{ADB}$ does not guarantee the accuracy of the data included in this publication and accepts no responsibility for any consequence of their use. The mention of specific companies or products of manufacturers does not imply that they are endorsed or recommended by ADB in preference to others of a similar nature that are not mentioned.

By making any designation of or reference to a particular territory or geographic area, or by using the term "country" in this document, $\mathrm{ADB}$ does not intend to make any judgments as to the legal or other status of any territory or area.

This work is available under the Creative Commons Attribution 3.0 IGO license (CC BY 3.0 IGO)

https://creativecommons.org/licenses/by/3.0/igo/. By using the content of this publication, you agree to be bound by the terms of this license. For attribution, translations, adaptations, and permissions, please read the provisions and terms of use at https://www.adb.org/terms-use\#openaccess.

This CC license does not apply to non-ADB copyright materials in this publication. If the material is attributed to another source, please contact the copyright owner or publisher of that source for permission to reproduce it. ADB cannot be held liable for any claims that arise as a result of your use of the material.

Please contact pubsmarketing@adb.org if you have questions or comments with respect to content, or if you wish to obtain copyright permission for your intended use that does not fall within these terms, or for permission to use the ADB logo.

Notes:

In this publication, “\$” refers to United States dollars.

ADB recognizes "Russia" as the Russian Federation.

Corrigenda to ADB publications may be found at http://www.adb.org/publications/corrigenda.

On the cover: Empowering women and girls. ADB projects in Georgia help improve women's access to jobs and livelihood opportunities through education and training in non-traditional occupations, and creating an enabling environment for women's economic empowerment (ADB Photo Library; Ketevan Chkheidze; United Water Supply Company of Georgia). 


\section{Contents}

Tables and Boxes

Acknowledgments

Abbreviations

Terminology

viii

Executive Summary

$\mathrm{X}$

I. Introduction

A. Purpose of the Report 1

B. Methodology 1

II. Background and Context 2

A. Economic and Political Context 2

B. International Ranking and Indicators on Gender 5

C. Gender Equality Policies and Commitments 6

III. Cross-Cutting Gender Issues 11

A. The Persistence of Traditional Gender Stereotypes and Norms 11

B. Women and Political Representation 14

C. Women's Economic Empowerment $\quad 15$

D. Human Development 20

E. Violence against Women 23

F. The Sex Ratio Gap 28

G. Specific Challenges for Conflict-Affected Women and Girls 28

H. Activism on Gender Equality and Women's Rights 30

IV. Asian Development Bank in Georgia 32

A. ADB Gender Policy and Processes 32

B. ADB in Georgia 34

C. Mainstreaming Gender in ADB's Operations and Priority Sectors in Georgia 34

$\begin{array}{ll}\text { Conclusion } & 59\end{array}$

$\begin{array}{ll}\text { References } & 62\end{array}$

$\begin{array}{ll}\text { Appendix: List of Key Informants } & 67\end{array}$ 


\section{Tables and Boxes}

\section{Tables}

$1 \quad$ Key Indicators for Georgia, 2018

2 Comparative Gender Equality Ranking of Georgia for South Caucasus Region 5 and Central Asia Former Soviet Union Countries

3 Comparative Ranking of Georgia for Women's Political Representation 15 for South Caucasus Region and Central Asia Former Soviet Union Countries

\section{Boxes}

1 Georgia State Concept on Gender Equality

2 Engaging Georgia's Rugby Players in Shifting Gender Norms and Assumptions $\quad 13$

3 The United Nations Global Compact 16

4 Current Status of Domestic Violence Shelters and Crisis Centers in Georgia 26

5 Some Key Gender Statistics for Georgia 31

6 Key Elements of ADB's Gender Policy $\quad 32$

7 Testimonial of a Female Public Transport Customer in Tbilisi 38

8 Addressing Social Dimensions of Transport 42

9 Water Supply in Poti: Impacts for Women and their Families 46

10 Gender Entry Points for Project Designs in Energy Subsectors 54

11 Supporting Female Entrepreneurs through a Targeted Approach 56 


\section{Acknowledgments}

The Country Gender Assessment (CGA) was prepared under the Asian Development Bank (ADB) Regional Technical Assistance (RETA) 9088: Strengthening Gender-Inclusive Growth in Central and West Asia. The overall CGA process was supervised by the Central and West Asia Department (CWRD) gender team, comprising Mary Alice Rosero (social development specialist on gender and development); Ketevan Chkheidze (international implementation consultant and gender specialist based in Georgia); and Leavides G. Domingo-Cabarrubias, (gender consultant). Maria Ava Golda Destura and Fritz Tadeo Tuliao provided invaluable assistance to navigate ADB's financial and logistical systems. We also acknowledge the important contributions of staff from ADB's Resident Mission in Georgia, specifically Michiel Van der Auwera, head of portfolio administration unit; George Luarsabishvili, economics officer; and Tea Papuashvili, associate project analyst-for providing guidance and constructive inputs to improve the writing and presentation of data in various sections of the document.

Alyson Brody (gender and social development consultant) researched and wrote the CGA.

We are grateful for the full support of the CWRD management team: Yesim Elhan-Kayalar (Georgia Resident Mission country director); Nianshan Zhang (advisor and head of the Portfolio, Results, Safeguards and Gender Unit); Hong Wei (deputy director general); and Werner Liepach (director general).

The report benefited from valuable inputs of sector specialist peer reviewers: Atsumasa Sakai, energy specialist, CWEN; Priyanka Sood, senior financial sector specialist, CWPF; Kenji Takamiya, principal economist, CWRC; and Maureen Mamayson, project analyst, CWTC. ADB's Gender Equality Thematic Group and SDTC-Gender team, led by Sonomi Tanaka, provided insightful comments, specifically from reviews by Keiko Nowacka, social development specialist (gender and development), and Malika Shagazatova, gender consultant.

The CGA team would like to convey appreciation and gratitude to the Government of Georgia and the staff and representatives from the various ministries and government agencies for their support, technical inputs, and participation during interviews and focus group discussions. We would like to recognize members of the Inter-Agency Commission on Gender Equality, Violence against Women and Domestic Violence for their detailed comments on the document: Sopio Japaridze, chair of the commission and assistant to the Prime Minister of Georgia on Human Rights and Gender Equality Issues; Mariam Jajanidze, advisor to the Human Rights Secretary, Prime Minister's Office of Georgia; Margaret Shakarashvili, European Union project expert; and Marika Jobava, consultant, UN Women Project Component on Supporting the Commission.

We are also grateful to our development partners and civil society organizations for sharing their expertise and experiences in advancing women's empowerment and gender equality in Georgia. 


\section{Abbreviations}

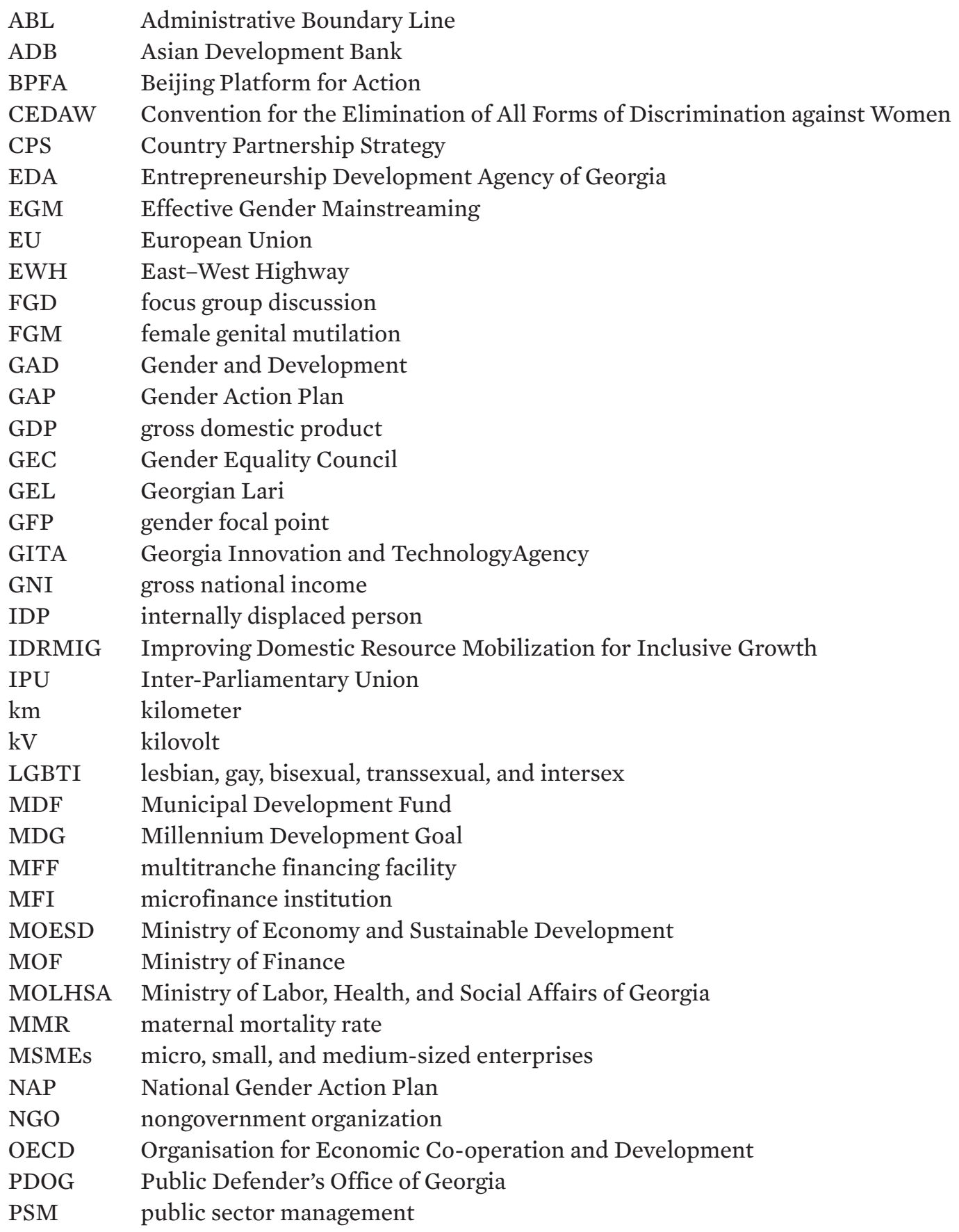




$\begin{array}{ll}\text { SDG } & \text { Sustainable Development Goal } \\ \text { SGE } & \text { Some Gender Elements } \\ \text { STEM } & \text { science, technology, engineering, and mathematics } \\ \text { STI } & \text { Sustainable Transport Initiative } \\ \text { SUTIP } & \text { Sustainable Urban Transport Investment Program } \\ \text { TA } & \text { technical assistance } \\ \text { UN } & \text { United Nations } \\ \text { UNDP } & \text { United Nations Development Programme } \\ \text { UNFPA } & \text { United Nations Population Fund } \\ \text { UN SCR } & \text { United Nations Security Council Resolution } \\ \text { USAID } & \text { United States Agency for International Development } \\ \text { USIIP } & \text { Urban Services Improvement Investment Program } \\ \text { UWSCG } & \text { United Water Supply Company of Georgia } \\ \text { VAW } & \text { violence against women } \\ \text { WB } & \text { World Bank } \\ \text { WEF } & \text { World Economic Forum } \\ \text { WEF GGI } & \text { World Economic Forum Global Gender Gap Index } \\ \text { WIC } & \text { Women's Information Center } \\ \text { WID } & \text { Women in Development } \\ \text { WSS } & \text { water supply and sanitation }\end{array}$




\section{Terminology}

\section{Gender}

Gender refers to the social facets of class, religion, and culture that condition the way in which masculine and feminine roles and status are constructed in each society. Gender relations are neither static nor immutable. Rather they are changeable, subject to modification, renegotiation, and reinterpretation, unlike the universal and constant biological (sex) differences between males and females. ${ }^{1}$

\section{Gender Discrimination}

Gender discrimination is defined as "Any distinction, exclusion, or restriction made on the basis of sex which has the effect or purpose of impairing or nullifying the recognition, enjoyment or exercise by women, irrespective of their marital status, on the basis of equality of men and women, of human rights and fundamental freedoms in the political, economic, social, cultural, civil or any other field." ${ }^{2}$

\section{Gender Equality}

Gender equality refers to the equal rights, responsibilities, and opportunities of women and men, and girls and boys. Equality does not mean women and men will become the same, but that women's and men's rights, responsibilities, and opportunities will not depend on whether they are born male or female. ${ }^{3}$

\section{Gender Equity}

Gender equity denotes the equivalence in life outcomes for women and men, recognizing their different needs and interests, and requiring a redistribution of power and resources. ${ }^{4}$

\section{Gender Mainstreaming}

An organizational strategy to bring a gender perspective to all aspects of an institution's policy and activities, through building gender capacity and accountability (footnote 4).

1 C. Moser. 1993. Gender Planning and Development: Theory, Practice and Training. London, UK: Routledge; ADB. 2003. Gender and Development: Framework, Policies and Strategies. Manila.

2 CEDAW. Article 1. In Gender Equality Glossary. UN Women. https://trainingcentre.unwomen.org/mod/glossary/ view.php?id=36.

3 UN Women. Gender Equality Glossary. https://trainingcentre.unwomen.org/mod/glossary/view.php?id=36\&mode $=$ letter\&hook=g\&sortkey $=$.

4 H. Reeves and S. Baden. 2000. Gender and Development: Concepts and Definitions. Brighton, UK: Institute of Development Studies. 


\section{Women's Empowerment}

A bottom-up process of transforming gender power relations through individuals or groups developing awareness of women's subordination and building their capacity to challenge it (footnote 4).

\section{Women's Rights}

The recognition that women's rights are human rights and that women experience injustices solely because of their gender (footnote 4 ). 


\section{Executive Summary}

Georgia gained independence from the former Soviet Union in 1991, but a period of political instability and conflict hampered the country's development. The first decade of the 2000s saw rapid economic growth, but this was short-lived due to the 2008 conflict with the Russian Federation and the global financial crisis in 2008 and 2009. The period between 2010 and 2014 saw a period of rapid economic development, with annual growth in gross domestic product (GDP) from $\$ 11.6$ trillion to $\$ 16.5$ trillion, and a gross national income (GNI) per capita from $\$ 3,000$ in 2010 to $\$ 4,490$ in 2014. But growth dipped slightly between 2014 and 2016, with GDP at $\$ 14.38$ billion and GNI per capita at $\$ 3,830$.

However, economic growth has been very unevenly spread, mainly occurring in urban areas-particularly the capital, Tbilisi. About one-fourth of the population (21.9\%) lives in absolute poverty. Women account for a significant proportion of the poorest; for example, women comprise the bottom $40 \%$ of the income distribution, and female-headed households are overrepresented among the poor. Although overall poverty levels dropped from $42.7 \%$ to around $20 \%$ between 2010 and 2015, they remain among the highest in the Eastern Europe and Central Asia region.

Since 2012, the government has focused on enabling more inclusive economic growth in Georgia. Key commitments set out in the Socioeconomic Development Strategy of Georgia (Georgia 2020) include the following:

- promotion of fast and efficient economic growth through investments in productive capacity, a strengthened private sector, and inclusive employment opportunities;

- investments in transport, energy, logistical, and agricultural infrastructure;

- environmentally sustainable, green growth, and disaster mitigation strategies;

- improvements in the quality of education; and

- labor market development through investments in vocational training and compliance with European labor standards and laws, and programs for entrepreneurship and self-employment.

International ranking and indicators on gender. Georgia made some significant strides forward in creating an enabling environment for gender equality in the past 30 years. The recognition of equal rights for all is a cornerstone of its constitution, and dedicated legislation has been put in place to promote nondiscrimination and women's rights. However, these measures have not translated into overall progress against regionally and globally comparable gender equality outcomes. Over the past 10 years, Georgia's ranking in the World Economic Forum Global Gender Gap Index (WEF GGI) has steadily deteriorated. In 2017 Georgia ranked 94th out of 144 countries, compared to 90th in 2016, 88th in 2010, and 54th in 2006. This puts Georgia among the lowest five countries for gender equality within the Eastern Europe and Central Asia region, just above Tajikistan, Armenia, Azerbaijan, and Hungary. 
Although Georgia achieved near gender parity in educational attainment, the country needs further improvements on key global indicators of economic status and political voice. According to the most recent United Nations Development Programme (UNDP) Global Gender Index figures, women's labor force participation rate was $57.3 \%$, compared to $78.4 \%$ for men. Even though the number of female parliamentarians has been rising in the last few years, women still hold only $16 \%$ of seats in the Parliament in 2017. Georgia ranked 114th of 144 countries for women's political empowerment in the 2017 WEF GGI. Georgia also has skewed female-to-male sex ratios at birth.

International and national commitments on gender equality. Georgia ratified the Convention on the Elimination of All Forms of Discrimination against Women (CEDAW) in 1994 with no reservations. In 1995, Georgia was a signatory to the Beijing Platform for Action (BPFA), which sets strategic objectives and targets for governments in 12 critical gender equality areas, including poverty, education, violence against women, economic participation, and power and decision-making. In addition, Georgia integrated the Millennium Development Goals (MDGs)-including Goal 3 on promoting gender equality and empowering womenin its National Development Strategy. The implementation of commitments under CEDAW, the BPFA, and the MDGs is visible in the design of national legislation, policy frameworks, and mechanisms to guarantee gender equality and women's rights, measures to prevent and respond to violence against women, and gender-responsive amendments to the labor code.

In 2015, the Government of Georgia responded favorably to the introduction of the Sustainable Development Goals (SDGs), which replaced the MDGs. The government showed a high level of support to the prioritization of all 17 of the SDGs, including SDG 5 on gender equality, and the development of nationally relevant indicators is currently under way.

In March 2010, the Georgia Law on Gender Equality was passed (hereafter referred to as the GE Law). The GE Law prohibits gender-related discrimination and puts in place provisions for guaranteeing gender equality. These include ensuring equal access to education for boys and girls, equal employment opportunities for women and men, ensuring fair and equitable working conditions and pay, promoting equal rights and freedoms of women and men, enabling equal access to information, and supporting elimination of gender-based violence and harassment.

Institutional mechanisms on gender equality. The National Gender Equality Council (GEC) was established within Georgia's Parliament in 2004, initially as an advisory body. The primary objective of the GEC is to ensure systematic and coordinated governmental processes on gender equality issues, including overseeing the implementation and monitoring of the GE Law and liaising with GECs across the country. The GEC became a permanent body after the adoption of the GE Law, with members appointed every 4 years when a new Parliament is elected. Its members include 17 members of Parliament, whose composition depends on the proportion of party members elected to Parliament. The vice-speaker of the Parliament is the GEC's chair. In addition, amendments to the GE Law in 2016 now require all Municipal Parliaments (Sakrebulos) to appoint a gender advisor and to create a local-level GEC. The process of putting these measures in place is still under way for many municipalities.

In July 2017, the Inter-Agency Commission on Gender Equality, Violence against Women and Domestic Violence (IAC) was established by official government decree, following the CEDAW Committee's recommendation. The IAC is chaired by the assistant to the Prime 
Minister on Gender Equality and Human Rights and comprises deputy ministers and appointed gender focal points (GFPs) from relevant line ministries, and representatives from other branches of the government. It includes members of the GEC, the Supreme Court of Justice, and the Public Defender's Office, and gender experts from development agencies, including UN Women, the National Democratic Institute, and the World Bank (WB).

Meeting twice a year, the commission addresses issues, such as supporting the effective implementation of functions and coordination of activities of respective state bodies in the field of gender equality, violence against women, domestic violence, and women's empowerment. It is also responsible for implementing the United Nations Security Council Resolution (UN SCR) 1325 on women, peace, and security. The IAC has been responsible for developing 2-year National Gender Action Plans (NAPs) and evaluating progress against them since 2017. The IAC plays an important role in enabling knowledge-sharing and coordination between ministries to ensure they institutionalize gender dimensions into all new laws and amendments.

Gender stereotypes and norms. The gender equality gaps in Georgia highlighted in global and regional indexes reflect a situation where women's roles, opportunities, and rights are often constrained by conservative sociocultural norms and gender stereotypes. Conservative gender roles are widely accepted in Georgia. Women are expected to undertake the majority of unpaid care work within the household, and there are few examples of men and women sharing care responsibilities. Studies conducted in 2010 and 2013 indicate that many women and men reinforce these gender norms through their own values and perceptions, particularly when they have less access to modern technology and ideas.

Women's political representation. There is public support for increasing women's role in decision-making, yet their political representation remains low in Georgia. The number of female parliamentarians has been slowly rising from $6.4 \%$ in 2008 to $16 \%$ in 2017 , far below the target of at least $30 \%$ outlined in the BPFA, and amounts to only 23 of 150 parliamentary seats. Georgia ranked 114th of 144 countries for women's political empowerment in the 2017 WEF GGI and 123rd of 193 countries in the 2018 Inter-Parliamentary Union (IPU) global table of women in national parliaments. This places Georgia well below the global average for most middle- and low-income countries, as well as lagging behind other former Soviet Union and Central Asia countries in the South Caucasus region, such as Armenia, Azerbaijan, Kazakhstan, the Kyrgyz Republic, Tajikistan, and Turkmenistan.

Women are also underrepresented in local government. In executive branches of government in Georgia, women accounted for only $15.4 \%$ of Sakrebulo members in 2018. In the local self-government elections in October 2017, all elected mayors of municipalities were male.

Women's economic empowerment. Official figures from the National Statistics Office of Georgia indicate the participation of women ages 15 and over in the formal labor market is lower than that of men: in 2012-2015, around $46 \%$ of women were employed compared with $53 \%$ of men. Among younger women, the discrepancy is significantly higher-in 2014, only $19 \%$ of women ages between 15 and 34 were employed, compared with $35 \%$ of men. The discrepancy among younger women can be largely attributed to the burden of unpaid care work, including caring for small children below school age, coupled with the lack of subsidized childcare facilities, such as kindergarten schools. Recent gender-responsive changes to the labor code, including extended paid maternity leave periods, may help to encourage more women to 
enter the formal labor market. However, currently, only public-sector institutions are obliged to implement this legislation, and many private-sector companies opt out, providing minimal maternity leave for female employees.

Occupations are strongly segregated by gender, with a much higher share of men in stereotypically male professions, such as engineering, construction, energy, transport and communications, gas, and water supply. The majority of women are employed in jobs with a caring or service dimension. Women account for around $75 \%$ of employees in the health care and social sectors, $60 \%$ of people working in the hospitality sector, and $84 \%$ of school teachers. Fewer than $10 \%$ of women work in construction, while $23 \%$ are employed in transport and communications. Many women also work in the informal sector and in unpaid subsistence farm work.

There is a significant gender wage gap between men and women, with women earning $64 \%$ of what men earned on average in 2017. This is partly because men are generally employed in higher-paying professions and attain more senior positions than women due to vertical segregation. However, where women and men work in the same fields, men's average monthly wages are often higher than those of women. This is true even in sectors where women are predominantly employed, such as education, health care, and hospitality. In 2015, women's average monthly salary in the education sector was $65 \%$ of men's average monthly salary; and in restaurant and hotel work, was $66 \%$ of men's salary. One exception to this trend were the electricity, water, and gas sectors, with near gender parity in wages, with women earning $97 \%$ of men's salary.

Access to land and property. Georgia's women are legally entitled to own and inherit land and property, but customary practices usually give men privilege in property inheritance, ownership, and administration. The rate of land ownership is consequently higher for men: the 2014 agricultural census found that $70 \%$ of total agricultural holdings were operated by men: of 642,209 holdings, women held only 198,446. The preference for passing land and property to sons rather than daughters is particularly high among ethnic minority families.

Gender and education. There is parity in school enrollment rates in Georgia for both boys and girls at both primary and secondary levels. This translates into high national literacy rates, which are nearly $100 \%$ for both women and men. However, figures indicate that around a quarter of boys and girls do not attend primary school, particularly children in disadvantaged and marginalized groups. A slightly higher number of boys (91\%) of the relevant age group progress to secondary school than girls (89\%).

Gender norms and perceptions also strongly influence the curriculum and the choice of subjects for specialist study. Over $80 \%$ of students of arts and humanities, and $70 \%$ focusing on health at tertiary level are female; while only around $30 \%$ of women are studying engineering, manufacturing, and construction, with less than a quarter enrolled in agriculture courses.

Gender and health. Life expectancy differs for women and men in Georgia: the majority of women live to over 80 years old, outliving men by almost 9 years. Lifestyle factors contribute to this disparity: $57 \%$ of all males over the age of 15 are tobacco consumers, compared with $6 \%$ of females; and drug and alcohol use are very common among men. 
Georgia has made significant progress in reducing its maternal mortality ratio (MMR). According to the Maternal Mortality Estimation Inter-Agency Group in 2000, the MMR was 60 per 100,000 live births in Georgia, and by 2015, this had reduced to 36 per 100,000. In 2016, the estimated MMR was 23 per 100,000. According to data from the 2010 Georgia Reproductive Health Survey, almost $98 \%$ of pregnant women received at least one antenatal examination. However, attention is needed to ensure all women have equal access to these facilities as the figures showed there was a gap in the use of these services between urban women (93\%) and rural women (86\%). Many internally displaced persons (IDPs) who are women living in IDP settlements also lack access to sexual and reproductive health and services information.

Violence against women. Violence against Women (VAW) committed by a husband, partner, or other family member is a pervasive issue for Georgia, but not addressed until very recently. A national survey of women and men ages 15-64 conducted by UN Women and the National Statistical Office in 2017 indicates that one in seven women experienced physical, sexual, and/or emotional violence at the hands of an intimate partner. According to the Ministry of Internal Affairs' data on restraining orders issued in 2016, cases of violence affected 3,012 families and 5,667 people in total. Data on abusers and victims showed that $92 \%$ of the abusers were men and $87 \%$ of the victims were women.

Though attitudes are beginning to change, particularly among younger people, VAW is still widely accepted. Nearly a quarter of women (22\%) and 31\% of men participating in the 2017 UN Women study agreed that VAW is justifiable in some circumstances. Only $38 \%$ of men and $44 \%$ of women agreed that marital rape is a crime.

In 2006, the Law of Georgia on the Prevention of Domestic Violence, Protection, and Assistance of Victims of Domestic Violence (DV Law) was introduced, supported by 2-year NAPs on the Elimination of Violence, Protection, and Support to its Victims; and including domestic violence in the State Fund for Protection's mandate. Prior to this, Georgia did not have specific domestic violence legislation. In 2014, Georgia signed the Council of Europe Convention on Preventing and Combating Violence against Women and Domestic Violence (the Istanbul Convention). Prior to ratification, significant work was conducted with the aim of harmonizing domestic legislation with the Istanbul Convention. In total, 24 laws were amended and national awareness-raising campaigns were undertaken.

The existing legislation on violence against women is largely dominated by the domestic violence law, which identifies different forms of violence. However, legislation may be further improved, in addressing other forms of VAW, such as sexual harassment in the workplace and public spaces. Notably, one in five women participating in the 2017 national survey reported having experienced sexual harassment, including inappropriate staring or leering, sexually suggestive comments or jokes, and inappropriate hugging, touching, or kissing.

The sex ratio gap. There is a notable gap between the numbers of boys and girls in Georgia, leading to a worrisome situation of "missing girls." In 2018, there were 108 boys for every 100 girls for children aged $0-4$. The gap has narrowed since 2013, when there were 112 boys for every 100 girls in this age-group. This difference is more prevalent in rural regions, where the average sex ratio gap in 2005-2013 was 113.4, compared to 109.5 in urban areas. The gap is also much higher in regions with a high proportion of ethnic minority population. 
Specific challenges for conflict-affected women and girls. Women and girls affected by conflict face particular difficulties. Around half of IDPs are women and girls. Many live below the poverty line, lacking access to livelihoods, and faced with poor living conditions. Domestic violence is a growing threat as tensions rise within IDP families, but incidences of VAW often go unreported by IDPs because of fear or stigma, and acceptance of violence as a social norm.

Mainstreaming gender in key sectors. ADB is committed to promoting gender equality through a twin-track strategy that promotes gender mainstreaming in all areas of its operation, while retaining a specific focus on women and girls in projects where special assistance is needed to ensure their full participation in mainstream projects. ADB's priority sectors in Georgia are transport, urban transport, water and other urban infrastructure and services, energy, public sector management, and finance.

Transport. Since 2009 ADB has funded a multitranche financing facility (MFF) to improve the East-West Highway (EWH)-a major transport corridor-through the construction of a bypass road for Kobuleti, a popular destination for domestic tourism. However, due to a perception there are no specific gender concerns relating to the construction and use of highways or bypasses and other major roads, no Gender Action Plan (GAP) was developed for the Kobuleti bypass project. Efforts are being made to pursue gender equality in other road projects. Another transport project to improve 50 kilometers $(\mathrm{km})$ of a secondary road linking to the EWH was launched in 2017, to run until 2022. Gender features were adopted for the Secondary Roads Improvement Project and the main focus is on engaging women in consultations, providing business training for women, and road safety awareness. Similar gender design features were included in the 2018 project, East-West Highway (Khevi-Ubisa Section) Improvement Project, with the addition of other features, such as women-friendly roadside facilities; sex-disaggregation of traffic data, including accidents; incorporating a gender perspective in road safety programs and the road maintenance strategy; and building the gender capacity of the Roads Department.

Key issues considered in designing and implementing transport projects are access, safety, and providing equal opportunities for employment in the sector. When thinking about the gender aspects of safety for major roads, it is important to consider who will be using them, how, when, and why. For example, less than half of all drivers in Georgia are female, particularly those women living in regional areas, so they are more likely to be passengers or use public transport to access schools, hospitals, or workplaces. Because of this, they may need to walk or wait for public transport alongside roads, often with small children. They may need to cross roads to reach their destinations, making the provision of footpaths, footbridges, and intermediate means of transport an important consideration for road planners. Male road users are more likely to drive on the roads, so may not encounter the same issues, but will be exposed to potential risk if there are no mandatory road safety measures in place for drivers, or if road signs and lighting are inadequate. Basic amenities, such as disabled access toilets, must also be provided for both women and men on major transport routes.

The transport sector could potentially offer employment opportunities for women as well as men in both administrative and technical areas. In practice, few women are employed in this sector, and the majority work in the stereotypically "female" social and environmental safeguards field or in human resources. 
Urban transport. The improvement of environmentally sustainable public transport systems, intercity connections, and pedestrian facilities in Tbilisi, and in small towns and secondary cities, is also a key priority of ADB in Georgia. Major infrastructure projects funded by ADB under the Sustainable Urban Transport Investment Program (SUTIP) are the construction of a new underground metro station in Tbilisi; the improvement of a main road connecting Zugdidi to Mestia in Western Georgia; coastal protection in Batumi; Tbilisi metro rehabilitation; and the development of a highway between Tbilisi and Rustavi, a commuter town located $25 \mathrm{~km}$ from the capital. All tranches of the SUTIP include GAPs and specific activities to address gender inequalities.

A key gender issue for the urban transport sector is the different transport needs of women and men. Georgia's women often do not drive cars unless they are in the capital, and they are more likely to use public transport than men. Women constitute the majority of those using the metro and the buses, but there is currently a lack of formal data for tracking usage and accessibility according to gender, age, disability, and other variables. There is also no information to indicate whether the services are affordable for all, including the poorest and more vulnerable groups. Women also face safety issues, such as sexual and other forms of harassment when using transport services. A 2015 ADB study on sexual harassment on public transport in Georgia found that $45 \%$ of respondents had been sexually harassed on public transport in the past 6 months. However, the primarily male decision makers within the urban transport sector do not give this issue sufficient attention. Lastly, while efforts have been made to create employment opportunities for women in ADB-funded urban transport initiatives, there are currently no female train or bus drivers, and no women working in construction or other technical areas. Women also have limited representation in decision-making positions, with only 2 of 12 female top managers in 2017.

Water and other urban infrastructure and services. Through technical assistance and loan projects, ADB supports the development of urban infrastructure fit for purpose as cities and towns grow. Key areas are the provision of high-quality drinking water, effective sewerage, wastewater, and solid waste treatment in urban areas.

ADB also funds the development of liveable urban areas through support for inclusive, economically competitive, and environmentally sustainable urban clusters. Attention is given to ensuring the specific needs of differently abled persons, senior citizens, women, and children are taken into account in planning processes.

ADB supports the Government of Georgia's goal to supply the population with water 24 hours a day, to streamline water supply and drainage systems in all urban centers and towns, and to ensure their proper functioning and further improvement. The implementing agency is the United Water Supply Company of Georgia (UWSCG). Since the launch of the program, up to $100 \%$ of targeted households-including those headed by females-now have access to a 24-hour potable water supply. Studies show that improving women's access to water means they have more time for income generation, skills building, and leisure, as well as for responding to their families' needs. However, the lack of gender-disaggregated data on payment practices in target areas means there is no clear picture of which women and men have most difficulty in paying, the reasons for this, or which groups may be excluded from the services. 
Considerably fewer women than men are employed in the water and sanitation sector in Georgia, with the majority working in administrative office roles. Engineers are overwhelmingly male and very few women are in management positions-for example, only two females were department heads in the UWSCG in 2017. Perceptions that women are not equipped to take on technical positions or will find work too tough in this typically male-dominated sector reinforce this gender gap.

Energy. ADB supported the Government of Georgia to improve its electricity transmission and distribution network, and to enhance energy efficiency through the rehabilitation of aging assets. There is currently no GAP for ADB-funded energy sector projects. However, there are multiple gender concerns in the sector. The traditional roles of men and women affect energy consumption and use of natural resources, making a gender analysis of Georgia's context for rural and urban areas vital.

Households in regional towns and villages still often rely on wood for heating and cooking. Burning solid biomass in unventilated spaces can be extremely detrimental to health, leading to respiratory diseases and increased morbidity, with women and children disproportionately affected. The provision of domestic gas or electricity supplies would dramatically improve the quality of life for many families, but this must be affordable. Energy insecurity and high costs pose serious challenges in the access to energy, especially for poor women. Requirements for connection or user fees that are not affordable neglect the needs of female-headed households and other vulnerable groups. It is important to hear from women what types of energy they prefer, what times they would like to have access to energy if a 24-hour supply is not available, and how they would like to pay for the service.

The ADB-funded initiatives provided employment opportunities in target areas, but efforts are needed to ensure these are extended to women. The growing energy sector has the potential to offer significant jobs and skills training for both women and men, including in the development, sales, and installation of renewable energy sources, such as solar panels.

Finance and public sector management. ADB supported the Government of Georgia's Ministry of Finance (MOF) and Ministry of Economy and Sustainable Development (MOESD) through the \$250 million Improving Domestic Resource Mobilization for Inclusive Growth Program, which ran in 2014-2016. The project's objectives were to

- reduce debt and improve fiscal risk management;

- enable robust revenue and public expenditure management;

- enhance the generation of domestic savings, with a focus on creating better pension systems, especially for women; and

- support the mobilization of private resources for investment through capital market development and enterprise support, including micro, small, and medium-sized enterprises (MSMEs).

A GAP was prepared, in line with the project's overall goal of contributing to improved living conditions and employment opportunities for citizens, particularly women. Key gender issues for finance and public sector management (PSM) projects include gender inequities in pension provision, common in many countries because of women's typically lower income and extended periods of leave from work for maternity. A key performance indicator for 
the GAP was the inclusion of measures to ensure women are not negatively impacted by pension reforms. The current universal pension favors women because of their longevity and possibility to enter into retirement at 60,5 years ahead of men, who are not eligible until they reach 65 . The current universal pension conditions were retained and will supplement a private pension scheme to which contributions can be paid up to the age of 70 . Although women's income from private pensions may be lower than those of men on average for the reasons outlined above, it is assumed that combined pensions will eventually lead to higher living standards for elderly women and men.

Gender responsiveness has been an intrinsic aspect of ADB-funded projects for MSME development. The GAP sets numerical targets for the allocation of funding and training opportunities for female entrepreneurs under public sector loans. The two implementing agencies for MSME development, the Enterprise Development Agency (EDA) and the Georgia Innovation and Technology Agency (GITA), responded by allocating up to $40 \%$ of grants and loans to female entrepreneurs to support innovation. This amounted to GEL2 million (\$754.7 million) in 2016 for EDA alone. Between 2015 and 2016, 40\% of EDA's 4,876 total beneficiaries were female entrepreneurs.

Private sector operations in Georgia have been active in the finance sector since 2007, supporting small and medium-sized enterprises (SMEs) through banks and microfinance institutions (MFIs). In 2015, ADB provided a loan and technical assistance with a gender entry point, targeting women through services and products offered to MSMEs, that also contributes considerably to women's access to finance and financial literacy. The project includes targets for women's inclusion in banking services, MSME products, and financial literacy; and is aimed at increasing lending to MSMEs, not only in terms of capital but also in location, such as in rural areas, and providing enhanced access to longer-term finance for MSMEs.

Setting gender targets for funding entrepreneurs is an excellent first step to promoting women in business, but they need to be part of a long-term strategy that fosters genderequitable access. Women are often disadvantaged at the start-up stage of businesses and female entrepreneurs are often unable to scale up because of their lack of access to capital, business training, and market linkages. 


\section{Introduction}

\section{A. Purpose of the Report}

The Asian Development Bank (ADB) has been operational in Georgia since 2007, working closely in partnership with the Government of Georgia to achieve improvements in areas that include finance, water and sanitation, transport, and energy. ADB takes a gender-integrated approach to all its work, to ensure the programs it funds meet the specific needs of both women and men, and-where possible-contribute toward the achievement of broader gender equality goals.

As part of the gender mainstreaming process, ADB commissions Country Gender Assessments (CGAs), intended to map key gender equality issues and concerns across multiple areas, with a particular focus on the sectors supported through ADB funding. Chapter II of this Georgia CGA and Sector Review provides a detailed contextual and background analysis of Georgia, supported by recent statistical data. Chapter III provides a comprehensive, up-to-date gender analysis of key socioeconomic areas and issues for Georgia, including equality of rights, political representation and equality of voice, economic opportunities and employment, education, health, and violence against women (VAW).

Chapter IV focuses specifically on ADB in Georgia, with a gender analysis of the five core sectors for ADB Georgia outlined in its most recent Country Partnership Strategy (CPS), 2014-2018 covering transport, including sustainable urban transport; water and sanitation; energy; and finance and public sector management (PSM). Chapter IV also reviews progress and identifies gaps in these areas in gender mainstreaming and provides key entry points and recommendations for each sector to inform future planning.

The report will be of primary interest to ADB staff and partners in Georgia and the South Caucasus region, but it is also relevant to a wide range of other development actors who design or undertake projects in the country and region.

\section{B. Methodology}

The report is partly based on qualitative and quantitative data collected during key informant interviews and focus group discussions (FGDs) with stakeholders from relevant government departments in November 2017-including ADB's implementing partner agencies and ministries, United Nations (UN) agencies, the World Bank(WB), nongovernment organizations (NGOs), beneficiaries, and relevant ADB staff (Appendix). The report also benefits from a comprehensive desk review of the latest statistical data and qualitative research on gender and development in Georgia. 


\section{Background and Context}

\section{A. Economic and Political Context}

Georgia is located in the Caucasus region and shares borders with Armenia, Azerbaijan, the Russian Federation, and Turkey. It has a population of 3.7 million. ${ }^{1}$ Ethnic Georgians make up $86 \%$ of the population, with the remaining $14 \%$ composed of diverse ethnic minorities, particularly Azeri and Armenian. ${ }^{2}$ A powerful kingdom in the 10th to the 13th centuries, Georgia underwent a period of Turkish and then Persian rule and was annexed by the Russian Empire in the 19th century. Georgia was an independent state from 1918 to 1921, when it was incorporated into the former Soviet Union following the Bolshevik revolution. In 1936, Georgia became a constituent republic of the Soviet Union until its collapse. Georgia declared sovereignty on 19 November 1989 and independence on 9 April 1991. ${ }^{3}$

After achieving independence, a dual process of state building and transition from central planning to a market-driven economy began. Economic shifts included the liberalization of prices for some goods and services, increases in the average earnings of employees, and increased interest rates to promote a culture of saving. In 1992, legal and government resolutions and decrees restricting monopolistic institutions and practices and promoting competition were issued for the first time in Georgia. ${ }^{4}$ However, a violent military coup d'état in 1991 interrupted these reform processes, which lasted until 1992 when a new interim government was established, led by Eduard Shevardnadze. ${ }^{5}$ Equally destabilizing were violent military separatist coups in regions such as Abkhazia ${ }^{6}$ from 1991 to 1993 . The civil unrest contributed to a protracted crisis of economic stagnation, high inflation, and soaring rates of unemployment (footnote 4). Between 1994 and 1995, a new economic reform policy aimed at stabilization was introduced, supported by the World Bank (WB) and the International Monetary Fund. However, endemic corruption and the persistence of

1 World Economic Forum (WEF) website. http://reports.weforum.org/global-enabling-trade-report-2016/ economy-profiles/\#economy=GEO.

2 The largest ethnic minority groups in Georgia are Azeris (6.3\%) and Armenians (4.5\%). Other ethnic groups include Russians, Ossetians, Yezidis, Ukrainians, Chechens, and Caucasus Greeks. Geostat. 2016. http://geostat. ge/cms/site_images/_files/english/population/Census_release_ENG_2016.pdf (accessed 16 February 2018).

3 Encyclopedia Britannica. https://www.britannica.com/place/Georgia.

4 V. Papava. 2013. Reforming of the Post-Soviet Georgia's Economy in 1991-2011. Tbilisi: Center for Applied Economic Studies.

5 T. Goltz. 2009. Georgia Diary: A Chronicle of War and Chaos in the Post-Soviet Caucasus. London, UK: Routledge.

6 The Abkhazia conflict, which lasted for 13 months from August 1992, was led by ethnic Abkhazians fighting for secession with Georgia. The war caused tens of thousands of casualties and led to the displacement of around 250,000 people. Abkhazia is a northwestern region of Georgia on the Black Sea coast. A. Petersen. 2008. The 1992-3 Georgia-Abkhazia War: A Forgotten Conflict. Caucasian Review of Internal Affairs. 2 (4). http://georgica. tsu.edu.ge/files/05-Security/Petersen-2008.pdf. 
Soviet-style governance resulted in continued economic stagnation and widespread disillusionment with the government. ${ }^{7}$

The peaceful Rose Revolution of $2003^{8}$ brought positive change as a new political administration introduced reforms promoting democratic values and principles. The country began undergoing a transition period marked by liberal economic reforms aimed at ensuring economic growth based on liberalization and private sector development. Measures to promote a favorable climate for market growth included tax reductions, deregulation of business practices, customs reform, and trade liberalization. These changes were accompanied by an anticorruption strategy aimed at reforming law enforcement and judicial systems, as well as the fiscal, administrative, and public service sectors. ${ }^{9}$

The first decade of the 2000s saw rapid economic growth. However, the short but intense military conflict that erupted between Georgia and the Russian Federation in 2008 protracted political instability, and the global financial crash in 2008-2009 undermined the country's economic recovery. Between 2010 and 2014, the country again had rapid economic growth, with annual growth in gross domestic product (GDP) from $\$ 11.6$ trillion to $\$ 16.5$ trillion and a gross national income (GNI) per capita rise from $\$ 3,000$ in 2010 to $\$ 4,490$ in $2014 .^{10}$ Growth dipped slightly between 2014 and 2016, with GDP at \$14.4 trillion and GNI per capita at $\$ 3,830$ (footnote 12 ).

Economic growth has been very unevenly spread, mainly occurring in urban areas-particularly the capital, Tbilisi. Although overall poverty levels dropped from $42.7 \%$ to around $20 \%$ between 2010 and 2015, these remain among the highest in the Eastern Europe and Central Asia region. ${ }^{11}$ Nearly one-fourth of the population (21.9\%) lives in absolute poverty. ${ }^{12}$ Much of the poverty is concentrated in rural areas, where nearly half of the population of Georgia (43\%) live. Rural populations are mainly employed in agriculture, forestry, or fishing, ${ }^{13}$ which only accounted for $9.3 \%$ of Georgia's GDP in 2016 , compared with $25.4 \%$ for industry and $65.4 \%$ for services. ${ }^{14}$ Women account for a significant proportion of the poorest. Nearly $27 \%$ of

7 L. Shelly. 2007. Introduction. In L. Shelly et al., eds. Organized Crime and Corruption in Georgia. London, UK: Routledge.

8 The revolution was led by opposition forces to President Eduard Shevardnadze (the former head of the Georgian Communist Party) amid allegations of irregularities in parliamentary elections. E.R. Scott. 2007. Georgia's AntiCorruption Revolution. In L. Shelly et al. Organized Crime and Corruption in Georgia. New York: Routledge.

9 V. Papava. 2006. The Political Economy of the Rose Revolution. In Orbis 50 (4). Elsevier. https://www.fpri.org/ docs/media/papava.georgiaroserevolution.pdf; Footnote 8; EU Special Advisor on Constitutional Reform and Human Rights in Georgia. 2013. Georgia in Transition. Report on the Human Rights Dimension: Background, Steps Taken and Remaining Challenges. Tbilisi: EU/PDO.

10 The World Bank. Database on Georgia. https://data.worldbank.org/country/georgia?view=chart (accessed 15 February 2018).

11 World Bank Group. 2016. Georgia Country Gender Assessment. Poverty and Equity Global Practice. http:// documents.worldbank.org/curated/en/733891487232457573/pdf/112838-WP-P157626-Georgia-CGA-2016-finalPUBLIC.pdf; and ADB pages on Georgia. https://www.adb.org/countries/georgia/overview (accessed 16 February 2018). The World Bank Group adopted in 2013 the shared prosperity goal that defines it as the growth of real income of the bottom $40 \%$.

12 National Statistics Office of Georgia (NSO). Geostats statistical database. http://www.geostat.ge/index. php?action=0\&lang=eng (accessed May 2018).

13 In 2016, 866,000 of the 1,763,000 economically active population worked in agriculture, forestry, or fishing. ADB. Key Indicators for Asia and the Pacific 2016. https://www.adb.org/sites/default/files/publication/357006/geo.pdf.

${ }^{14}$ ADB. 2016. Key Indicators for Asia and the Pacific. https://www.adb.org/sites/default/files/publication/357006/ geo.pdf. 
the population lives in households headed by a woman, and female household heads are overrepresented among the poor and the bottom $40 \%$ of the income distribution (footnote 13 ).

The October 2012 parliamentary elections led to the first peaceful, democratic transfer of power in the country's post-Soviet history. ${ }^{15}$ The election was won by the center-left opposition, Georgian Dream-Democratic Georgia, the leading party of the six-party Georgian Dream coalition. In 2016, the party cemented its victory, winning a large majority of votes in the national election. ${ }^{16}$ The government focuses on enabling more inclusive economic growth in Georgia, with key commitments set out in the Socio-Economic Development Strategy of Georgia (Georgia 2020), developed by the Ministry of Economy and Sustainable Development and the Ministry of Finance in 2014. Key commitments outlined in the SocioEconomic Development Strategy of Georgia 2020 include the following: ${ }^{17}$

- promotion of fast and efficient economic growth through investments in productive capacity, a strengthened private sector, and inclusive employment opportunities;

- investments in transport, energy, logistical, and agricultural infrastructure;

- environmentally sustainable, green growth, and disaster mitigation strategies;

- improvements in the quality of education; and

- labor market development through investments in vocational training and compliance with European labor standards and laws, and programs for entrepreneurship and self-employment.

The Government of Georgia is currently undergoing a process of consideration for accession to the European Union (EU) and, as an interim measure, signed an Association Agreement and a Free Trade Agreement with the EU. ${ }^{18}$

Table 1: Key Indicators for Georgia, 2018

\begin{tabular}{|ll} 
Population & 3.7 million \\
\hline Gross domestic product & $\$ 14.38$ billion \\
\hline Gross national income per capita & $\$ 3,830$ \\
\hline Percentage of population below poverty level & $20 \%$
\end{tabular}

Sources: World Economic Forum website. http://reports.weforum.org/ globalenabling-trade-report-2016/economy-profiles/\#economy=GEO; The World Bank. Database on Georgia. https://data.worldbank.org/country/georgia?view=chart.

${ }^{15}$ A team of observers from the Office for Democratic Institutions and Human Rights monitored the election. http:// www.osce.org/odihr/elections/Georgia2012.; and EU Special Adviser on Constitutional and Legal Reform and Human Rights in Georgia. 2013. Georgia In Transition, Report on the Human Rights Dimension: Background, Steps Taken and Remaining Challenges, Assessment, and Recommendations by Thomas Hammarberg. Tbilisi: EU/PDO.

${ }^{16}$ Ruling Party Claims Victory in Georgia's Elections. The Guardian. https://www.theguardian.com/world/2016/ oct/10/ruling-party-ivanishvili-claims-victory-georgia-elections.

17 Government of Georgia. 2014. Socio-Economic Strategy of Georgia “Georgia 2020.” https://www.adb.org/sites/ default/files/linked-documents/cps-geo-2014-2018-sd-01.pdf.

${ }^{18}$ European Commission. http://europa.eu/rapid/press-release_IP-16-2369_en.htm. 


\section{B. International Ranking and Indicators on Gender}

Georgia made some significant strides creating an enabling environment for gender equality in the past 30 years. The equal rights of women and men are enshrined in the Constitution of Georgia, ${ }^{19}$ and further supported through the GE Law and other targeted legislation. However, these measures have not translated into overall progress against gender equality outcomes when compared to other countries globally and regionally. Over the past 10 years, Georgia's ranking in the World Economic Forum Global Gender Gap Index (WEF GGI) steadily deteriorated. In 2017, Georgia ranked 94th out of 144 countries, compared to 90th in 2016, 88th in 2010, and 54th in 2006. ${ }^{20}$ This puts Georgia among the lowest five countries for gender equality within the Eastern Europe and Central Asia region, just above Armenia, Azerbaijan, and Tajikistan.

While Georgia achieved near gender parity in educational attainment, ${ }^{21}$ Georgia fares poorly in other key global indicators of economic status and political voice. According to the most recent UNDP GGI figures, women's labor force participation rate was only $57.3 \%$, compared to $78.4 \%$ for men. ${ }^{22}$ Though the number of female members of Parliament rose from $6.4 \%$ in 2008 to $15 \%$ in 2017 , Georgia still ranked 114th of 144 countries for women's political empowerment in the 2017 WEF GGI (footnote 20), well behind many other countries in the region (Table 2). Georgia also has one of the worst female-to-male sex ratios at birth in the world (footnote 20).

Table 2: Comparative Gender Equality Ranking of Georgia for South Caucasus Region and Central Asia Former Soviet Union Countries

\begin{tabular}{|lc|}
\hline Country & Ranking \\
\hline Armenia & 97 \\
\hline Azerbaijan & 98 \\
\hline Georgia & 94 \\
\hline Kazakhstan & 52 \\
\hline Kyrgyz Republic & 85 \\
\hline Tajikistan & 95 \\
\hline
\end{tabular}

Source: World Economic Forum (WEF). 2017.

The Global Gender Gap Report.

${ }^{19}$ Article 14 of the Constitution of Georgia states that "Everyone is free by birth and is equal before the law, regardless of race, color, language, sex, religion, political, and other opinions, national, ethnic, and social belonging, origin, property, and title, place of residence."

${ }^{20}$ World Economic Forum (WEF). 2017. The Global Gender Gap Report. http://www3.weforum.org/docs/WEF GGGR 2017.pdf. The Global Gender Gap Report benchmarks 144 countries' progress toward gender parity across four thematic dimensions: Economic Participation and Opportunity, Educational Attainment, Health and Survival, and Political Empowerment.

${ }^{21}$ According to the most recent UNDP Human Development Report figures (2015), 96\% of women and 97\% of men received at least some secondary education. http://www.hdr.undp.org/en/composite/GII (accessed May 2018).

${ }^{22}$ UNDP. Human Development Reports. http://www.hdr.undp.org/en/composite/GII (accessed 1 May 2018). 


\section{Gender Equality Policies and Commitments}

\section{International Commitments}

Georgia ratified the Convention on the Elimination of All Forms of Elimination against Women (CEDAW) in 1994 with no reservations. ${ }^{23}$ Under the convention, signatories are expected to "take all appropriate measure to ensure the full development and advancement of women" 24 and to "pursue by all appropriate means and without delay a policy of eliminating discrimination against women."25 The convention commits governments to reflect the principles of equality between women and men in all legislation, procedures, and institutions. ${ }^{26}$

In 1995, Georgia was a signatory to the Beijing Platform for Action (BPFA), a global agenda for women's empowerment. ${ }^{27}$ Progress in translating these gender equality-focused agreements into reality has been slow, but the past 5 years have seen increased awareness of gender issuesparticularly of the need to end violence against women-and political commitments to tackle them (section 4). Concrete actions are being taken in response to the CEDAW Committee's recommendations in 2014, which called upon Georgia to strengthen its Gender Equality Council (GEC), establish a comprehensive mechanism to implement and monitor gender equality policies, take action to fight gender stereotyping, take measures to prevent child marriage and domestic violence, and give effective protection to victims of violence ${ }^{28}$ (section III. E.). In 2000, Georgia integrated the Millennium Development Goals (MDGs)-including Goal 3 on promoting gender equality and empowering women-in its National Development Strategy.

Georgia is also party to the following relevant international agreements:

- The International Covenant on Civil and Political Rights, which commits signatories to uphold the right to access to justice for human rights violations, protect the equal rights of men and women, and prohibits forced marriage (footnote 28).

- The International Covenant for Economic, Social and Cultural Rights, which protects the equal rights of men and women, applies special protections to mothers, and calls for governments to ensure the right to the highest attainable standard of health and education (footnote 28).

- The European Convention of Human Rights, which protects the right to life and to respect for private and family life, and prohibits discrimination (footnote 28).

${ }^{23}$ The UN General Assembly adopted the CEDAW in 1979. The convention defines what constitutes discrimination against women and sets up an agenda for national action to end such discrimination. The convention defines discrimination against women as "...any distinction, exclusion, or restriction made on the basis of sex which has the effect or purpose of impairing or nullifying the recognition, enjoyment or exercise by women, irrespective of their marital status, on a basis of equality of men and women, of human rights and fundamental freedoms in the political, economic, social, cultural, civil, or any other field." UN Women. http://www.un.org/womenwatch/daw/ cedaw/cedaw.htm. Under the CEDAW, periodic reports on progress against gender equality goals are submitted to the CEDAW Committee by the government, and a Shadow Report is also submitted by nongovernment institutions. The committee reviews the reports and provides recommendations to the government for future gender equalityfocused actions. The latest Georgia CEDAW report was submitted in 2006 and combines the second and third periodic reports. A Shadow Report was submitted in 2013, compiled by 13 Georgian women's rights organizations and two women's networks.

${ }^{24}$ CEDAW. Article 3.

${ }^{25}$ CEDAW. Article 2.

${ }^{26}$ UN Women. http://www.un.org/womenwatch/daw/cedaw/cedaw.htm.

27 The BPFA was drawn up by nongovernment activists attending the parallel forum. UN Women. The Beijing Platform for Action: Inspiration Then and Now. http://beijing20.unwomen.org/en/about.

${ }^{28}$ C. Zampas et al. 2018. Human Rights in the Context of Sexual and Reproductive Health and Well-Being in Georgia: Country Assessment. Tbilisi: Public Defender's Office of Georgia (PDOG). 
In 2015, the UN adopted a set of Sustainable Development Goal (SDGs) to end poverty, protect the planet, and ensure prosperity for all as part of a new 2030 Agenda for Sustainable Development, with the overarching goal to "leave no one behind." 29 Each of the 17 SDGs has specific targets to be achieved over the next 15 years, with a series of indicators for measuring progress. Gender equality has been mainstreamed across the SDGs, and stand-alone Goal 5 aims to "achieve gender equality and empower all women and girls." The Government of Georgia gives a high level of support to prioritizing all 17 SDGs and the development of country-specific targets. ${ }^{30}$ The process of incorporating the SDGs into national policy documents is planned for $2018,{ }^{31}$ but as there is no working group dedicated to implementing SDG 5 or to mainstreaming gender across the SDGs, it is not yet clear how gender equality targets will be identified and achieved.

\section{National Legislation}

Gender equality law. As part of the reforms brought by the Rose Revolution, in 2006, the government adopted a State Concept on Gender Equality.

In March 2010, the concept was enshrined in the GE Law. The law was developed through a consultative process involving international organizations, government, and local NGOs. It prohibits gender-related discrimination and puts in place provisions for guaranteeing gender equality. These include ensuring equal access to education for boys and girls, equal employment opportunities for women and men, fair and equitable working conditions and pay, promoting equal rights and freedoms of women and men, enabling equal access to information, and supporting elimination of gender-based violence and harassment. The law also calls for the systematic generation of gender-disaggregated data. ${ }^{32}$

The GE Law is a useful advocacy tool, demonstrating state endorsement of gender equality and women's rights, but obtaining sufficient evidence of transgressions often create constraints

\section{Box 1: Georgia State Concept on Gender Equality}

The Georgia State Concept on Gender Equality "aims to encourage the equal and effective implementation of the rights and opportunities for women and men. The Concept recognizes the principles of gender equality in all spheres of public and social life and provides for the relevant measures for prevention and elimination of all forms of discrimination on the ground of sex as well as for the advancing gender equality." It highlights equal political participation, equal employment opportunities and social justice as key drivers of these changes.

Source: E. Duban. 2010. Gender Assessment, USAID Georgia. Tbilisi: USAID.

\footnotetext{
${ }^{29}$ Sustainable Development Knowledge Platform. https://sustainabledevelopment.un.org/?menu=1300.

${ }^{30}$ A technical working group that included members of line ministries, the National Statistical Office of Georgia, donor agencies, and the UNDP was established to develop Georgia-adjusted indicators, set baselines, and establish timelines for implementation. Global Agenda for Sustainable Development and Georgian Path from 2015. https:// sdgsgeorgiasite.wordpress.com.

${ }^{31}$ Global Agenda for Sustainable Development and Georgian Path from 2015. https://idfi.ge/en/global_agenda_for sustainable_development_and_georgian_path_from_2015.

32 E. Duban. 2010. Gender Assessment, USAID Georgia. Tbilisi: USAID.
} 
for its implementation. ${ }^{33}$ It also relies on a narrow definition of gender, failing to recognize the rights of the lesbian, gay, bisexual, transsexual, and intersex (LGBTI) communities, who currently are obliged to report any violations under the new Non-Discrimination Law $^{34}$ (see below). Furthermore, key concepts and tools, such as gender mainstreaming, gender impact assessments, and gender-responsive budgeting are not defined in the law and there is no common approach to their inclusion in gender equality training for state ministries and other institutions (footnote 33).

Nondiscrimination law. The Law on Elimination of all Forms of Discrimination (NonDiscrimination Law) was adopted in 2014. This law clearly states the "unacceptability of discrimination" on the basis of one's gender identity or sexual orientation along with race, color, language, national, ethnic or social belonging, sex, pregnancy or maternity, marital or health status, disability, age, nationality, origin, place of birth, place of residence, internal displacement, material or social status, religion or belief, political or any other ground..$^{35}$ The Non-Discrimination Law includes the principle of equality established by CEDAW. ${ }^{36}$ In addition to protecting rights to nondiscrimination, it sets out available complaint mechanisms and procedural paths to obtain remedies (footnote 33).

However, there are significant gaps in the current Non-Discrimination Law. Notably, it does not prohibit sexual harassment ${ }^{37}$ in institutional or workplace settings and/or other forms of harassment, such as offensive verbal or physical abuse in public places and unfair, discriminatory treatment in the workplace (footnote 33). It also fails to protect the right to reasonable adjustments for differently abled persons in the workplace (footnote 33 ).

\section{Institutional Mechanisms on Gender Equality}

The Gender Equality Council of Georgia. The National GEC was established within the Parliament of Georgia in 2004 and is defined by the GE Law as a permanent body. The primary objective of the GEC is to ensure systematic and coordinated governmental processes on gender equality issues, including overseeing the implementation and monitoring of the GE Law. For example, the National GEC cooperates with GECs within the Supreme Councils of the Autonomous Republics of Abkhazia and Adjara, Municipal GECs, and gender advisors of Municipal City Assemblies.

The National GEC is chaired by the vice-speaker of the Parliament and its members are appointed every 4 years when a new Parliament is elected. Its members include 17 members of the Parliament, whose composition depends on the proportion of party members elected to the Parliament. One of the members of the Parliament is appointed as chair of the GEC,

${ }^{33}$ GEC of Georgia and UNDP. 2018. Gender Equality in Georgia: Barriers and Recommendations. Tbilisi: Parliament of Georgia.

${ }^{34}$ Women's Information Center (WIC) 2014. CEDAW Shadow Report: Alternative Report to CEDAW Concerning Women's Rights and Gender Issues in Georgia. Tbilisi. http://tbinternet.ohchr.org/Treaties/CEDAW/Shared\%20 Documents/GEO/INT_CEDAW_NGO_GEO_17610_E.pdf.

${ }^{35}$ Article 2 of the Non-Discrimination Law. The law includes the principle of equality.

${ }^{36}$ OECD Development Centre. Social Institutions and Gender Index. https://www.genderindex.org/country/ georgia/\#_ftn5 (accessed 14 February 2018).

${ }^{37}$ Sexual harassment is defined as a situation "where an unwanted conduct related to the sex of a person occurs with the purpose or effect of violating the dignity of a person, and of creating an intimidating, hostile, degrading, humiliating, or offensive environment" Article 2(2)(3), Revised Equal Treatment Directive; see also Article 40, Istanbul Convention. Cited in Gender Equality Council of Georgia and UNDP. January 2018. Georgia: Barriers and Recommendations (1 and 2). Tbilisi: Parliament of Georgia. Footnote 33, p. 50. 
who appoints a council coordinator to liaise with different stakeholder groups that include donors, UN agencies such as UN Women and UNDP, the National Democratic Institute, ADB, a consultative group of NGOs, and parliamentary staff. The council members are divided into thematic groups, which work on issues, such as gender-sensitive labor force changes, discrimination, political representation, and VAW.

The existence of the National GEC is a very positive step for Georgia, but its power is severely curtailed. Support of parliamentarians is required to initiate any substantive changes to the GE Law and the impermanent nature of the GEC results in a lack of institutional memory and commitment. The GEC also has relatively few human or financial resources to support its activities. ${ }^{38}$

Inter-Agency Commission on Gender Equality, Violence against Women and Domestic Violence. In July 2017, the Inter-Agency Commission on Gender Equality, Violence against Women and Domestic Violence (IAC) was established by official government decree, following the CEDAW Committee's recommendation. The assistant to the Prime Minister on Gender Equality and Human Rights chairs the IAC that comprises deputy ministers and appointed gender focal points (GFPs) from relevant line ministries, as well as representatives from other branches of government. It includes members of the National GEC, the Supreme Court of Justice, and the Public Defender's Office of Georgia (PDOG); and gender experts from development agencies that include UN Women, the National Democratic Institute, and the WB.

Meeting twice a year, the commission addresses issues, such as supporting the effective implementation of functions and coordination of activities of respective state bodies in the field of gender equality, violence against women, domestic violence, and women's empowerment. It is also responsible for the implementation of UN Security Council Resolution (SCR) $1325 .^{39}$

The IAC has been responsible for developing 2-year National Gender Action Plans (NAPS) and evaluating progress against them since $2017^{40}$ The first NAP on women's advancement was approved in 1998 following the ratification of CEDAW, and every 4 years, a revised plan on gender equality is developed. There are NAPs now on Gender Equality, VAW, and Peace and Security. ${ }^{41}$ Before the formation of the IAC, the GEC was responsible for developing the NAPs. Currently, the NAPs are developed through a participatory, consultative process led by the IAC's executive branch, chaired by the assistant to the Prime Minister on human rights and gender equality issues. The IAC liaises with thematic groups of donors, UN agencies, NGOs, and parliamentary staff; and develops NAPs based on evidence from gender audits and previous evaluations. The NAPs require approval by the parliamentary Cabinet of Ministries.

38 In 2017, the council was allocated \$400,000. Personal communication, Gender Equality Council coordinator. 13 November 2017. Tbilisi.

${ }^{39}$ UN SCR 1325 reaffirms the important role of women in the prevention and resolution of conflicts, peace negotiations, peace-building, peacekeeping, humanitarian response, and in post-conflict reconstruction; and stresses the importance of their equal participation and full involvement in all efforts for the maintenance and promotion of peace and security. UN OSAGI. http://www.un.org/womenwatch/osagi/wps/.

${ }^{40}$ The task of developing and evaluating the 2014-2016 NAPs was the GEC's responsibility, but this responsibility has been passed to the IAC.

${ }^{41}$ The Peace and Security NAP focuses on implementing UN Security Council Resolution (UN SCR) 1325. The Security Council adopted Resolution 1325 on women and peace and security on 31 October 2000. 
The IAC plays an important role in enabling knowledge sharing and coordination between ministries to ensure they institutionalize gender dimensions in all new laws and amendments. However, a key challenge is maintaining institutional memory, capacity, and political will, given that ministerial representatives change every 4 years. Limited time and financial resources compound this challenge: many ministries failed to allocate gender budget lines for the implementation of NAPs. ${ }^{42}$

Local-level gender equality councils. In 2016, amendments were included in the GE Law requiring all Municipal Parliaments (Sakrebulos) ${ }^{43}$ to create a local GEC and Municipal City Halls to appoint GFPs. ${ }^{44}$ The local GECs are responsible for reporting cases of discrimination and developing strategies to address local needs and concerns. In 2017, most Sakrebulos had not yet implemented this process, but there were reports of progress for several City Hallsincluding in Tbilisi-which already appointed a gender advisor and were developing locally relevant Gender Action Plans (GAPs). ${ }^{45}$ Translating these requirements into success at the local levels will require adequate distribution of resources and the engagement of local civil society organizations to provide support and demand accountability. Some international donors are currently supporting capacity-building activities for local-level GFPs, but more consistency is needed to ensure these opportunities are available on a national scale.

${ }^{42}$ A 20-year review of the BPFA for Georgia identifies internal barriers to gender-responsive budgeting, noting: "Misunderstanding about gender responsible budgets as additional funds led to refusal, based on the need to fund for more important priorities. There was no share or percentage allocated annually in the national budget for the investment in the promotion of gender equality and the empowerment of women." Georgia-Beijing + 20. 2014. National Review of the Implementation of the Beijing Declaration and Platform for Action. Tbilisi. p. 14.

${ }^{43}$ In Georgia, the Sakrebulo develops local legislation and plans, which are approved and implemented by City Halls. Local mayors are appointed to govern Municipal City Halls.

${ }^{44}$ Based on information from interview with a member of the Parliament and member of National GEC, Dmitri Tskitishvili. 14 November 2017. Tbilisi.

${ }^{45}$ At the time of writing, the Tbilisi Sakrebulo was developing a GAP with the active engagement of the deputy head of the City Sakrebulo. 


\section{Cross-Cutting Gender Issues}

\section{A. The Persistence of Traditional Gender Stereotypes and Norms}

The gender equality gaps in Georgia highlighted in global and regional indexes reflect a situation where women's roles, opportunities, and rights are often constrained by conservative sociocultural norms and gender stereotypes. These issues are most prevalent in rural and remote areas, particularly among conflict-affected people and ethnic minorities. However, they also affect Georgia's women in urban areas. There is a widespread and largely unquestioned acceptance of conservative gender roles in Georgia. ${ }^{46}$ A nationwide survey conducted in 2009 found that women are expected to undertake the majority of unpaid care work within the household, which may include food preparation, fetching water and fuel in poorer or more remote households, and looking after young children, often in addition to engaging in paid employment or unpaid farm work. ${ }^{47}$ The study found few examples of men and women sharing care responsibilities.

The same survey indicated that men were expected to be the main breadwinners, and in $25 \%$ of cases, they were the sole financial earners. A qualitative study conducted in 2010 revealed the extent to which social perceptions often reinforce these gender norms. Male respondents ages 35-59 in a focus group discussion agreed that women were often capable of doing "male" work such as herding cattle, but felt that men could not do "women's" work. One respondent said: "How can it happen? A man cannot raise children, can he? A family should be taken care of, laundry should be washed, meals should be cooked, and a man cannot do it, he cannot wash laundry as it is not in his genes." ${ }^{48}$ Another recent study that compared data from 1996, 2008 , and 2010 found that many young people ages 15-20 continue to reinforce these gender stereotypes through their own values and perceptions-particularly those living in rural areas with less access to modern technology and ideas. ${ }^{49}$

Given that gender equality and women's empowerment were integral aspects of Soviet ideology, the persistence of a rigidly gendered division of labor may appear somewhat contradictory. According to Communist theory, the participation of both women and men in the labor force was vital for the creation of a strong, self-sufficient state, and emancipating

46 This was identified as a key challenge by many interviewees from parliamentary offices, government ministries, UN agencies, and NGOs for this report; also see CEDAW Committee. 2014. Concluding Observations on the Combined Fourth and Fifth Periodic Reports of Georgia. http://www.undocs.org/CEDAW/C/GEO/CO/4-5.

${ }^{47}$ I. Badurashvili et al. 2008. Gender Relations in Modern Georgian Society. Tbilisi: UNDP and UNFPA. https:// en.calameo.com/books/0007135292c924c76db7f.

${ }^{48}$ L. Tsuladze. 2010.Behind the Scenes: Qualitative Research Results. In National Research on Domestic Violence in Georgia. M. Chitashvili et al. Tbilisi: Fountain.

${ }^{49}$ E. Japaridze et al. 2013. Gender Attitudes and Perceptions among Young People in Georgia. Tbilisi: Gender Centre for Social Studies Gender Equality Programme. 
women from the burden of domestic responsibilities was considered both a means to facilitating their economic contribution and an end in itself. ${ }^{50}$ During the Bolshevik era, these ideas translated into measures that included the provision of state-funded communal child care facilities and a section of the Communist Party-the Zhenotdel-was appointed to focus specifically on women's issues. The media was also mobilized to promote awareness of women's rights (footnote 50). Yet there was a disconnect between the State's support for women's inclusion in the labor market and the reality of women's empowerment: though most women were formally employed, they were relegated to lower-paid jobs often involving domestic tasks. They were also still expected to undertake unpaid care work in the home, and this burden grew even heavier when many state-run day care centers closed due to lack of funding (footnote 50).

Some argue that the end of Soviet rule and a surge of Georgian nationalism had the effect of reinforcing gender stereotypes. For example, the female ideal is strongly connected to the notion of motherhood along with reinforcing some of the traditional perceptions regarding family and religion (footnote 50). Socialization, the reproduction of stereotypes through media and educational materials, and public lack of awareness of gender inequality contribute to the further entrenchment of these ideas. ${ }^{51}$ Gender norms are also reproduced through implicit and unquestioned assumptions that may be transferred by teachers and others who influence the behavior and thinking of young people. ${ }^{52}$

The 2014 Georgia CEDAW Report recommended that the Government of Georgia eliminate gender stereotyping and mainstream gender perspectives in curricula and textbooks (footnote 34). The government is beginning to respond to these recommendations and recognizes that educational institutions play a vital role in shaping perceptions of young girls and boys about gender roles and norms, and in demonstrating positive role models. Organizations such as UN Women and the United Nations Population Fund (UNFPA) are working with the Ministry of Education and Science of Georgia to challenge gender stereotypes in parts of the national curriculum. However, it is a challenge to introduce culturally sensitive topics, such as sexual and reproductive health education, in schools.

UN Women and UNFPA are leading two national campaigns, "He for She" and "Men Care," where well-known male celebrities, such as sports stars and actors, promote progressive ideas on gender through their actions and words.

${ }^{50}$ M. Barkaia. 2018. The Country of the Happiest Women?: Ideology and Gender in Soviet Georgia, In M. Barkaia and A. Waterson, eds. Gender in Georgia: Feminist Perspectives on Culture, Nation and History in the South Caucasus. New York: Berghahn Books.

${ }^{51}$ E. Japaridze et al. 2016; Implementation of Gender Policy in Georgia: 2016 Progress Report on National Action Plan of 2014-2016 for the Implementation of Gender Equality Policy in Georgia. http://www.parliament.ge/en/ajax/ downloadFile/72000/Gender_Equality_NAP_report_2016_ENG_Edited_Final_July_2017; and E. Duban (2010), footnote 32

52 Observation of several interviewees for this report; and N. Sumbadze. 2018. Gender Equality: Still a Disputed Value in Georgian Society. In M. Barkaia and A. Waterson, eds. Gender in Georgia: Feminist Perspectives on Culture, Nation and History in the South Caucasus. New York: Berghahn Books. 


\section{Box 2: Engaging Georgia's Rugby Players in Shifting Gender Norms and Assumptions}

"He for She" is a global campaign led by UN Women and the United Nations Population Fund (UNFPA) aimed at encouraging men all over the world to join the fight for gender equality and show that it is a human rights issue, not only a women's issue.

The Georgian Rugby Union has been working with UN Women since 2010 to support their work to end violence against women and promote gender equality. The team devoted a number of international matches to the cause of ending violence against women and girls and joined "He for She" soon after its launch in 2014 at the match between the Georgia and Japan national rugby teams, where the tradition of girls accompanying rugby players to the pitch was born with the motto "my team supports me."

A public awareness-raising campaign conducted with the participation of Georgia's rugby players contributed significantly to changes in public attitudes. The campaign includes public billboards and widely viewed videos featuring famous rugby players condemning violence against women and girls. The players also met women and men around the country to talk about VAW and gender equality, encouraging them to question stereotypes and norms. They are starting with perceptions of their own sport: instead of boys, girls now accompany the players to the pitch before they start the match. Rugby is the national game of Georgia and the rugby players are the most respected among the country's athletes. Because of this, the example they set for other men and boys has been profound.

Source: UN Chronicle. Georgian Rugby Team Unites to End Violence against Women and Girls. 2016. https:// unchronicle.un.org/article/georgian-rugby-unites-end-violence-against-women-and-girls.

Initiatives such as "He for She" mean that concepts of gender and gender equality are gradually becoming part of the national consciousness. ${ }^{53}$ According to the results of a recent national survey, less than a quarter of Georgia's men and women now think there is gender equality in their country. ${ }^{54}$

Traditional gender norms and stereotypes also influence how people identifying as LGBTI are perceived. While generally tolerated they often experience unfair treatment. ${ }^{55}$ It is prohibited to discriminate against LGBTI people in employment and other key areas under the labor code and the Non-Discrimination Law. However, progress in aligning these legal freedoms with social change has been slow, with the media helping to reinforce negative and misinformed stereotypes. ${ }^{56}$

${ }^{53} 65 \%$ of those responding to a 2014 World Values Survey conducted in Georgia felt that women should have equal opportunities to work and be economically independent.

${ }^{54}$ Caucasus Research Resources Center. 2014. Women's Political Participation in Georgia. In M. Barkaia and A. Waterson, eds. 2018. Gender in Georgia: Feminist Perspectives on Culture, Nation and History in the South Caucasus. New York: Berghahn Books.

55 N. Gvianishvili. 2012. Transgender Persons in Georgia. Situation of LGBT Persons in Georgia. Tblisi: Women's Initiatives Supporting Group. http://women.ge/data/docs/publications/WISG_situation-of-lgbt-persons-inGeorgia_ENG-www.pdf.

${ }^{56}$ N. Gvianishvili. 2018. Being Transgender in Georgia. In M. Barkaia. and A. Waterson, eds. Gender in Georgia: Feminist Perspectives on Culture, Nation and History in the South Caucasus. New York: Berghahn Books. 


\section{B. Women and Political Representation}

SDG 5 calls for governments to "ensure women's full and effective participation and equal opportunities for leadership in all levels of decision-making in political, economic and public life." ${ }^{57}$ There is public support for increasing women's role in decision-making, yet their political representation remains low in Georgia. The number of female parliamentarians has risen from $6.4 \%$ in 2008 , but was still only $16 \%$ in $2017,{ }^{58}$ far below the target of at least $30 \%$ outlined in the BPFA and a mere 23 out of 150 parliamentary seats. Georgia ranked 114th of 144 countries for women's political empowerment in the 2017 WEF GGI (footnote 20), and 123rd of 193 countries in the 2018 Inter-Parliamentary Union (IPU) global table of women in national parliaments. ${ }^{59}$ The latest WEF GGI figures place Georgia in 114th place of 144 countries for women's political empowerment. ${ }^{60}$ This means Georgia is well below the global average for most middle- and low-income countries in gender equality indicators, as well as lagging behind other South Caucasus and Central Asia's former Soviet countries such as Armenia, Azerbaijan, Kazakhstan, the Kyrgyz Republic, Tajikistan, and Turkmenistan (footnote 20).

Women are also underrepresented in local government. In executive branches of the government in Georgia, women account for only $15.4 \%$ of Sakrebulo members (footnote 33). This figure remains unchanged since the 2010 elections. In the local self-government elections held in October 2017, all elected mayors of municipalities were male. ${ }^{61}$

A key factor hampering women's political empowerment is the current composition of political parties. Few women are included in the top $10 \%$ of most party lists or in leadership contests, which means their chances of being elected are greatly reduced. In rural communities, female participation at the local government level is even lower. In 2015, members of the Task Force on Women's Political Participation called for the introduction of a zebra quota system that would require every second person on proportional party electoral lists to be female, with an incentive of $30 \%$ additional funding for cooperating parties. ${ }^{62}$ However, the proposed revisions were strongly rejected by the majority male Parliament. Smaller parties voluntarily take up this quota system, ${ }^{63}$ but not larger parties-including the current ruling party, Georgian Dream. In 2017, the task force led a reinvigorated campaign for a mandatory zebra quota system for proportional party lists, with public support demonstrated by 37,000 signatures collected from citizens. The revisions would have guaranteed at least $25 \%-$ $30 \%$ female representation in Parliament. However, in March 2018, the Parliament of Georgia voted down the legislative proposal. ${ }^{64}$

${ }^{57}$ UN Department of Economic and Social Affairs. https://sustainabledevelopment.un.org/sdg5.

${ }^{58}$ IPU. 2017. Women in Politics. https://www.ipu.org/resources/publications/infographics/2017-03/women-in -politics-2017.

${ }^{59}$ IPU. 2018. http://archive.ipu.org/wmn-e/classif.htm (accessed 2 May 2018).

${ }^{60}$ WEF. 2016. The Global Gender Gap Report. http://www3.weforum.org/docs/GGGR16/WEF_Global_Gender_Gap_ Report_2016.pdf.

${ }^{61}$ Central Election Committee. 2017. Municipal Elections 2017. http://cesko.ge/eng/elections/2017.

${ }^{62}$ Georgia has a mixed parliamentary system where $50 \%$ of parliamentarians are elected by majority vote and $50 \%$ by proportional party lists.

${ }^{63}$ K. Chkeidze. 2018. Women's Political Representation in Post-Soviet Georgia. In M. Barkaia and A. Waterson. Gender in Georgia: Feminist Perspectives on Culture, Nation and History in the South Caucasus. New York: Berghahn Books; and GEC of Georgia and UNDP (2018), footnote 33, p. 50.

${ }^{64}$ The bill was endorsed by three parliamentary committees and was also supported by civil society groups, as well as foreign diplomats. Further discussions are planned in the near future. 
Table 3: Comparative Ranking of Georgia for Women's Political Representation for South Caucasus Region and Central Asia Former Soviet Union Countries

\begin{tabular}{|lc|}
\hline Country & Ranking \\
\hline Armenia & 108 \\
\hline Azerbaijan & 117 \\
\hline Georgia & 123 \\
\hline Kazakhstan & 59 \\
\hline Kyrgyz Republic & 100 \\
\hline Turkmenistan & 65 \\
\hline Tajikistan & 102 \\
\hline Uzbekistan & 123 \\
\hline
\end{tabular}

Source: Inter-Parliamentary Union (IPU). Women in National Parliaments. http://archive.ipu.org/wmn-e/ classif.htm (accessed 30 January 2018).

The culture of political parties and other institutions needs to change if more women are to successfully run for office. ${ }^{65}$ Recruitment for most parties lacks transparency, while the overwhelmingly male leadership and importance of having internal party connections means that men are often favored over women. Moreover, the long, unsociable hours politicians are expected to work prevent many women from putting themselves forward because of concerns over coordinating their professional lives with unpaid care responsibilities. Furthermore, evidence indicates that achieving high office in Georgia is not a guarantee that women will promote gender equality (footnote 32 ). One reason may be female politicians' concern that focusing on women's rights will undermine their credibility. Therefore, continued support and capacity building is vital once women are elected to political office (footnote 65).

\section{Women's Economic Empowerment}

\section{Employment and Labor Rights}

Official figures from the National Statistics Office of Georgia indicate that the participation of women ages 15 and over in the formal labor market is lower than that of men. From 2012 to 2017, women's employment rate varied between $46.9 \%$ and $50.8 \%$ while men's employment rate did not deviate much from $63 \% .{ }^{66}$ Among younger women, the discrepancy is significantly higher-in 2014, only 19\% of women ages between 15 and 34 were employed, compared with $35 \%$ of men. The lower labor participation rates for younger women can be largely attributed to the burden of unpaid care work, including caring for small children below school age, coupled with the lack of subsidized childcare facilities, such as kindergarten schools. A recent WB study notes "childcare responsibilities are associated with greatly reduced female labor force participation; this negative association is large enough to swamp the positive impact of more education on women's labor activity (footnote 11). According to the WB "evidence

65 Interview with program manager, National Democratic Institute (NDI), 15 November 2017. Tbilisi.

66 National Statistical Office of Georgia. 2017. Employment and Unemployment: Economic Status by Sex. Tbilisi: Government of Geogia. 


\section{Box 3: The United Nations Global Compact}

An international instrument that could be effectively deployed to promote gender equitable practices for both public and private sector employers in Georgia is the UN Global Compact, a strategic policy initiative for businesses that are committed to aligning their operations and strategies with 10 universally accepted principles in the areas of human rights, labor, environment, and anticorruption. UN Women developed seven Women's Empowerment Principles that focus on the gender dimensions of Corporate Social Responsibility and are being promoted by UN Women in Georgia. So far, eight private companies in Georgia have signed up to the principles, which are

1. Establish high-level corporate leadership for gender equality through the introduction of company-wide goals and targets for gender equality supported at the highest level and enshrined in company policies.

2. Treat all women and men fairly at work; respect and support human rights and nondiscrimination by ensuring equal pay remuneration, including benefits, for work of equal value, ensuring workplace policies and practices are free from gender-based discrimination, offering flexible working conditions, workplace crèches, and ensuring at least $30 \%$ of women in decision-making positions.

3. Ensure the health, safety, and well-being of all women and men workers by providing safe work conditions, establishing a zero-tolerance policy toward all forms of violence at work, including verbal and/or physical abuse and sexual harassment, and providing health insurance and other services to employees.

4. Promote education, training, and professional development for women by investing in workplace policies and programs that open avenues for skills building and advancement of women, and encouraging women to enter nontraditional fields of work.

5. Implement enterprise development, supply chain, and marketing practices that empower women by expanding business relationships with women-owned enterprises, including small businesses, and supporting gender-responsive solutions to accessing credit.

6. Promote equality through community initiatives and advocacy, working with business partners, community leaders, and others to eliminate discrimination and open opportunities for women and girls, and leading by example.

7. Measure and publicly report on progress to achieve gender equality, measuring and reporting progress in promoting gender equality, and making public gender-responsive company policies.

Source: Based on Women's Empowerment Principles. http://www.weprinciples.org/Site/Ungc/.

shows that these [gender] gaps result in a loss in economic output equivalent to $11 \%$ of gross domestic product." ${ }^{67}$

Therefore, provision of affordable crèches and kindergarten schools is vital to encourage more young women to enter the formal market. However, changes are also required within the workplace given that implicit, often unrecognized, forms of discrimination by employers contribute to the gender imbalance. It is not uncommon for prospective employers to favor male applicants or to ask young women if they plan to get married or have children, and for

${ }^{67}$ World Bank Group. 2017. Gender-Based Violence in Georgia: Links among Conflict, Economic Opportunities and Services. Washington, DC. p viii. 
this to affect their choice of candidate. ${ }^{68}$ There are also no consistent practices for maternity provision. Under the GE Law, women are entitled to 6 months' paid maternity leave, and this is further endorsed by the Georgian Labor Code. ${ }^{69}$ However, only public sector institutions are obliged to implement this legislation, and many private sector companies opt out, providing minimal maternity leave for female employees. The possibility of sharing parental leave is rarely an option. The GE Law has no provision for paternal leave and many companies make it difficult for men to take it, even when they are entitled to do so. A revised Labor Code with clear rules for employees on gender-related discrimination would be a step forward, ${ }^{70}$ but without the enforcement of rules for all private sector companies, supported by clear reporting mechanisms, women will continue to be marginalized in the workplace.

\section{Gender Stereotypes in Employment}

Occupations are strongly segregated by gender, with a much higher share of men in stereotypically male professions such as engineering, construction, energy, transport and communications, and gas and water supply. The majority of women are employed in jobs with a caring or service aspect. Women account for around $75 \%$ of employees in the healthcare and social sectors, $60 \%$ of those working in the hospitality sector, and $84 \%$ of school teachers (footnote 66 ). Less than $10 \%$ of women work in construction, while $23 \%$ are employed in transport and communications. ${ }^{71}$

Many women also work in the informal sector and in unpaid subsistence farm work. Farm work undertaken by women includes managing crops and livestock, dairy production, and processing. A UN Women study found that, on average, women engage in agricultural work 80 days per year more than men. ${ }^{72}$ However, this work often goes unrecognized and is undervalued because it is not remunerated, forming part of the unpaid care work women are expected to take on. Georgia's women are also engaged in other informal sector jobs, such as domestic work, where they do not have the protection of formal labor laws and consequently face many potential risks, including unsafe work conditions and violence.

Even within these female-dominated sectors, women rarely occupy executive, upper management, or other decision-making positions and have fewer opportunities for promotion and career advancement. ${ }^{73}$ Men generally own and manage farms. According to official statistics, men head $70 \%$ of farms, while only $30 \%$ of women are farm owners or managersand the figure is much lower for women under the age of $60 .{ }^{74}$

${ }^{68}$ Several informants made this point, including Dmitri Tskitishvili, who is a member of Parliament and chair of Gender Equality Council.

${ }^{69}$ Amendments to the Labor Code in 2014 increased official leave during pregnancy, childbirth, and care of infants from 477 to 730 calendar days, of which paid leave increased from 126 to 183 calendar days. Georgia-Beijing +20 (2014), footnote 42.

70 Interview with Dmitri Tskitishvili, footnote 44.

${ }^{71}$ National Statistics Office of Georgia. 2017. Men and Women in Georgia: Statistical Publication. http://www.geostat. ge/cms/site_images/_files/english/health/W\&M\%20in\%20ENG_2017.pdf.

72 A UN Women study found that men engage in agriculture 263.92 days per year compared with 344.25 days for women. UN Women. 2016. Gender Assessment of Agriculture and Local Development Systems. Tbilisi.

${ }^{73}$ A study of employment patterns in three Georgia ministries in 2005-2008 revealed increasing vertical segregation in which the numbers of female staff in leadership positions (minister, deputy minister, head of department, deputy head of department, lead specialists) decreased, while women in assistant positions remained the same. J. Charita, J. and M. Tokmazishvili. 2009. Gender Dimensions of the Financial Policy of Georgia. UNDP SIDA. http:// undp.org.ge/new/files/24 802145990 gender-dimersion-eng.pdf.

${ }^{74}$ UN Women. 2016. Gender Assessment of Agriculture and Local Development Systems. Tbilisi. 


\section{The Gender Wage Gap}

The composition of the labor force by educational attainment is similar among women and men. According to the latest available figures, approximately $10 \%$ of participants in the labor market completed primary school, $60 \%$ of men and $58 \%$ of women completed secondary school, and $30 \%$ of men and $32 \%$ of women completed tertiary education (footnote 11). Despite the gender parity in educational attainment, there is a significant wage gap between men and women. For example, women earned $65 \%$ of what men earned on average in 2015 (footnote 71). This is partly because men are generally employed in higher-paying professions, command higher entry-level salaries, and attain more senior positions than women due to vertical segregation. ${ }^{75}$ Georgia also does not have minimum wage legislation. Where women and men work in the same fields, men's average monthly wages are often higher than those of women. For example, in 2015 , women earned $81 \%$ of men's monthly salary in the transport and communications sector. This is true even in sectors where women are predominantly employed, such as education, healthcare, and hospitality. In 2015, women's average monthly salary in the education sector was $65 \%$ of men's average monthly salary, and in restaurant and hotel work, it was $66 \%$ of men's salary. One exception to this trend are the electricity, water, and gas sectors where there is near gender parity in wages, with women earning $97 \%$ of men's salary (footnote 71).

High levels of unemployment following the global recession in 2008 to 2009 deepened the gender wage gap. Unemployment is largely focused in urban areas: in 2011, unemployment rates were close to $30 \%$ among both urban men and women, and around $6 \%$ among women and $9 \%$ among men in rural areas (footnote 11). Unemployment rates were lower among women at $12.7 \%$ in 2017 compared to $15 \%$ for men (footnote 71 ). However, women are more likely than men to be among the long-term unemployed. That the largest share of unemployed women has completed higher education points to a serious gender gap in skilled professions (footnote 71).

\section{Women Entrepreneurs}

Both men and women are engaged in entrepreneurship in Georgia, but women are more likely to own micro-businesses and least likely to own large businesses. Nearly $40 \%$ of Georgia's firms have at least one female owner but, at the same time, women are in the top manager position in only $19.7 \%$ of firms (footnote 32 ).

A recent study of Georgia's female entrepreneurs ages between 32 and 60 revealed many started their own businesses due to the need for an income to support their families due to high unemployment and the need for flexible working conditions. Most respondents said their desire to start a business is supported by Georgia's flexible and entrepreneur-friendly state policies. Barriers encountered by the women include lack of relevant skills and knowledge, and poor access to start-up capital and bank loans. Lack of financial capital due to a low level

75 Another contributing factor to the gender wage gap could be some women's decision to take the option of early retirement at the age of 60 , thus reducing overall female earnings in particular sectors. 
of property and asset ownership was identified as a particular problem faced by women wishing to start a business. ${ }^{76}$

The Ministry of Economy and Sustainable Development (MOESD) launched a program with the Ministry of Agriculture to promote entrepreneurship in Georgia, including among women. The program aims to stimulate local production, especially in the least economically developed regions, by providing training and access to financing. The program is not designed to address gender issues directly, but created new opportunities for women (footnote 49). Both government agencies increasingly give support for potential female entrepreneurs (see Box 11, section IV. B.). However, this support needs to be provided systematically, with adequate funding in tandem with shifts in gender norms that undermine women's access to resources. Additionally, it is important to ensure women's economic empowerment is not restricted to self-employment, but that women have equal access to well-paid formal employment with wages on a par with those of men.

\section{Gender Gap in Access to Land and Property}

Georgia's women are legally entitled to own and inherit land and property, ${ }^{77}$ but customary practices usually give privileges to men in property inheritance, ownership, and administration. ${ }^{78}$ According to the pilot survey on Measuring the Asset Ownership and Entrepreneurship from a Gender Perspective, ownership of core asset is higher for men than for women, and the biggest gender gap is in ownership of agricultural land. According to the study, men account for more than twice the number of documented owners of agricultural land compared to women; there is a $13 \%$ gender gap in documented dwelling ownership; livestock ownership among women is $38.6 \%$, and $41.6 \%$ among men; and men are more able to exclusively sell assets than women..$^{79}$ The preference for passing land and property to sons rather than daughters is particularly high among ethnic minority families. ${ }^{80}$

The low level of property ownership for women means they experience challenges in obtaining loans and grants for the purpose of moving beyond micro-businesses to small and medium businesses due to lack of collateral. However, data on the number of women and men accessing loans, the size of the loans, assets used to guarantee the loans, the type of loan institution (commercial bank, microfinance institution (MFI), private lender), and repayment rates are needed to fully understand the gender implications of accessing credit in Georgia ${ }^{81}$

${ }^{76}$ I. Bakhtadze. 2012. Key Features of Georgian Women Entrepreneurs Recent Success: Why it is Important for Georgia to Share US Experience. Paper from 7th Silk Road International Conference Challenges and Opportunities of Sustainable Economic Development in Eurasian Countries. Tbilisi.

77 Article 21 of the Constitution guarantees equal property rights: "Abrogation of the universal right to ownership, acquisition, alienation or inheritance of property shall be inadmissible" (Chapter One, Article 21.1, Constitutional Law of Georgia. www.parliament.ge/uploads/other/28/28803.pdf).

${ }^{78}$ N. Dudwick. 2015. "Missing Women” in the South Caucasus: Local Perceptions and Proposed Solutions. Report 94705. Washington, DC: World Bank.

${ }^{79}$ Geostat and ADB. 2018. Pilot Survey on Measuring Asset Ownership and Entrepreneurship from a Gender Perspective. Tbilisi.

${ }^{80}$ European Centre for Minority Development in Georgia. 2013. European Needs Assessment of Ethnic Minority Women in Georgia. Tbilisi.

${ }^{81}$ The available data indicates as many women as men take out loans from both financial institutions and other lenders, and both men and women experience similar challenges in accessing business-related credit. E. Duban (2010), footnote 32 . However, this information conflicts with qualitative information gathered through interviews for this report, and with evidence from many other global regions. 


\section{Human Development}

\section{Gender Dimensions of Education}

Primary and secondary education is free in Georgia. Primary education is compulsory for all children, but attendance in secondary school is optional. There is parity in school enrollment rates in Georgia for both boys and girls, at both primary and secondary levels. ${ }^{82}$ This translates into high national literacy rates, which are at nearly $100 \%$ for both women and men (footnote 71). However, figures indicate around a quarter of boys and girls do not attend primary school ${ }^{83}$ particularly children in disadvantaged and marginalized groups (footnote 33). A slightly higher number of boys (91\%) of the relevant age group progress to secondary school than girls (87\%). ${ }^{84}$

In contrast, enrollment in tertiary education in Georgia is well below the average for the Eastern Europe and Central Asia region: only 27\% of boys and 33\% of girls in 2012 attended higher education, compared with an average for the Europe and Central Asia region of $60.5 \%$ of boys and $69.9 \%$ of girls. ${ }^{85}$ High tuition fees may be one factor contributing to these low figures. Patriarchal norms may also create a barrier for girls' higher education-studies find that if parents cannot afford to educate all their children, they prefer to send their sons to university or technical college. ${ }^{86}$ There is also currently little incentive to pursue tertiary education as unemployment is higher among those with higher qualifications. For example, the rate of unemployment among young people with vocational training is $8 \%$ higher than unemployment rate of young people with only elementary education (footnote 17).

The school dropout rate is low, but varies between regions. In some remote and impoverished rural areas, girls may be required to leave school early to help with unpaid care work at home while boys may leave to support agricultural and other activities. Among ethnic Azerbaijani communities living in Georgia, parents may place less emphasis on the education of girls, and some girls leave school as early as ages 13 or 14 to marry. ${ }^{87}$

The quality of education is a challenge in Georgia. In the Organisation for Economic Cooperation and Development's (OECD) 2009 Program for International Student Assessment, Georgia's students scored below the OECD average. Only $38 \%$ of students were considered proficient in reading literacy at or above the threshold set for functional illiteracy, and only $31 \%$ were proficient in mathematics at or above the threshold (footnote 17). In 2012, the Ministry of Education and Science revised the national curriculum and textbooks to achieve a more outcome-oriented approach to learning. ${ }^{88}$ Earlier in 2018, the Prime Minister of Georgia announced that education reforms will be implemented in the next 5 years, until 2023, to align Georgia's educational system with Europe's system of education. The

82 Based on figures from population census in 2014. Footnote 71.

${ }^{83}$ UNICEF. 2011. An Update of the Situation of Children in Georgia. Tbilisi: UNICEF.

${ }^{84}$ World Bank Gender Data Portal. http://datatopics.worldbank.org/gender/country/georgia (accessed 1 February 2018).

${ }^{85}$ World Bank Gender Data Portal. http://datatopics.worldbank.org/gender/country/europe-\&-central-asia (accessed 1 February 2018).

${ }^{86}$ Millennium Challenge Account Georgia, Social and Gender Integration Plan. 2014. http://www.mcageorgia.ge/ $\mathrm{cms} / \mathrm{kcfinder} /$ upload/files/Social\%20and\%20Gender\%20Integration\%20Plan\%20Aug\%2027\%2C\%202014.pdf.

${ }^{87}$ World Bank Group (2016), footnote 11; GEC of Georgia and UNDP (2018), footnote 33; and Georgia-Beijing + 20 (2014), footnote 44 .

${ }^{88}$ Georgia-Beijing + 20 (2014), footnote 44 . 
reforms will focus on strengthening five core areas: early and preschool education, general education, vocational education, higher education, and science; and training teachers in new teaching methodologies, building new school infrastructure, and increasing teachers' salaries. A 10\% allocation from GDP, private sector investment, and donor funds will fund this education reform. ${ }^{89}$

A significant challenge in the education system is the implicit gender biases and norms replicated through the curriculum and in the experience of education for many young people in Georgia. A gender analysis conducted in 2012 found that Georgian school textbooks often perpetuate gender stereotypes and discriminatory ideas. Representations of famous or powerful men far outnumber those of women, who are either invisible in the textbooks or portrayed in traditional domestic roles..$^{90} \mathrm{~A}$ lack of gender sensitivity among teachers was also observed. The study showed that many teachers treated female and male students differently, using terms such as "smart" and "strong" for boys and "emotional" and "weak" for girls (footnote 90).

Gender norms and perceptions also strongly influence the choice of subjects for specialist study. Over $80 \%$ of students of arts and humanities, and over $70 \%$ focusing on health at tertiary level are female, while around a quarter of women are studying engineering, manufacturing, and construction. ${ }^{91}$ Girls are less likely than boys to say that they aspire to education in science, technology, engineering, and mathematics (STEM) programs. Teachers, parents, and textbooks reinforce the notion STEM subjects are more appropriate for boys than girls. ${ }^{92}$

To meet the demands of development, adopt policies, and improve economic diversification, Georgia needs knowledge solutions at different levels. Improvements are needed in public sector management, workforce skill development, civil service reform, budget planning, and public audits. To meet the labor market's demands, vocational institutions should ensure they attract a gender-balanced pool of students for fields of study, such as STEM subjects in high demand among employers. Gender norms and stereotyping should be addressed to facilitate more gender-equitable employment opportunities. As a member of the Central Asia Regional Economic Cooperation (CAREC), Georgia should focus on inclusive skill building in sectors where women are currently less visible, as well as emphasizing the role of gender equality in the development process, contributing to building regional knowledge platforms, and conducting gender-sensitive labor market analyses. Further, Georgia's partnership with the EU places emphasis on ensuring better matching of skills and jobs in the labor market, as well as providing equal opportunities in education and in employment. The Association Agreement between the EU and Georgia ${ }^{93}$ includes provisions on gender equality and antidiscrimination in employment. The Deep and Comprehensive Free Trade Agreement

${ }^{89}$ Government of Georgia. 2018. Prime Minister Presents Education Reform Vision at Ikalto Monastery Complex. http://gov.ge/print.php?gg=1\&sec_id=497\&info_id=67853\&lang_id=ENG.

${ }^{90}$ I. Khomeriki et al. 2012. Gender Equality Issues in Studying Social Sciences: Gender Analysis of Textbooks. Tbilisi: Centre for Civil Integration and Inter-Ethnic Relations. Quoted in Beijing + 20 (2014), footnote 42; and GEC of Georgia and UNDP (2018), footnote 33.

${ }^{91}$ World Bank. Europe and Central Asia: Gender at a Glance. http://documents.worldbank.org/curated/ en/404201467993235447/pdf/100410-BRI-GAAG-GEO-041315-PUBLIC-Box393223B-ADD-SERIES-Europeand-Central-Asia-ECA-gender-at-a-glance.pdf (accessed 1 February 2018).

92 Millennium Challenge Account-Georgia. 2014. Social and Gender Integration Plan. 2014. http://www.mcageorgia. $\mathrm{ge} / \mathrm{cms} / \mathrm{kcfinder} / \mathrm{upload} /$ files/Social\%20and\%20Gender\%20Integration\%20Plan\%20Aug\%2027\%2C\%202014. pdf. Cited in GEC of Georgia and UNDP (2018), footnote 33, p. 65.

93 Association Agreement between the European Union and Georgia. 2014. https://eeas.europa.eu/delegations/ georgia/6913/association-agenda-between-georgia-and-eu_en (accessed 29 October 2018). 
with the EU includes provisions on enhancing economic opportunities of men and women, and commitment to gender equality and antidiscrimination, especially in employment (footnote 11). The fulfillment of these commitments is envisaged to contribute to meeting key global indicators in the areas of education and economic empowerment.

\section{Gender Dimensions of Health}

Georgia inherited a centralized healthcare model from the former Soviet Union when it gained independence in 1991. As part of the reform process, a decentralized health system has been developed in several stages. The first wave occurred in 1995 when 12 regional health authorities were established. In 2007, a state insurance policy for healthcare was introduced where hospitals would provide care under insurance schemes for the general population and state-funded care to vulnerable people, such as the very poor, internally displaced persons (IDPs), and the elderly (footnote 30 ). As of 2018, 95\% of healthcare provision is private, and the majority of Georgians rely on private health insurance schemes, paid by the Ministry of Labor, Health and Social Protection (MOLHSA). However, these state-funded health insurance schemes often do not cover the most basic needs and exclude chronic diseases. Women from minority communities face particular challenges in their access to healthcare facilities and medical service. ${ }^{94}$

Life expectancy differs for women and men in Georgia: the majority of women live to over 80 years old, outliving men by almost 9 years. Lifestyle factors contribute to this disparity: $57 \%$ of all males over the age of 15 are tobacco consumers compared with $6 \%$ of females (54), and drug and alcohol use is very common among men. ${ }^{95}$

Over the past 2 decades, the overall health and life expectancy of mothers and children improved due to modern methods of family planning, perinatal care and delivery, combined with parenting classes. Georgia made significant progress in reducing its maternal mortality ratio (MMR). According to the Maternal Mortality Estimation Inter-Agency Group, in 2000, the MMR was 60 per 100,000 live births in Georgia and by 2015, this was reduced to 36 per 100,000. In 2016, the estimated MMR was 23 per 100,000 (footnote 26). According to data from the 2010 Georgia Reproductive Health Survey, almost $98 \%$ of pregnant women received at least one antenatal examination. ${ }^{96}$ However, attention is needed to ensure all women have equal access to these facilities as the figures showed there was a gap in the use of these services between urban women (93\%) and rural women (86\%). ${ }^{97}$ Many IDP women living in IDP settlements also lack access to sexual and reproductive health and services information (footnote 28).

To address these challenges, a National Maternal and Newborn Health Strategy (2017-2030) and a 3-year Action Plan (2017-2019) were introduced in 2017. The main goal is to ensure that by 2030, there are no preventable deaths of mothers or newborns, or stillbirths, that

\footnotetext{
${ }^{94}$ EU Special Advisor on Constitutional and Legal Reform and Human Rights in Georgia. 2013. Georgia in Transition, Report on the Human Rights Dimension: Background, Steps Taken and Remaining Challenges: Assessment and Recommendations by Thomas Hammarberg. Tbilisi: EU/PDO.

${ }^{95}$ World Bank. 2011. World Development Report 2012: Gender and Development. Washington, DC: World Bank.

${ }^{96}$ National Center for Disease Control and Health. 2012. Reproductive Health Survey, Georgia 2010: Final Report. Tbilisi: NCDC.

${ }^{97}$ World Bank Group (2016), footnote 11; Duban (2010), footnote 32.
} 
every child is wanted, and that every unwanted pregnancy is prevented through appropriate education and full access to all high-quality integrated services. ${ }^{98}$

\section{E. Violence against Women}

\section{Prevalence of Violence against Women in Georgia}

VAW committed by a husband, partner, or other family member is a critical and pervasive issue for Georgia, but one which has historically remained behind closed doors. During the Soviet rule, the myth that Communism eradicated all forms of gender inequality resulted in a political denial of domestic violence and a concomitant lack of data on the issue, despite common knowledge it was happening in many families. This veil of silence was intensified in the Stalinist era from the mid-1930s, when Soviet-led public narratives about the vital role of the family, coupled with Georgian notions of the family as a private space for state resistance prevented women from speaking up about domestic abuse. ${ }^{99}$

It is only since the Rose Revolution that data was collected revealing the extent of physical, sexual, emotional, and economic abuse experienced by women. UN Women and the National Statistical Office conducted a nationwide survey on VAW in 2017, targeting women and men ages 15-64. The survey found that approximately $14 \%$ of women ages 15-64 (one in seven women) reported they experienced physical, sexual, and/or emotional violence at the hands of an intimate partner. ${ }^{100}$ The study also found that $19 \%$ of women and $9.6 \%$ of men knew of someone who had experienced domestic violence. The highest rates of reported intimate partner violence were in Tbilisi and Samtskhe-Javakheti, a region in southern Georgia.

Evidence indicates violence is often not an isolated act. A nationwide baseline survey on VAW conducted in 2009 by UNFPA found that $34.7 \%$ of women experiencing intimate partner violence had been injured multiple times (especially those in the 45 to 49 -year-old age group). ${ }^{101} \mathrm{~A}$ Georgian $\mathrm{NGO}^{102}$ conducted a survey where $22 \%$ of respondents reported their husbands subjected them to physical violence every week, while $43 \%$ said their husbands used physical violence after learning their wives were pregnant. According to the Ministry of Internal Affairs' data on restraining orders issued in 2016, cases of violence affected 3,012 families and 5,667 people in total. Of those cases, 2,877 restraining orders were approved. Data on abusers and victims showed that $92 \%$ of the abusers were men and $87 \%$ of the victims were women. ${ }^{103}$ VAW is also perpetrated by non-partners: according to the UN Women survey, $26 \%$ of women had experienced sexual violence and/or sexual harassment by a person who was not an intimate partner. ${ }^{104}$

98 Zampas et al. (2018), footnote 28; GEC of Georgia and UNDP (2018), footnote 33.

99 T. Sabedashvili. 2018. The Domestic Violence Challenge to Soviet Women's Empowerment Policies. In Gender in Georgia: Feminist Perspectives on Culture, Nation and History in the South Caucasus, New York: Berghahn Books.

100 UN Women and National Statistical Office. 2017. National Study on Violence against Women: Summary Report. http://www2.unwomen.org/-/media/field\%20office\%20georgia/attachments/publications/2018/national\%20 study\%20on\%20violence\%20against\%20women\%202017.pdf?la=ka\&vs=1053.

101 M. Chitashvili et al. 2010. National Research on Domestic Violence against Women in Georgia. Fountain: Tbilisi.

102 N. Kuprashvili. 2010. Georgia Combating Violence in the Home, Institute for War \& Peace Reporting. http://www. iwpr.net/?p=crs\&s=f\&o=361469\&apc_state=henpcrs.

103 Public Defender's Office of Georgia. 2016. Women's Rights and Gender Equality. Tbilisi.

${ }^{104}$ UN Women and National Statistical Office (2017), footnote 100. 
There is a broad consensus this emerging information only scratches the surface of a deeply rooted social problem and many women fail to report their experiences due to a combination of shame and a tacit acceptance of violence as an integral part of married life. During focus group discussions (FGDs) for the 2009 UNFPA study, many participants indicated they or their daughters were subjected to emotional abuse or other forms of violence from men, but they learned to tolerate it as "no big deal" and preferable to being single or divorced. The courage and self-awareness required to speak out against abuse is reflected in the words of one respondent, who noted "I was experiencing...economic violence from my husband and psychological violence from his family, but it took me 17 years to realize I was a victim." 105 The 2017 UN Women survey found that though attitudes are beginning to change, particularly among younger people, VAW is still widely accepted. Nearly a quarter (22\%) of women and $31 \%$ of men agreed that VAW is justifiable in some circumstances. Only $38 \%$ of men and $44 \%$ of women felt that marital rape is a crime (footnote 100).

There is a notable disparity between observed incidences of domestic violence and formal data for the IDP community. Despite reports from experts and services providers that female IDPs are particularly vulnerable to abuse due to psychological trauma, and growing problems of unemployment and alcohol and drug dependence among men, almost all of them "state they have never encountered any violence and have never been victims of violence themselves" (footnote 48).

The true extent of the problem also remains unknown because of the perceived stigma attached to formally reporting incidences or seeking assistance following domestic violence. Thirty-three percent of women and 50\% of men participating in the 2017 survey said that family abuse is a private affair and not a legal matter (footnote 100). Ingrained social taboos, compounded by patriarchal norms about men's marital rights, make reporting sexual violence particularly difficult. Mistrust of law enforcement agencies adds to women's unwillingness to report it. Those who do go to the authorities often find they are unable to deal with the problem effectively, or do not take reports of emotional and psychological violence seriously (footnote 101). A WB study found that $82 \%$ of female respondents did not report VAW to the police, with $61 \%$ worried that reporting it would stigmatize them. ${ }^{106}$ Financial concerns and fears about safety prevent many abused women from leaving a husband when there are few economic opportunities, especially for those with young children. Although services, such as shelters for victims of abuse, are increasingly provided, there is low awareness of these among the most vulnerable women. All these constraints mean violence often escalates to dangerous and even fatal levels before it is brought to the attention of the authorities (footnote 101).

\section{Factors Contributing to Violence against Women}

There is a clear connection between gender norms that prescribe male and female roles and behaviors, and VAW social narratives of Georgian masculinity that portray men as household heads, decision makers, and providers for their families are increasingly at odds with the realities of male unemployment and the tendency for wives to be wage earners or even the main breadwinners. The frustrations at this perceived failure can quickly translate into resentment and jealousy, resulting in emotional and psychological abuse that can turn into

\footnotetext{
105 Interview with VAW survivor living in a shelter. M. Chitashvili et al. (2010), footnote 101.
}

${ }^{106}$ World Bank Group (2016), footnote 11; World Bank Group (2017), footnote 67. 
physical and sexual abuse, especially when fuelled by alcohol. ${ }^{107}$ However, deeper underlying factors, relating to gender inequality and linked to conservative ideas about tradition and male power, have the effect of normalizing violence, including abusive remarks as well as physical and sexual abuse, within relationships between men and women. Public awareness-raising and ground-level work with both women and men are required to bring about the radical shifts in perceptions and behaviors needed to address VAW. This is beginning to happen in Georgia, exemplified by the "He for She" campaign, but considerable work and resources are still needed for lasting change.

\section{Measures to Combat Violence against Women and Girls}

In 2006, the Law of Georgia on the Prevention of Domestic Violence, Protection, and Assistance of Victims of Domestic Violence (DV Law) was introduced, supported by 2-year National Gender Action Plans (NAPS) on the Elimination of Violence, Protection, and Support to its Victims and the inclusion of domestic violence in the mandate of the State Fund for Protection. Prior to this, there was no specific domestic violence legislation in Georgia. Local NGOs, international donors, and parliamentary champions strongly supported the introduction of the DV Law. The passing of the draft Law was galvanized by a surge in public awareness and demand, following a high-profile case in 2005 where the wife of a well-known politician murdered her husband in self-defense after suffering years of systematic abuse. ${ }^{108}$ The DV Law marked the first time domestic violence was officially recognized as a crime, defined as the "violation of constitutional rights and freedoms committed by one family member in relation to other family member, through physical, psychological, economic, sexual abuse, or violence." ${ }^{109}$ It included provisions for protecting and rehabilitating victims, for working with perpetrators to prevent re-offense, and for criminal prosecution, where necessary.

The initial version of the law was vague and very difficult to implement, due to a lack of clear procedures and services to deal with perpetrators and to protect victims of abuse. Another barrier to effective implementation of the law was the failure of government representatives to take it seriously. ${ }^{110}$ Many (often male) police officers also demonstrated very poor understanding of the issues and failed to intervene effectively in cases of domestic abuse (footnote 48). In 2014, the widely publicized news that 17 women were murdered in cases of domestic violence was another watershed moment for Georgia, prompting much stronger actions to address and prevent VAW. ${ }^{111}$ The DV Law has been bolstered through the ratification of the Council of Europe Convention on Preventing and Combating Violence against Women and Domestic Violence (the Istanbul Convention) in 2014. The convention establishes codes for extending protection to victims of VAW, and prosecuting perpetrators. Revisions to the law expand the definition of VAW beyond domestic violence to "any act of gender-based violence that results in or is likely to result in physical, sexual, psychological, or economic harm or suffering to women, including threats of such acts, coercion or arbitrary deprivation of liberty, whether occurring in public or in private life" (footnote 51).

107 Chitashvili et al. (2010), footnote 101; World Bank Group (2017), footnote 67.

108 R. Pkhakadze and T. Jamaspishvili. 2007. Domestic Violence, a Burning Issue in Georgia. In Gender and Development.15(1).Oxford:TaylorandFrancis.http://www.tandfonline.com/doi/abs/10.1080/13552070601179052.

109 Law of Georgia on Gender Equality. https://matsne.gov.ge/en/document/download/91624/3/en/pdf.

110 T. Sabedahvili. 2011. The Identification and Regulation of Domestic Violence in Georgia (1991-2006). PhD dissertation, Budapest, Central European University.

111 Public Defenders Office of Georgia. 2015. Violence against Women and Domestic Violence in Georgia, Special Report. Tbilisi. 


\section{Responding to Cases of Violence against Women}

VAW is an extremely complex issue that requires multi-stakeholder cooperation and effective, ground-level interventions to assist survivors, prosecute perpetrators, and help to prevent further abuses. The signing of the Istanbul Convention places the onus on the government to ensure the adequate provision of safe spaces and services, such as postcrisis support and rehabilitation for women survivors of abuse, as well as programs to prevent perpetrators from re-offending. At present, the DV Law recognizes the need for such measures, and both state mechanisms and NGOs provide assistance that includes short-term crisis centers and longerterm shelters. However, complex criteria for admission to shelters and insufficient funding means the urgent needs of many women are not currently being met (Box 4). Furthermore, monitoring by the Public Defender's Office of Georgia (PDOG) found that people with disabilities still face problems accessing shelters (footnote 111).

Implementing the DV Law also requires greater awareness and knowledge of key professionals-including police officers, social workers, healthcare providers, and legal representatives-who have a duty of care for those affected by domestic violence. Evidence indicates current responses are inadequate. Police officers continue to treat victims of domestic violence with indifference and often fail to protect women in life-threatening situations, while many social workers lack specific expertise in domestic violence cases. ${ }^{112}$ Effective coordination of professionals involved in VAW cases is vital for ensuring cases are dealt with in a sensitive and efficient way, and victims are not exposed to further violence. A National Referral Mechanism was established in 2009 to foster cooperation between relevant government entities and services on the issue of VAW, but this resulted in little concrete action (footnote 112).

\section{Box 4: Current Status of Domestic Violence Shelters and Crisis Centers in Georgia}

There are currently five state-run shelters where women can stay up to three months (renewable). Currently the approval process requires a protective or restrictive order, official victim status, or the acknowledgement that the person seeking shelter is the survivor of a domestic violence crime under investigation. Crisis shelters are also available to VAW survivors. Unlike domestic violence shelters, they do not require VAW survivors to attain formal victim status and, therefore, are consistently at full capacity. Currently, there are three crisis centers in Tbilisi and four others throughout the country. Three of the crisis centers are state-run and NGOs run the remaining centers. The crisis centers are improving their coordination with the shelters, so that a survivor can transfer from the first to the second if necessary.

Sources: Public Defenders Office of Georgia. 2015. Violence against Women and Domestic Violence in Georgia, Special Report. Tbilisi.; World Bank Group. 2017. Gender-Based Violence in Georgia: Links among Conflict, Economic Opportunities and Services. Washington, DC. p. 81.

112 N. Javakhishvili and N. Buthsashvili. 2018. Domestic Violence in Georgia: State and Community Responses, 2006-2015. In M. Barkaia. and A. Waterson, eds. 2018. Gender in Georgia: Feminist Perspectives on Culture, Nation and History in the South Caucasus. New York: Berghahn Books. 
Steps are being taken to address these gaps. For example, the PDOG is working with agencies such as UN Women to pilot and monitor services that include hotlines, crisis centers, and shelters for abused women. They worked with lawyers and prosecutors through Georgia's bar association to develop special prosecutors' capacity on VAW, and with members of the ministry of corrections to support rehabilitation and behavior change or correction programs for perpetrators. Police officers, healthcare providers, and government ministers also received training. The focus is increasingly on institutionalizing on-the-job training for all relevant professionals. For example, all newly recruited police officers now receive training on VAW, and lawyers have continuous training on gender as part of their membership of the bar.

\section{The Need for Wider Understandings of Violence against Women}

Despite a far higher level of commitment to addressing VAW, the current law still fails to address many forms of violence. Notably, sexual harassment is not formally recognized, despite being widespread and pervasive in Georgia in the workplace and in public places. One in five women participating in the 2017 UN Women survey on VAW reported experiencing sexual harassment, including inappropriate staring or leering, sexually suggestive comments or jokes and inappropriate hugging, touching or kissing (footnote 100). In a recent survey about experiences of using public transport, $45 \%$ of respondents said they were exposed to some form of sexual harassment in the past 6 months. ${ }^{113}$

Gender equality activists from multiple organizations-including the Women's Information Fund of Georgia, UN Women, and UNDP-united around the issue to lobby government and raise public awareness. In October 2017, they presented a petition signed by over 1,000 people to the Committee for the Protection of Human Rights, demanding legislative prohibition of sexual harassment and amendments to the law and the Code of Administrative Offenses. Some government bodies demonstrated a commitment to tackling the problem-for example, the Ministry for Internal Affairs has been working with UN Women to develop a risk assessment methodology that will enable the development of measures, such as video monitoring. However, the media and many politicians significantly downplayed the seriousness of the issue. ${ }^{114}$

Female genital mutilation (FGM) $)^{115}$ and early marriage remain concerns for many women and girls who are part of the $13 \%$ Muslim population. There are no official statistics, but FGM is reportedly practiced among the Avar community in the Kakheti region of Georgia, and with strong indications the practice is covertly done in other communities. ${ }^{116}$ Under the Istanbul Convention, FGM is now criminalized, with potential imprisonment of up to 4 years. However, cultural sensitivities and deep-rooted beliefs make it difficult to enforce this legislation (footnote 33). Efforts are under way to engage local religious and community leaders in helping to change attitudes.

113 ADB. 2015a. A Safe Public Transportation System for Women and Girls. Policy Brief. Manila: ADB.

114 This was the opinion of many key informants interviewed for this report.

115 FGM is a practice that involves altering or injuring the female genitalia for nonmedical reasons, and is internationally recognized as a human rights violation. OHCHR, UNAIDS, UNDP, UNECA, UNESCO, UNFPA, UNHCR, UNICEF, UNIFEM, and WHO. Eliminating Female Genital Mutilation-An Interagency Statement. 2008. Cited in GEC and UNDP (2018), footnote 33, p 58.

116 GEC of Georgia and UNDP (2018), footnote 33, p. 59. 


\section{F. The Sex Ratio Gap}

There is a notable gap between the numbers of boys and girls born in Georgia, leading to a worrying situation of "missing girls." 117 According to the UNDP Human Development Report, in 2018 the sex ratio for 0-4 year olds was 108 boys for every 100 girls in Georgia. ${ }^{118}$ The gap has narrowed in recent years. Between 2003 and 2013 the sex ratio it was an average of 112 boys for every 100 girls (footnote 11). This difference is more prevalent in rural regions, where the average sex ratio gap during 2005-2013 was 113.4, as compared to 109.5 in urban areas (footnote 11). The gap is also much higher in regions with a high proportion of ethnic Azeris or Armenians, but evidence indicates that sex selection also occurs in some primarily Georgian communities. ${ }^{119}$ The phenomenon is largely created by parental preference for sons, ${ }^{120}$ coupled with a desire for smaller families and the available technology to both determine the sex of a child and terminate pregnancies. Evidence indicates a strong desire among Georgia's parents for a male heir who will continue the family line ${ }^{121}$ and provide financial security in their old age. ${ }^{122}$ Patriarchal norms that confer higher social status on boys and men also add to the pressure to bear sons. ${ }^{123}$

\section{G. Specific Challenges for Conflict-Affected Women and Girls}

The internal displacement of thousands of people remains a critical concern for Georgia. During the civil wars of the 1990s, an estimated 233,453 people were displaced. In 2008, the conflict between Georgia and the Russian Federation led to the further displacement of approximately 22,000 Georgians living in the disputed territory, many of whom have not been able to return to their homes (footnote 11). According to the Ministry of Internally Displaced Persons from the Occupied Territories, Accommodation, and Refugees of Georgia, in 2013,

117 M. Das Gupta. 2015. "Missing Girls" in the South Caucasus Countries: Trends, Possible Causes, and Policy Options. Policy Research Working Paper 7236. Washington, DC: World Bank.

118 UNDP. 2018. Statistical Update: Human Development Reports. http://hdr.undp.org/en/countries/profiles/GEO.

119 Birth registration data in 2010-2016 indicate the highest ratios of boys to girls were recorded in the Southeastern regions of Khvemo Kartli (113.2) and Samtskhe-Javakheti (111.5), which have relatively large numbers of Azeri Muslim, Armenian, and other ethnic minority populations-and also in the primarily Georgian regions of Kakheti (113.2). C. Guilmoto and S. Tafuro. 2017. Sex Ratio at Birth in Georgia: an Overview Based on the 2014 General Population Census Data. Tbilisi: UNFPA and Geostat.

120 This preference seems more pronounced among men. During a 2013 study of attitudes and perceptions among young men and women in Georgia, the vast majority of the interviewed males preferred to have a son if they were to have only one child, whereas relatively more females reported that the child's sex was irrelevant. Footnote 49.

${ }^{121}$ Inheritance follows a patrilineal system in Georgia, meaning the descent line is obtained through men (mostly from father to sons), which women join by marrying a male family member. Female members of the family usually move to their husband's family home or village when they are married. C. Guilmoto. 2015. Gender-Biased Sex Selection in Georgia. Tbilisi: UNFPA, UNDP, and UN Women.

122 C. Guilmoto and S. Tafuro. 2017. Sex Ratio at Birth in Georgia: An Overview Based on the 2014 General Population Census Data. Tbilisi: UNFPA and Geostat. http://georgia.unfpa.org/sites/default/files/pub-pdf/4.\%20SRB\%20 Trends_ENGL_Final_0.pdf.

${ }^{123}$ A recent study notes "In Western Georgia, men don't celebrate the birth of a baby girl, but fire off a gun when a boy is born." Dudwick. 2015. "Missing Women" in the South Caucasus: Local Perceptions and Proposed Solutions. Report 94705 (February). World Bank, Washington, DC. p. 12. 
there were 258,599 IDPs in the country, of which 157,276 were living in IDP centers and 101,323 with relatives or in private housing. ${ }^{124}$

In addition to the intense loss and trauma of leaving behind homes, property, and communities, IDPs face unemployment, ${ }^{125}$ have few rights, and are rarely involved in elections or consultations on development projects. They also lack basic necessities, including food, health services, clean water, decent roads, schools, hospitals, and energy, ${ }^{126}$ but steps are being taken to address these issues. ${ }^{127}$ In 2014, a survey of female and male IDPs from Abkhazia found one of their most urgent needs was the installation of a natural gas supply (footnote 124).

Thousands more people are also still affected by conflict in Georgia, for example, for those who live near the Administrative Boundary Lines (ABLs) between Georgia and the breakaway regions such as Abkhazia: movement is very restricted for citizens of Georgia who live in villages adjacent to the ABLs. These women and men are obliged to go through military checkpoints at the ABLs when they wish to cross into Georgia for employment or other purposes. Evidence indicates they are also dealing with the daily stress of living close to a conflict zone, with high levels of addiction to drugs and alcohol among men and antidepressants among women. ${ }^{128}$

Around half of IDPs are women and girls. ${ }^{129}$ Many live below the poverty line, lacking access to livelihoods and with poor living conditions. ${ }^{130}$ Domestic violence is a growing threat as tensions rise within IDP families, but female IDPs rarely report incidences of VAW because of fear or stigma, and acceptance of violence as a social norm (footnote 32). According to the Public Defender's Office of Georgia:

The conflicts have particularly affected women and children, resulting in a shifting socioeconomic role for women which, in turn, exposed them to increased risk of violence. Trauma inflicted by the conflict and persistently poor social conditions are directly correlated with domestic violence, with women and children most often the victims. This problem is exacerbated by a lack of proper protection mechanisms, crisis centers, and psychological rehabilitation services. ${ }^{131}$

Women's participation is also low within the two official negotiation processes concerning the conflict, the Geneva International Discussions and the Incident Prevention and Response Mechanism. ${ }^{132}$

${ }^{124}$ UN Women Georgia. 2014. Study on Needs and Priorities of IDPs and Conflict-Affected Women and Girls. Tbilisi: UN Women.

${ }^{125}$ In a survey led by UN Women in $2014,50.7 \%$ of IDPs and other conflict-affected people stated they were unemployed. Footnote 124.

126 UN Women (2014), footnote 124; UN Women Georgia. 2016. No One Left Behind: Lessons Learned from the Grassroots Mobilisation of Women in Georgia. Tbilisi: UN Women.

127 Personal communication, Margaret Shakarashvili, April 2018.

${ }^{128}$ Interview with the director, Women's Information Center (WIC). 15 November 2017. Tbilisi.

129 Internal Displacement Monitoring Center. http://www.internal-displacement.org/europe-the-caucasus-andcentralasia/georgia/figures-analysis (accessed 4 May 2018).

${ }^{130}$ Interview with the director, WIC, footnote 128.

131 Public Defender's Office of Georgia. 2017. Special Report on the Rights of Women and Children in Conflict-Affected Regions. p. 36. Cited in GEC and UNDP (2018), footnote 33.

132 GEC and UNDP (2018), footnote 33. Based on data from World Bank, Gender Data Portal. http://datatopics. worldbank.org/gender/country/georgia. 
The Government of Georgia put some measures in place to support conflict-affected people and made efforts to ensure greater gender sensitivity in this area. In 2012, the government adopted a regulation to provide IDPs with appropriate long-term accommodation, in line with the UN Guiding Principles on Internal Displacement. This was amended in 2013 to enable all family members, including women and juveniles, to become the co-owners of property provided by the government (footnote 88 ).

The Parliament of Georgia adopted a NAP on the UN SCR 1325 in December 2011. The NAP sets out actions under the four pillars of the UN SCR 1325:

1. Support of women's participation in peace building and security.

2. Addressing women's needs in conflict prevention and eliminating all forms of VAW during conflict and in the post-conflict period.

3. Protection of women and girls from all threats, including social, physical, economic, and political.

4. Relief and recovery: Supporting the specific needs of women and girls.

A Mental Health Strategy and Action Plan, 2015-2020 commits the government to meeting the needs of particularly vulnerable groups, including women and IDPs. However, the plan does not include any specific measures tailored to the needs of women, IDPs, and people living in conflict-affected areas (including women); and they do not specifically address mental health consequences of conflict-related sexual violence. IDP and conflict-affected women, including those living near the ABL, reported a lack of information and access to psycho-rehabilitation services (footnote 28).

\section{H. Activism on Gender Equality and Women's Rights}

The recent advances in gender-responsive legislation, government mechanisms, and public awareness can largely be attributed to the lobbying of Georgia's civil society groups, who use the media and other methods to campaign for issues, such as VAW, sexual harassment, and women's political representation. However, although at least 80 active NGOs focus on gender issues, these are largely dedicated to specific concerns, such as domestic violence and women's political representation. Greater solidarity between organizations is needed to lobby government around a shared gender equality and women's rights platform. ${ }^{133}$ The seeds of a national women's movement are present, but are currently most evident among young, urban women. There is an identified need for greater social mobilization that reaches beyond Tbilisi to other regions of Georgia, manifested both through local actions and national solidarity to ensure that the gender equality agenda continues to make progress and to mitigate against possible backlash.

133 T. Sabedashvili. 2007. Gender and Democratization: The Case of Georgia, 1991-2006. Tbilisi: Heinrich Böll Foundation. https://ge.boell.org/sites/default/files/gender_and_democratisation_eng.pdf. 


\section{Box 5: Some Key Gender Statistics for Georgia}

- Georgia ranked 94th of 144 countries in the 2017 World Economic Forum Global Gender Gap Index (WEF GGI).

- Georgia ranked 114th of 144 countries for women's political representation in the 2017 WEF GGI.

- Women constituted only 16\% of members of Georgia's Parliament in 2018.

- One in seven women have experienced physical, sexual, and/or emotional violence by an intimate partner.

- 109 boys were born for every 100 girls in 2017.

- Women are in the top manager position in only $19.7 \%$ of firms.

- Women earned $64 \%$ of what men earned on average in 2017.

- $\quad$ Only $18 \%$ of women ages between 15 and 24 were employed in 2016.

Note: All statistics correct as of February 2018.

Sources: UNDP. Human Development Reports. http://www.hdr.undp.org/en/composite/GII (accessed 1 May 2018); World Economic Forum (WEF). 2017. The Global Gender Gap Report. http://www3.weforum. org/docs/WEF_GGGR_2017.pdf. 


\section{Asian Development Bank in Georgia}

\section{A. ADB Gender Policy and Processes}

ADB is committed to ensuring gender-sensitive development that contributes to gender equality and women's empowerment. In 1998, ADB progressed from a Women in Development (WID) to a Gender and Development (GAD) approach, which sees gender as a crosscutting issue influencing all social and economic processes. ${ }^{134}$ The shift reflects the recognition that women's needs and concerns cannot be addressed in isolation from the social and personal relations through which gender inequalities are perpetuated and reproduced. ADB holds that addressing these inequalities is not only an issue of rights or social justice, but also that "it makes economic sense and is good development practice." ${ }^{135}$ ADB is committed to reflecting gender dynamics and promoting gender equality through a twin-track strategy that promotes gender mainstreaming in all areas of its work-including macroeconomic and sector work, and lending and technical assistance (TA) operations-while retaining a specific focus on women

\section{Box 6: Key Elements of ADB's Gender Policy}

The key elements of ADB's gender policy are as follows:

- Gender sensitivity: Observe how ADB operations affect women and men, and take into account women's needs and perspectives in planning processes.

- Gender analysis: Systematically assess the impact of a project on men and women, and on the economic and social relationship between them.

- Gender planning: Formulate specific strategies that aim to bring about equal opportunities for men and women.

- Mainstreaming: Consider gender issues in all aspects of ADB's operations, and encourage women's participation in decision-making for development activities.

- Agenda setting: Assist partner country governments in developing strategies, plans, and targets to reduce gender disparities, particularly in education, health, legal rights, employment, and income-earning opportunities.

Source: ADB. 2003. Gender and Development Framework and Policy. Manila.

${ }^{134}$ WID, adopted by many development agencies, was criticized because it treated women's issues in isolation from their relationships with men. This led to an industry-wide shift to a GAD approach, which focuses on the social relations between women and men, and recognizes the importance of actively engaging men in changing inequitable gender norms. ADB. 2003. Gender and Development Framework and Policy. Manila; and R. Shahrashoub and C. Miller. 1995. From WID to GAD: Conceptual Shifts in the Women and Development Discourse. United Nations Research Institute Occasional Paper Series. United Nations Research Institute for Social Development.

135 ADB. 2003. Gender and Development Framework and Policy. Manila. p 3. 
and girls in projects where special assistance is needed to ensure their full participation in mainstream projects.

These principles are supported through mechanisms that include

- an ADB-wide Gender and Development Plan of Action;

- increased in-house gender capacity, including the recruitment of country and regional gender advisors;

- gender-integrated country partnership strategies;

- the inclusion of gender considerations as part of the initial poverty and social assessment required for all ADB projects; and

- the development of GAPs with clear targets and outcomes for all projects with a Gender Equality categorization (see below).

\section{ADB Gender Categories}

$\mathrm{ADB}$ follows a four-tier gender categorization system to assess the extent to which gender is integrated in project design. These categories were used since 1998 to monitor ADB's gender performance. The categorization is applied "at entry" when projects are approved.

The categories are

1. Gender Equity Theme. The project outcome directly addresses gender equality and/or women's empowerment by narrowing gender disparities through promoting access to social services, such as education, health, water supply, and sanitation; access to economic or financial resources or opportunities; access to basic rural or urban infrastructure; and enhancement of women's voice and rights.

2. Effective Gender Mainstreaming (EGM). The project outcome does not directly address gender equality or women's empowerment, but the project outputs are designed to deliver tangible benefits to women by directly improving their access to economic or financial resources, social services, or basic rural or urban infrastructure, and/or by enhancing their voice and rights, which contribute to gender equality and women's empowerment.

3. Some Gender Elements. The project is likely to directly improve women's access to services, opportunities, and improved voice, but does not meet EGM design criteria; or efforts were made to include some gender features.

\section{No Gender Elements.}

All program and projects are now required to include gender elements. The ADB Operational Plan, 2013-2020 $0^{136}$ calls for meaningful integration of gender issues into country partnership strategies, for a higher number of programs with a gender equality theme, and for an emphasis on gender-focused policy dialogue, as well as knowledge and capacity development on gender.

136 ADB. 2013. Gender Equality and Women's Empowerment: Operational Plan 2013-2020. Moving the Agenda Forward in Asia and the Pacific. Manila. https://www.adb.org/sites/default/files/institutional-document/33881/files/ gender-operational-plan.pdf. 


\section{B. ADB in Georgia}

Country Partnership Strategy, 2014-2018. ${ }^{137}$ Georgia joined ADB in 2007 and is in the final year of its first 5-year strategy, 2014-2018. The strategy is aligned with the Government of Georgia's Socioeconomic Development Strategy (2020), which is focused on the achievement of inclusive economic growth by ensuring macroeconomic stability and effective public administration, improving private sector competitiveness, developing human capital, and increasing access to finance.

ADB's 2014-2018 Country Partnership Strategy (CPS) focuses on promoting inclusive and environmentally sustainable economic growth, while developing human resources and supporting social protection initiatives. The strategy addresses identified gaps in transport; logistics; energy; municipal infrastructure; skilled labor (particularly engineers and technicians); business skills; micro, small, and medium-sized enterprises (MSMEs); and limited access to affordable bank financing. It supports private sector development, good governance, innovation, and knowledge solutions. The strategy emphasizes the importance of integrating gender dimensions across all areas of work.

Priority areas for ADB assistance for Georgia are as follows: ${ }^{138}$

- Transport, with a focus on regional connectivity and enhancing Georgia's potential as a transit corridor, improving some secondary roads, and developing sustainable urban transport systems.

- Water and other urban infrastructure and services, with a focus on developing reliable water and sanitation systems and facilitate better urban mobility.

- Energy, generation and transmission network development, particularly the creation of an environmentally sustainable energy network.

- Finance and public sector management (PSM), with a focus on public resource management, pension systems, capital market development, and the promotion of MSMEs.

\section{Mainstreaming Gender in ADB Operations and Priority Sectors in Georgia}

The section below reviews the five priority sectors for the CPS 2014-2018: transport, sustainable urban transport, water supply and sanitation (WSS), energy, and finance and PSM-through a gender lens. ${ }^{139}$ It outlines the current situation with regard to mainstreaming gender and promoting gender equality through ADB-funded projects in Georgia. It sets out key gender issues and concerns, and outlines good practices and progress against ADB

137 Based on ADB. 2014. Georgia Country Partnership Strategy, 2014-2018. Tbilisi: Georgia Resident Mission. https:// www.adb.org/documents/georgia-country-partnership-strategy-2014-2018.

138 More detailed information on each priority area is included in section C.

139 References for the section are ADB program documents, such as ADB project completion reports, GAPs, and monitoring and evaluation. The section also benefits greatly from qualitative data gathered through interviews and focus group discussions with relevant stakeholders (see Appendix for details). Interview questionnaires were developed with guidance from ADB Gender Sector Tool Kits, and from the gender advisor in the Georgia Resident Mission. All recommendations include inputs from key informants. 
gender equality requirements and indicators in project GAPs. It also provides specific gendersensitive entry points and recommendations for each sector.

\section{Transport}

The Government of Georgia's 2020 strategy outlines the important potential role of Georgia as a regional hub and trade corridor linking Europe and Asia, and connecting landlocked countries by road, due to its geographical position. This is viewed as an important source of revenue and a driver of economic growth. The government also highlights the need to improve secondary roads, many of them in poor condition. The final priority is to develop the transport-related workforce with improved knowledge and skills.

ADB strongly supports these priorities, working mainly with the Ministry of Regional Development and Infrastructure. The priority investment is the improvement of Georgia's East-West Highway (EWH), which provides the fastest and shortest surface transport link between the East and West of the country, and is part of the Europe-Asia corridor through the Caucasus. The Road Corridor Investment Program was initiated in $2009 .{ }^{140}$ The first and third tranches were used for the construction of a new 30-kilometer $(\mathrm{km})$ two-lane road and for upgrading $2 \mathrm{~km}$ of a two-lane road to a four-lane road bypassing Kobuleti, a Black Sea resort area. The aim of the bypass, which was completed in 2018, is to reduce travel times and relieve congestion in Kobuleti, to improve the quality of life for town dwellers, and attract a higher number of tourists. Currently, the construction of the Batumi bypass road is in progress. The implementing agency for these projects is the Roads Department of the Ministry of Regional Development and Infrastructure.

The amount of $\$ 80$ million was also provided for improving $50 \mathrm{~km}$ of secondary roads, under the Secondary Roads Improvement Project, launched in 2017 and will run until 2022. ${ }^{141}$ The project is implemented by the Roads Department. Additionally, two upcoming road projects in the pipeline are the Khevi-Ubisa road project, which is part of the $\mathrm{EWH}$; and construction of the Kvesheti-Kobi road, a section of the North-South Highway. ${ }^{142}$ The project also includes road safety awareness campaigns and capacity building for Roads Department staff and contractors on road management. ${ }^{143}$ In addition, ADB is supporting the formulation of a national transport policy for more efficient, accessible, and sustainable transport.

Efforts are made to pursue gender equality in roads projects, but some are classified as No Gender Elements, and others as Some Gender Elements. Due to a perception there are no specific gender concerns relating to the construction and use of bypasses and other major roads, no GAP was developed for the Kobuleti bypass project. However, the secondary road project has a GAP.

As the ADB Tool Kit on Gender and Transport highlights, ${ }^{144}$ "transport infrastructure and services are often incorrectly considered 'gender neutral.' It is wrongly assumed that transport projects equally benefit men and women and there is no significant difference in their travel

${ }^{140}$ ADB. 2009. Report and Recommendation of the President to the Board of Director-Georgia: Road Corridor Investment Program. Manila.

141 ADB. 2016. Project Administration Manual, Georgia: Secondary Roads Improvement Project. Manila.

142 ADB. 2017. Country Operations Business Plan-Georgia: 2018-2020. Manila.

143 ADB. 2014. Georgia Transport Sector Assessment, Strategy and Road Map. Manila.

${ }^{144}$ ADB. 2013. Gender and Transport Tool Kit: Maximizing the Benefits of Mobility for All. Manila. p. 1. 
patterns, modes of transport access, and utilization of transport infrastructure and services... Gender dimensions of transport become more evident when transport investments are viewed in terms of enabling the mobility of people for different purposes and needs, and by different modes-which are experienced differently by women and men, girls and boys-rather than in terms of mere investment in hard infrastructure that equally benefit all social groups."

Gender issues and concerns for the transport sector include the following:

\section{Access and Safety}

When thinking about the gender aspects of safety for major roads, it is important to consider who will be using them, how, when, and why. For example, less than half of all drivers in Georgia are female, ${ }^{145}$ particularly those women living in regional areas, so they are more likely to be passengers or use public transport to access schools, hospitals, or workplaces. Because of this, they may need to walk or wait for public transport alongside roads, often with small children. They may need to cross roads to reach their destinations. Elderly women and men, and children going to and from school may also use roads in this way. The lack of suitable walkways, bridges, or bus stops raises serious safety concerns for these pedestrians, in addition to accessibility issues (footnote 144). At night, the risk is intensified if appropriate lighting is not provided.

Male road users are more likely to drive on the roads, hence, may not encounter the same issues, but will be exposed to potential risk if there are no mandatory road safety measures in place for drivers, or if road signs and lighting are inadequate. Basic amenities, such as disabled access toilets, must also be provided for both women and men on major transport routes. ${ }^{146}$

As of 2018, road safety and social audits are conducted as part of the road design process, but the methodology for these often does not include research with men and women in local communities. Where public consultations were held, their main purpose was often to share information about the roads. ${ }^{147}$ Therefore, to gain a detailed picture of local user needs, it is vital to conduct gender analyses that will inform the design of all roads, and to continue monitoring user satisfaction and perceptions of safety. ADB road projects started incorporating road users' perception surveys into the project design.

\section{Equal Opportunities for Employment in Transport}

As with other sectors included in this report, the rapidly growing transport sector could potentially offer employment opportunities to women as well as men in both administrative and technical areas. In practice, few women are employed in this sector, and the majority work in the stereotypically "female" social and environmental safeguards field and in human resources. ${ }^{148}$ Theoretically, women are encouraged to apply for more technical posts such as in engineering, but in practice, they tend not to do so. Currently, the Ministry of Regional Development and Infrastructure sponsors internships. If this opportunity is actively promoted

145 In 2016, 31,503 licenses were issued to women, compared to 63,919 issued to men. Only 154,481 cars are registered to women, compared to 872,014 registered to men. National Statistics Office (2017), footnote 71.

${ }^{146}$ Interview with the associate project analyst and GFP at the ADB Georgia Resident Mission, 16 November 2017, Tbilisi.

147 One informant noted that a risk of holding public consultations is all expectations raised cannot be met in the decision process, and can create negative feelings. Interview with the deputy chairman of the Ministry of Regional Development and Infrastructure of Georgia, Roads Department of Georgia, 15 November 2017, Tbilisi.

148 Interview. Footnote 147. 
among young women, this could provide an entry point for them to learn about the sector and gain confidence to apply for permanent posts.

\section{Urban Transport}

A priority for $\mathrm{ADB}$ in Georgia is the improvement of environmentally sustainable public transport systems, intercity connections, and pedestrian facilities in Tbilisi and in small towns and secondary cities. Public transport is very popular in Tbilisi, with increasingly high usage of the metro and buses. ${ }^{149}$ The Sustainable Urban Transport Investment Program (SUTIP) was launched in 2010, and is due to run until June 2020. The main executing agency for this program is the Municipal Development Fund (MDF) in Tbilisi. The program focus is the construction of a section of the Zugdidi-Mestia main road, coastal protection in Batumi city, ${ }^{150}$ a new underground metro station at the university in Tbilisi, metro rehabilitation, and the development of the highway between Tbilisi and Rustavi. ${ }^{151}$ In addition, a Tbilisi Transport Strategy was developed as part of the program, and a transport household survey was conducted in 2016.

The overall program of SUTIP is classified as EGM under ADB's project classification; and the four tranches of the program have GAPs. A gender specialist is situated within the MDF, with responsibility for coordinating gender-related activities, supported by an ADB gender specialist. Gender-responsive actions outlined in the SUTIP GAPs include ensuring the specific needs of women are met, facilitating effective outreach to beneficiaries (in particular, on road safety), and taking steps to create gender parity in the urban transport sector. The MDF coordinates with the Tbilisi City Hall and other municipalities included in the program to implement the GAPs. Following through from a successful partnership between ADB and the Tbilisi City Hall in the conduct of the subregional conference on Gender in Urban Transport and Governance, another joint initiative on piloting gender-inclusive urban spaces in Tbilisi is being planned. ADB will support Tbilisi City management in the design of gender-inclusive parks and in undertaking capacity-building activities for gender-sensitive urban planning.

Overall, ADB's requirements to the implementing agency resulted in a more gender-sensitive approach to urban transport. Key challenges to operationalizing the plan are low recognition of the importance of the issue, lack of a separate budget line for gender within MDF, and a lack of political will in the integration of gender dimensions into planned and ongoing work.

Key issues for gender-responsive planning and implementing the urban transport in Georgia are as follows:

\section{Access, Affordability, and Inclusion}

Women and men have different transport needs, which also differ depending on where people live. As noted earlier, in Georgia, women often do not drive cars, ${ }^{152}$ and are more likely to use public transport than men. According to the Tbilisi Transport Company, of the 401,000 passengers who take the bus every day, $60 \%-70 \%$ are women and children. ${ }^{153}$ However, the

149 Tbilisi Transport Company website. http://ttc.com.ge/index.php?lang_id=ENG\&sec_id=74.

150 Batumi is the second largest city of Georgia, located on the Black Sea Coast in the southwest of the country.

151 A commuter-belt town $25 \mathrm{~km}$ from Tbilisi.

152 See statistic on number of women drivers in footnote 145.

153 Fotnote 149. 


\section{Box 7: Testimonial of a Female Public Transport Customer in Tbilisi}

"I study [at] Tbilisi State University. I leave for the University from [Rustavi]. For all these years, I had had to change several transport means, in particular the fixed-run taxi, metro, and bus, depending on traffic jams. After opening of the metro station, university accessing became much easier as it takes less time and I am not tired during traveling as I used to be...it is very beneficial and supporting from economic point of view, as well as from time management standpoint."

Source: Testimonials gathered in 2017 for the Sustainable Urban Transport Investment Program report on completed projects. ADB Resident Mission in Georgia, Tbilisi.

inadequate, regularly scheduled public transport to villages and some secondary towns makes it difficult for women to access employment and higher education opportunities. Better roads are also needed to facilitate mobility to places of work and to markets for female entrepreneurs (footnote 144).

$\mathrm{ADB}$ responded to these social needs through the funding of municipal transport infrastructure. The metro's rehabilitation and improvements to the public bus system in Tbilisi are designed to improve the quality of life for all, and to increase accessibility to workplaces and the University of Georgia. There are no gender-disaggregated figures available for the metro, but it is now the most used form of transport in Tbilisi, with 338,049 trips taken since it opened (footnote 149). ADB emphasized the value of providing clear, accessible information about the services for potential and actual users. Examples include the development of a multimodal transport website launched in 2011, designed to fit all users' needs and provide information on routes, real time information for each metro station and bus stop, and a gender-responsive urban transport road map. Testimonials from a cross-section of students and workers indicate the new services improved the quality of life for both male and female users.

As women are a primary target for these services, the GAP for the first tranche of funding (2010-2018) calls for a $2 \%$ increase in female users of municipal public transport compared to the 2008 baseline. In addition, ADB demonstrates a commitment to facilitating access to public transport by vulnerable groups, such as the elderly, differently abled, and women with small children. The need to pay attention to sidewalks, lights, waiting spaces, and other infrastructure facilities is outlined in the GAP. Anecdotal evidence indicates that women constitute the majority of those using the metro and buses, but there is currently a lack of formal data for tracking usage and accessibility according to gender, age, disability, and other variables. The GAP calls for the establishment of a gender-disaggregated public transport database, but this has been delayed and is expected to be addressed with strong support from the Tbilisi municipal government.

\section{Safety}

Promoting safety for all users of roads and urban public transport is a key concern for ADB. Personal safety on public transport and on roads is a critical issue for women and girls. Women are often subjected to sexual and other forms of harassment when using transport services. A 2015 ADB study on sexual harassment on public transport in Azerbaijan, Georgia, and Pakistan found that $45 \%$ of respondents experienced being sexually harassed on public transport in the past 6 months. As the metro carries 85,000 commuters per day, and assuming at least $50 \%$ of these commuters are female, the responses indicate there may be 3,800 sexual 
harassment incidents per day, 211 per hour, or as many as four female sexual harassment targets every minute on the metro. This translates to an incidence rate of approximately once a week per female commuter (footnote 113).

It is vital to address these issues through provisions such as effective lighting in streets, underpasses, and metros; awareness raising among public transport staff; and a zero-tolerance policy for public transport providers and users. Attention of the male decision makers to the issues of harassment and security for women within the urban transport sector is particularly crucial to eliminate the problem. ${ }^{154}$ With the exception of plans to install better lighting in the metro, there are currently no planned measures to address and reduce incidences of gender-based harassment.

To encourage safer driving among the mainly male car owners using the new road links, brochures were prepared and disseminated to raise awareness of issues on the safety of pedestrians (often women and the elderly), children, and drivers. In addition, awarenessraising workshops on safety issues were conducted with the local population, municipalities, and schools (targeting women and youth in particular). There are indications safety has improved on the roads, but there is still no conclusive gender-disaggregated data to demonstrate the impacts for women, men, and children.

\section{Equal Opportunities for Employment in Urban Transport}

The development of urban transport infrastructure potentially brings significant employment opportunities for both women and men at all levels, including technical and managerial. The GAP includes targets for creating equal employment opportunities for women under each tranche. This requirement is supported by a clause of the Labor Law that obliges the contractor to use best efforts to employ women and local people, including disadvantaged people, living in the vicinity of the project. These targets have made an impact-for example, the overall number of employees at the Municipal Development Fund (implementing agency) was 139 as of July 2018, of which 51 (36.7\%) were women. In the first 6 months of 2018, 33\% of newly hired employees were women. ${ }^{155}$ However, the distribution of work roles is strongly influenced by gender stereotypes. In July 2018, half of the employees in the safeguard unit were women, while there was only one female bus driver. Interviews and FGDs with key informants revealed that entrenched gender norms strongly color perceptions of which jobs are appropriate or attractive for women. Actively encouraging women to apply for posts as engineers and other technical roles, and supporting girls to study technical subjects at tertiary level would help to dispel these assumptions.

Women also have limited representation in decision-making positions, with only two female top managers out of 12 in 2017. ${ }^{156}$ UN Women conducted a gender audit in Tbilisi City Hall to understand the current situation and provide recommendations for addressing these gender gaps. ${ }^{157}$

154 This point was made by several informants, including the GFP at MDF, ADB gender advisor, and interviewees from UNFPA and UN Women, during interviews between 13 November 2017 and 22 November 2017 in Tbilisi.

155 ADB (Georgia Resident Mission). 2018. Georgia SUTIP GAP Monitoring Report. Tbilisi. July. Unpublished report provided to author.

156 Interview with the gender specialist for ADB-funded projects, MDF, 13 November 2017, Tbilisi.

157 Interview with the national program officer, UN Women, 15 November 2017, Tbilisi. 


\section{Promoting Women's Voices in Planning and Implementation}

As women are most likely to use public transport, it is vital their needs and perspectives inform planning, design, and construction. In line with the GAP, a gender analysis was conducted during the preparation stage of tranche 1, based on consultations held with groups of women. In addition, the MDF and local municipalities held public consultations about new roads. Women attended and actively participated in these consultations. There is great value in facilitating these participatory processes in the planning stages as they enable specific needs and concerns to be taken into account, and ensure greater buy-in from women and men in local communities, identifying any potential problems early on. However, there is a risk certain groups could be excluded if special efforts are not made to reach out to them-for example, women with care responsibilities, elderly or disabled women, ethnic minorities, and conflict-affected women. In addition to these consultations, data on needs of female and male customers were collected through a sex-disaggregated household survey conducted in Tbilisi in 2011, with a sample of 25,000 inhabitants, of which $50 \%$ were women. A follow-up survey was conducted in 2016. ${ }^{158}$

To monitor service provision within ADB-funded projects, micro-level committees were established at the community level to enable local people to raise concerns and make suggestions. An ADB requirement is $60 \%$ of members should be women. Affected community members can also register complaints or make suggestions through a website, in person at the mayor's office, or via a hotline. Currently, data are collected on the number of calls to the hotlines, but this is not gender-disaggregated.

\section{Gender Awareness and Training}

The GAP emphasizes the importance of providing gender training for urban transport staff at different levels to raise awareness of relevant gender issues; and to ensure gender dimensions are integrated in a systematic way throughout planning, implementation, and monitoring. In addition to liaising with local municipalities to conduct training sessions, workshops, and presentations, a workshop module on the gender aspects of urban transport and checklists for employees is in place. Several workshops were conducted on issues of gender and transport during the project implementation for staff of the MDF and the City Hall of Tbilisi, particularly for those involved in transport and urban planning. Interviews and FGDs with relevant MDF staff indicate the workshops are useful, and foster understanding of the issues, which led to more gender-sensitive working practices. However, the lack of a dedicated gender budget limits the capacity to run them. This means there are missed opportunities to positively influence employees who may be skeptical about the value of a gender-sensitive approach.

\section{Entry Points for Mainstreaming Gender in the Transport Sector}

Ensure that women's needs, issues, and preferences are taken into account during project planning and implementation. This can be done, for instance, through (i) a thorough gender analysis undertaken in the target areas by a project gender consultant hired specifically for this purpose; and (ii) creating conditions for women's meaningful involvement in project consultations and stakeholder meetings, such as by setting targets for their participation, identifying and addressing barriers for their participation, and building their capacity to express their views. In areas where women's participation is hampered by cultural or

158 ADB (Georgia Resident Mission). 2017. GEO GAP Monitoring Report. Tbilisi. Unpublished report provided to author. 
mobility issues, consultations can be done separately with women, at the times and in places convenient for them. Women's views should be properly taken note of and considered during project planning. Failure to recognize gender issues result in missed opportunities for the projects to address these. As previously discussed, in the construction of the Kobuleti bypass project, no GAP was developed due to the perception there are no gender-specific concerns relating to construction of bypasses and major roads. Gender issues would have been better ascertained if women were consulted during project design.

Highlight the importance of sex-disaggregated data collection in project monitoring mechanisms and in data collections systems of executing and implementing agencies. To plan and design transport infrastructure and services that address the needs of both women and men, data need to be collected, for example, on the different transport use and behaviors of men and women. Without sex-disaggregated data, it is difficult to set genderspecific indicators that need baseline data, and it would be impossible to assess whether targets were achieved. This is true for all sectors. Sex-disaggregated data collection should ideally be included during the project design stage when project monitoring mechanisms are established. Actions can also be included, where applicable, to support the executing and implementing agencies to institutionalize sex-disaggregation in their data collection and monitoring systems. Alternatively, ADB can support TAs aimed at assisting the executing and implementing agencies for this purpose. Lastly, highlighting the need for sex-disaggregated data collection in the "results monitoring" sections in the CPS will send a strong message on the importance of sex-disaggregated data in sector projects and programs.

Support awareness-raising and capacity-building activities for the government and sector partners. Building the capacity of sector planners and implementers to design and implement gender-inclusive projects can accelerate the achievement of gender-related targets in the region. The Conference on Gender in Urban Governance and Transport in Tbilisi in April 2018 provided a useful opportunity for project officers and implementers in Armenia, Azerbaijan, and Georgia to discuss gender issues in transport and urban governance and identify tools and strategies to mainstream gender into these sectors. Supporting more knowledge events similar to this will deepen relevant officials' understanding of gender concepts and ADB's gender policies and requirements; and provide venues for sharing experiences and discussing challenges and good practices for mainstreaming gender in transport projects, as well as facilitating the development of strategies to address these issues.

Take guidance from ADB's transport initiatives and tool kits. Although ADB's Sustainable Transport Initiative (STI) ${ }^{159}$ was published in 2010 and the Tool Kit on Gender and Transport ${ }^{160}$ was published in 2013, these documents are still relevant and can provide guidance for mainstreaming gender in the sector. The STI highlights approaches to address social dimensions of transport, including gender mainstreaming, participation, and negative social impacts. These approaches are in Box 8. The gender tool kit provides detailed discussions on why gender is important for the transport sector; integrates gender in ADB operations; offers guidelines for conducting gender analysis, policy dialogue, and undertaking capacity development; provides gender entry points for transport subsectors; and outlines ways to mitigate social risks.

159 ADB. 2010a. Sustainable Transport Initiative-Operational Plan. Manila. https://www.adb.org/documents/ sustainable-transport-initiative-operational-plan.

160 ADB. 2013a. Gender Tool Kit: Transport Maximizing the Benefits of Improved Mobility for All. Manila. 


\section{Box 8: Addressing Social Dimensions of Transport}

Effective approaches for addressing social dimensions of transport include the following:

(i) More participatory approaches to project planning and project strategies to protect against associated HIV and AIDS and human trafficking risks;

(ii) Incorporate complementary development programs and community-based maintenance;

(iii) Improve transport services;

(iv) Provide improved facilities, such as public toilets and pedestrian and bicycle lanes to make transport accessible and safe for all users and social groups, including women and the elderly;

(v) Apply core labor standards; and

(vi) Use tariff and subsidy options to increase access for vulnerable groups.

Source: ADB. 2010a. Sustainable Transport Initiative-Operational Plan. https://www.adb.org/ documents/sustainable-transport-initiative-operational-plan.

Integrate concrete measures to address social risks associated with transport projects. As suggested in the sexually transmitted infection, among the social risks associated with transport projects are HIV, AIDS, and human trafficking. Some projects recognized the increased mobility brought about by improved transport infrastructure and the influx of labor during construction are likely to increase the risks of sexually transmitted infections and human trafficking. In the Road Corridor Investment Program, project preparatory documents indicated public awareness campaigns and other mitigation measures would be developed to address the potential risks of STIs and human trafficking in the project areas (footnote 140). In SUTIP information campaigns, HIV and AIDS risks were included as an action item under the project summary poverty reduction and social strategy. ${ }^{161}$ However, no actions were actually included in the project design to address these social risks. Concrete measures in the project design and GAP, coupled with specific mechanisms to monitor the implementation of these actions, will ensure any adverse social impacts resulting from increased movement of goods and people will be adequately addressed. These actions may include awareness-raising activities, or a requirement for civil works contractors to undertake measures to prevent trafficking around construction sites. ADB can also support government programs to scale up responses to HIV, AIDS, and human trafficking, to undertake with other development partners, such as the World Health Organization or the International Organization for Migration.

Explore opportunities for increasing women's economic empowerment in the transport sector. Economic opportunities can take the form of (i) employment in project-related jobs, (ii) employment or promotion in transport sector jobs, and (iii) income-generating options resulting from improved transport services and increased connectivity. Most ADB-supported projects require civil works contractors to encourage the employment of local unskilled workers, women, and vulnerable groups; and to comply with core labor standards, including equal pay for equal work, and safe working conditions for male and female workers. These are included in the bidding documents. This is a good practice that should be continued in future transport projects, especially since the Georgia Labor Code requires implementing agencies

161 ADB. 2010b. Report and Recommendation of the President to the Board of Directors: Proposed Multitranche Financing Facility to Georgia for the Sustainable Urban Transport Investment Program. Manila. 
to make efforts to employ women and local people living in the vicinity of all projects. To complement these, ADB can support more proactive efforts, such as information drives on the types of job available for both men and women, training to enhance their capacity to perform the required tasks, and separate rest areas and toilets for women workers.

To facilitate the entry of more women in the transport sector, ADB can support the government's initiatives, such as the Ministry of Regional Development and Infrastructure-sponsored internships for relevant technical fields. ADB projects can encourage the recruitment of more women in the executing and implementing agencies. In the SUTIP project, the design and monitoring framework includes targets for percentage of women among the professional staff hired by the MDF, the executing agency. Conducting training and needs assessments, and collecting baseline sex-disaggregated data on human resources during project preparation will help set reasonable targets for women's participation in capacity-building training. In turn, this will enhance women's chances of being hired or promoted to more technical positions.

Finally, improved connectivity and mobility of people and goods may open new employment and income-earning options. ADB can explore the possibility of designing TA grants linked with transport projects, aimed at building the capacity of women to take advantage of these opportunities. Initiatives can include workshops on the available and emerging transportrelated business opportunities, training on business development, access to and linkages with finance and market opportunities, and other related skills.

Support technical assistance projects that can potentially open entry points for mainstreaming gender in the transport sector. For instance, an initiative to help build the capacity of sector agencies to mainstream gender into their programs and operations is currently being implemented in Georgia under CWRD's gender TA. ${ }^{162} \mathrm{~A}$ training module on gender mainstreaming in the transport sector and a training module for government officials in general are being developed and are expected to be institutionalized and made part of mandatory learning courses for government officials. A series of training for key government officials in the transport sector and other selected sector ministries will also be undertaken. Building the gender mainstreaming capacity of sector officials will facilitate the integration of gender considerations in $\mathrm{ADB}$-supported projects in this sector. In addition, ADB can support other initiatives (e.g., those financed through TA grants or support from other trust funds) specifically focused on gender and the transport sector, such as assessments of women's travel patterns, needs and priorities, or research on the challenges affecting women's use of public transport. The resulting reports or knowledge products on these can help guide project officers to integrate gender concerns into project design.

\section{Water and Other Urban Infrastructure and Services}

$\mathrm{ADB}$ is under the existing multitranche financing facility (MFF) operation developing urban infrastructure fit for purpose as cities and towns grow. ${ }^{163} \mathrm{~A}$ critical component is ensuring

162 The subproject, Building Gender Mainstreaming Capacity of Sector Agencies, is being implemented under the CWRD regional capacity development technical assistance, RETA 9088: Strengthening Gender-Inclusive Growth in Central and West Asia. ADB. 2016. Technical Assistance Report: Strengthening Gender-Inclusive Growth in Central and West Asia. Manila.

163 ADB (2010b), footnote 163; ADB. 2011. Report and Recommendation of the President to the Board of Directors: Proposed Multitranche Financing Facility to Georgia for the Urban Services Improvement Investment Program. Manila. 
basic service delivery of high-quality drinking water, effective sewerage, and wastewater, and solid waste treatment in urban areas, including small towns and secondary cities of Georgia.

ADB is also conceptualizing the development of liveable urban areas through a TA. Projects under this program include the Integrated Urban Plans for Balanced Regional Development, which focuses on the development of inclusive, safe, environmentally sustainable, and economically competitive urban clusters. As part of the project, integrated urban plans and guidelines for selected cities are developed to support inclusivity and ensure urban areas meet the specific needs of differently abled persons, senior citizens, women, and children.

Gender entry for urban services can include supporting development of guidelines on gender-sensitive urban planning as crucial aspects to meet the local population's needs. ADB plans to work in a number of secondary towns and support the development of gendersensitive urban plans to benefit local populations. Possibilities include investing in women and child-friendly urban spaces; planning and providing adequate lighting of streets, bus stops and public spaces; offering separate male and female toilet facilities, especially in urban areas and along highways; and providing accessibility for prams and wheelchairs. These measures could be integrated as part of guidelines in policies and programs guiding urban planners and infrastructure investments.

\section{Water Supply and Sanitation}

Water supply is a priority for the Government of Georgia. The 2020 strategy recognizes the critical need for fully-functioning water supply and drainage systems and high-quality drinking water for the country's development.

Access to water is a problem in some secondary towns. Of the urban population, $8 \%$ presently have no access to piped water supply and $17 \%$ have no access to a reticulated sewerage system. Women are affected most acutely as they are responsible for purchasing, fetching, or pumping water for domestic use. ${ }^{164}$ In response, ADB launched the MFF-GEO Urban Services Improvement Investment Program (USIIP) in December 2011, which is due to end in March 2021. Through the program, ADB is supporting the government's goal to supply the population with water 24 hours a day, to streamline water supply and drainage systems in all urban centers and towns, and to ensure their proper functioning and further improvement (footnote 17).

ADB's main implementing partner for water provision is the United Water Supply Company of Georgia (UWSCG), a state-owned company under the Ministry of Regional Development and Infrastructure, established in 2010 and operating in most regions of Georgia, excluding Tbilisi, Rustavi, and the Adjarian region. ADB's support (\$500 million) funds water and sewerage provision in 12 secondary towns and cities, including three main urban centers and three resort areas, and will benefit more than 350,000 residents. Prior to 2010, local municipalities managed all water and sewerage across Georgia. The UWSCG inherited an inefficient and outdated Soviet-style water and augment sewage infrastructure. Therefore, it is now focused on rehabilitating the existing infrastructure for water and sewage. The company's regional offices and services centers are equipped with modern laboratories for checking water quality, chlorination, and other elements.

${ }^{164}$ N. Sumbadze. 2008. Gender and Society: Georgia. SIDA/UNDP. http://www.ipseng.techtone.info/ files/5113/3491/5442/179-308eng.pdf. 
The USIIP was launched in 2011 and has six tranches. Under gender categorization, the program is classified as EGM and all tranches have specific GAPs. The GAPs were developed based on an initial social and gender analysis in partnership with the UWSCG with additional inputs from a project preparatory technical assistance. The GAPs are in the process of implementation, with technical support and monitoring provided by ADB's gender specialist at the Georgia Resident Mission. Gender is mainstreamed across all project outputs, including infrastructure improvement, institutional effectiveness, and project implementation. Key gender-responsive actions outlined in the GAP are promoting gender-equitable employment opportunities; undertaking gender-disaggregated data collection on beneficiary needs, water use and management, and sanitation practices; and improving outreach and services for beneficiaries, in particular, women in their role as household managers.

The MFF targets improvement of the water supply and sanitation (WSS) in Anaklia, Bolnisi, Chiatura, Gudauri, Jvari, Kutaisi, Marneuli, Mestia, Poti, Telavi, Ureki, and Zugdidi. Since the program began, water supply systems have been constructed or rehabilitated in the areas of Anaklia, Kutaisi, Mestia, and Poti. The impacts of these projects are significant. Whereas prior to the project, Anaklia's residents only had water supply for 12-14 hours a day; now, they and more than 10,000 visitors benefit from 24-hour continuous water supply and effective sewerage. Until the implementation of the project, up to 50,000 residents of Poti were supplied by water for 12-14 hours. Now, they benefit from a 20-24-hour quality water supply. ${ }^{165}$

Key issues for gender-responsive planning and implementation relating to water and sanitation in Georgia are as follows:

\section{Access, Affordability, and Inclusion}

Since the launch of the program, $100 \%$ of households-including those headed by femalesnow have access to 24-hour potable water supply in Anaklia and Mestia, and an additional 21,510 women in Kutaisi and Ureki have improved or new water supply. Progress in sewage provision has been slower, due to the lack of existing sewage networks in many areas and the need to construct new infrastructure. Currently, 100\% of households-including those headed by females-have access to domestic sanitation facilities, and a further 525 households in Ureki are connected to a new sewerage system (footnote 165).

Studies show that improving women's access to water means they have more time for income generation, skills building, and leisure, as well as for responding to their families' needs. ${ }^{166}$

Research for this report revealed the gender empowerment potential of water and sanitation programs (Box 9).

It is essential to ensure water and sanitation services are accessible to all, including the poorest women and households. A UN Women report from $2016^{167}$ highlights the critical importance of "dignified and safe sanitation" as "a human right for all genders" (footnote 167), and argues that sanitation needs are gendered due both to the biological differences between

165 ADB (Georgia Resident Mission). 2017. Completion Report: Completed Projects in WSS Sectors under USIIP Funding. Tbilisi. Unpublished report provided to author.

166 ADB. Gender Checklist: Water Supply and Sanitation. https://www.adb.org/sites/default/files/publication/28735/ gender-checklist-water.pdf.

167 Z. Burt et al. 2016. Towards Gender Equality through Sanitation Access. Discussion Paper No. 12. UN Women. http://www.unwomen.org/-/media/headquarters/attachments/sections/library/publications/2016/towardsgender-equality-through-sanitation.pdf?la=en\&vs=5952. 


\section{Box 9: Water Supply in Poti: Impacts for Women and their Families}

In 2017, the United Water Supply Company of Georgia (UWSCG) completed an ADB-funded project to rehabilitate and privatize water supply in Poti, a major seaport town located on the Black Sea coast in the region of Samegrelo-Zemo Svaneti in the west of the country. The water plant serves residents of Poti and the surrounding area with high-quality water pumped to users' homes 24 hours a day. This marks a sharp contrast with the previous system when poor quality water was available for only a few hours twice a week, usually very early in the morning.

Female users of the services who participated in focus group discussions and key informant interviews noted significant improvements in three key dimensions of their lives: time use, health, and family relations. An unlimited water supply meant they no longer needed to hurry home to undertake household responsibilities reliant on water, such as cooking, cleaning, and washing clothes. They were no longer obliged to wash clothes by hand as the high quality of water was now suitable for use in washing machines. Crucially, it was no longer necessary for the women to wake up at 2 a.m. or 3 a.m. to collect and store water for use throughout the week.

The women consequently felt relieved and more relaxed, were better able to plan in advance and had more free time for themselves and their families. No longer needing to carry heavy buckets of water had benefits for women's physical health, particularly for elderly women. Having a ready source of potable water also had both significant health and financial benefits-buying bottled water was no longer necessary, enabling some savings. These changes dramatically improved the women's and their families' well-being, leading to better relations within the home. One woman said: "there is now peace in my family."

Source: Based on information gathered through focus group discussions and key informant interviews with female users of water services in Poti.

males and females, and to the "norms, expectations surrounding them" (footnote 167). As the Tbilisi water utility is managed by a private company through a public-private partnership contract, improved services brought greater convenience and better quality water; however, this also resulted in increased prices compared to the state-subsidized and managed services in the past. While in theory, special water tariffs are available for Georgia's socially vulnerable members, there are no targeted programs for assisting groups such as the elderly, IDPs, or single mothers. The USWCG's informants reported some customers had difficulty paying their bills. However, the lack of gender-disaggregated data on payment practices in target areas means there is no clear picture of which women and men have most difficulty in paying, the reasons for this, ${ }^{168}$ or which groups may be excluded from the services. Anecdotal evidence collected during the FGD with the UWSCG's staff in Poti indicated that women were most likely to visit or call the water office's complaints hotline to inquire about their bills as revealed during key informant interviews and FGDs. However, as no statistical data is currently collected on those using the hotlines, it is not possible to formally record and track complainants by sex and type of problem raised. Generating this data could help inform more targeted future planning.

168 One untested assumption voiced during an interview with the Head of International Procurement and Donor Relations (16 November 2017, Tbilisi) and an FGD with nine female staff members of USWCG (20 November 2017, Poti) was that local people, used to heavily subsidized state water and sanitation services, were resisting paying for the improved, privatized service. 
A more focused approach where the specific needs of both women and men from different social groups are taken into account could yield significant social and gender equality benefits. In 2011, the UWSCG updated its database software to include a new function to identify the sex of existing customers and will also do a gender analysis of hotline calls for a more targeted approach to its beneficiaries.

\section{Promoting Women's Voices in Planning and Decision-Making}

As the primary collectors, users, and managers of water, women are often most aware of their own and their family's needs, so must be included in consultations, as well as in local and national decision-making bodies. In line with the GAP, efforts have been made to understand the needs of potential users of water and sanitation services, with attention to gender and poverty dimensions. For example, baseline studies of water management, household needs, and sanitation practices that integrated gender and poverty dimensions were conducted in 2013 and 2017 for seven targeted cities. The results of these studies were taken into account during project planning and public outreach campaigns.

The USWCG holds local public consultations attended by both women and men to provide information on forthcoming services, and to answer questions. A target of $50 \%$ female attendance has been recorded for these consultations, but there is no current detailed data to reflect other social dimensions such as age or poverty levels. Collecting this information is important to ensure consultations are as inclusive as possible. Georgia's regional and ethnic differences mean some women may have more freedom to attend and actively participate in public events than others. Social groups, such as the very poor, conflict-affected communities, the disabled, and the elderly may require additional outreach to encourage attendance. Women may also be constrained from attending public events because of care responsibilities in the home, so measures such as providing crèches and holding meetings at appropriate times may be necessary.

\section{Equal Opportunities for Employment in Water and Sanitation}

ADB's gender policy highlights the transformative potential of services, such as water and sanitation, in promoting the women's increased employment. Considerably fewer women than men are employed in the water and sanitation sector in Georgia, with the majority working in administrative office roles. As of 2018, women accounted for $29 \%$ of staff in the UWSCG (625 of 2,734 employees are women). A woman heads the company and one of the three deputy directors of the water utility is a woman. However, engineers are overwhelmingly male, and while there are improvements in women's employment in key management positions, there are still few women in management positions in the UWSCG. For example, women occupy only $11 \%$ of all managerial positions of different levels, and only five women (28\%) of 18 are heads of departments. ${ }^{169}$ Perceptions that women are not equipped to take on technical positions or will find work too tough in this typically male-dominated sector reinforce this gender gap. ${ }^{170}$ Added to this is the reality that fewer girls than boys study technical subjects such as engineering.

ADB's GAP for water and sanitation aims to address this disparity and includes an overall target of $15 \%$ women recruited in all areas of the water sector, a specific target of $30 \%$ female staff in customer care centers for ADB-funded projects, and a requirement to ensure

169 ADB. 2018. Georgia USIIP GAP Monitoring Report. July. Unpublished report provided to author.

170 Interview with the head of International Procurement and Donor Relations, UWSCG, 16 November 2017 , Tbilisi. 
increased representation of women in management. However, no policies are in place yet to formally realize this target though within the UWSCG, efforts were made to recruit more women qualified for the roles: ${ }^{171}$ in January-June 2018, of 153 persons recruited, 35 (22\%) were women. Notably, of an overall 333 meter readers at the UWSCG, 164 (49\%) are women; nevertheless, women's employment in service centers needs to be improved (footnote 169).

Strategies are urgently needed to increase the number of women in managerial positions. Key informants working for the UWSCG cited concerns about balancing home and work life as barriers to their seeking promotions, hence, creating flexible working hours and conditions would represent a positive step forward. It is also vital to continue supporting female managers once they are in their posts. One female head of department in the water and sanitation sector noted she was obliged to prove her worth to an extent not expected of male colleagues, and a change from within is required to address the sector's male-biased culture.

The provision of in-house training for women is also essential to build capacity and increase opportunities. In 2017, 124 women were trained in areas that included water quality management, customer services, and fuel distribution, compared to 491 men. ${ }^{172}$ While this is a positive step, employees of the UWSCG noted they would like more opportunities to request training in technical areas, and to also receive training on gender.

\section{Access to Information and Training}

Information on new water services is provided through brochures, public meetings, launches, and door-to-door communication. However, it is not clear whether women and men from all social groups-including the poorest and most marginalized-are able to access this information. Gaining a better understanding of the most effective ways to reach out to all sections of the population is one way to ensure more equitable distribution of essential services such as water and sanitation.

One of ADB's goals for water and sanitation is the provision of training on efficient water use and sanitation for target communities such as minority women. ${ }^{173}$ Local nongovernment organizations (NGOs) play a pivotal role in providing material and training to women and men in local communities on water, hygiene, and sanitation practices; customer rights; and complaint mechanisms as part of a public awareness-raising campaign in Anaklia, Chiatura, Kutaisi, Marneuli, Mestia, and Zugdidi. Methods used during the campaign included door-todoor meetings, workshops, distribution of brochures, involvement of youth and community leaders, and videos. The UWSCG also produced two brochures: one about general principles of hygiene, sanitation, and wise water use practices; and the other specifically targeting women as household managers (footnote 158).

\section{Entry Points for Mainstreaming Gender in Urban Water and Sanitation}

Ensure inclusion of all groups of the population, including women, during consultations and stakeholder meetings. It is important women are included in all consultations about

171 The head of International Procurement and Donor Relations Department for UWSCG (footnote 168) noted she made a particular effort to employ more women if they have the relevant skills. She said a change in gender-biased culture will only happen if there is a critical mass of female employees and, when that happens, women prove they are more than capable of taking on a range of roles.

172 Figures for January 2018. Supplied by head of International Projects Management Unit of UWSCG.

173 Egis BCEOM International. 2010. Developing an Urban Water Supply and Sanitation Sector Strategy and Regulatory Framework for Georgia. Tbilisi: ADB. 
the project, due to their important role as the main collectors and managers of water for household use and family hygiene. As discussed, the USWCG holds local public consultations related to WSS services, and both women and men attend these, with a $50 \%$ target for female attendance. Many of the ADB-supported projects also provide targets for women's participation in consultations. The USIIP's gender action plan includes targets for women's participation in outreach, surveys, and awareness programs on water use, health, hygiene, and consumer rights. This is a good practice that ensures women's views are heard and taken into account. Similar targets should be included in future projects.

It is important to recognize that women and men from different social groups, regions, and ethnicities may face different challenges in access to water and sanitation. Considering other social dimensions such as regional disparities, barriers faced by those belonging to some ethnic groups, persons with disabilities, the elderly, the very poor, or those in conflict-affected communities, will help ensure the consultations are inclusive, and these groups' concerns are also heard. Conducting poverty, social, and gender assessments during project preparation will help identify these groups, and actions can be included to encourage their participation. These actions may include undertaking outreach activities specifically for these vulnerable groups, holding meetings in convenient locations at suitable times, providing crèches for women with child care, and other domestic obligations.

Support executing agency's efforts to strengthen its sex-disaggregated data collections and analysis systems. The UWSCG has database software in place, updated in 2011 to include mechanisms to identify the sex of existing customers. This was consistent with the USIIP's target for creating a sex-disaggregated consumer database, aimed at developing targeted marketing campaigns for households headed by women. This a good start, which can be maximized through a more in-depth analysis of the data to be used for policy making and project planning. As discussed, sex-disaggregated data is vital to provide a clear picture of which women and men have most difficulty in paying water services, the reasons for this, and which groups may be excluded from the services. Disaggregating data of those who use hotlines to express complaints and feedback will provide an idea of the specific issues affecting women and men from different social groups. Collection and analysis of sex-disaggregated data can also inform better planning, taking into account the specific needs of both women and men from different social groups.

The USIIP also included a target for the sex-disaggregated database for human resource management in the UWSCG. Future projects can strengthen or build on this database and use the data in providing targets for women's participation in capacity-building training, employment, and promotion in the sector.

Support initiatives to build gender mainstreaming capacity of the executing agency. It is crucial that the executing agencies and related agencies associated with water and sanitation services understand not only ADB's gender requirements but the importance and rationale for integrating gender considerations into WSS programs and projects. For instance, as noted earlier, there still are perceptions women are not equipped to take on technical positions in the sector. Projects that include interventions to strengthen the service provider's institutional effectiveness and management capacity, such as the UWSCG in the USIIP project, provide opportunities for integrating gender components. The projects may include actions such as (i) inclusion of gender training as part of the capacity-building programs; (ii) organizing gender workshops for key officials, where they can share experiences with other sector 
officials in the region regarding challenges and good practices in implementing WSS projects; and (iii) providing targets for women's participation in all capacity-building activities. ADB can also support the UWSCG to integrate gender elements in its policies. As discussed earlier, although the agency made efforts to recruit qualified women in more technical positions, no policies are in place to formally realize targets for women's employment.

Increase women's access to training and employment opportunities in the sector. As previously discussed, women account for only $29 \%$ of the UWSCG's staff, $30 \%$ among heads of departments, and only $11 \%$ of all managerial positions, including different levels of managerial positions at the head office and regional branches (footnote 169). Consequently, they are also likely to have less access to training opportunities to advance their careers compared with men. ADB can support interventions to facilitate the entry or advancement of more women in the sector. The USIIP provides targets for women's recruitment in key management positions in the UWSCG, and for their participation in training. Future projects can build on these by analyzing the extent to which the targets were achieved and any challenges encountered. They can also use available sex-disaggregated human resource data as the basis for setting realistic targets.

In addition, $\mathrm{ADB}$ could support needs assessments as the basis for developing more targeted training programs specifically aimed at strengthening women's position in the sector. ADB could also support the development of recruitment processes that remove gender biases and offer a more level playing field between women and men. Lastly, ADB could encourage the creation of more employment opportunities and targets for women during the construction of WSS-related infrastructure. This is consistent with the Georgia Labor Code which requires water and sanitation providers to make efforts to employ women and local people, including disadvantaged people, living in the vicinity of all projects.

Continue women-targeted awareness campaigns on efficient water use, better sanitation practices, and customer rights. $\mathrm{ADB}$ has been supporting awareness-raising activities and training on efficient water use and good sanitation practices for target communities. Local NGOs are also providing relevant training and campaign materials in various communities. ADB can work with local NGOs and continue to support more awareness campaigns in other communities not yet reached. An integral part of effective WSS services is behavior change in the communities, and this starts with increasing their awareness of water, hygiene and sanitation practices, customer rights and complaint mechanisms, as well as the role of both women and men in water and sanitation. Methods should be explored to reach the most remote areas and most vulnerable groups. Effective practices, such as door-to-door meetings and involvement of youth and community leaders, should also be continued.

\section{Energy}

The government pledged to decrease Georgia's significant energy imports and increase its energy independence to ensure development is supported by a sustainable supply of electricity. The focus is on building a low-carbon energy infrastructure based on hydro, wind, and solar power, as well as exploiting geothermal water resources. ADB is supporting the government to improve its electricity transmission and distribution network, and to enhance energy efficiency through rehabilitating aging assets. Support for regional power transmission enhancement is boosting power system reliability and enhancing energy efficiency. 
Under the current CPS, the focus is on funding the building of new transmission lines to enhance its electricity grid and rehabilitating substations to develop sufficient capacity for the country, with a focus on West and East Georgia-including the Tbilisi metropolitan area and Kvemo Kartli Region. These initiatives brought about reliable electricity supply for local people and created new jobs in the energy sector. Completed projects ${ }^{174}$ are as follows:

- Project Jvari-Khorga, which will increase the reliability of the 220-kilovolt (kV) network of West Georgia;

- Rehabilitation of the Ksani $500 \mathrm{kV}$ and Marneuli $500 \mathrm{kV}$ substations, which increased the reliability of the power supply to Tbilisi and established a power transmission corridor from Ksani to Russ, strengthening Georgia's role as an international energy trading hub in the south Caucasus region;

- Extension of the Substation Marneuli-220, creating an additional power supply to the Eastern part of Georgia; and

- Replacement of an old power transformer in the Menji $220 \mathrm{kV}$ substation to improve energy supply and connect new customers.

ADB supports the Government of Georgia through the State Electrosystem Corporatization and Electricity Market Reforms Program. There are also private sector operations projects in the energy sector in Georgia: the Adjaristsqali Hydropower Project has been carried out since 2014 and it involved the construction and operation of a 185 megawatt run-ofthe-river hydropower plant in southwest Georgia. ADB is also considering financing the Nenskra Hydro Power Project, including construction, operation, and maintenance of a conventional reservoir-type hydropower plant located in the Nenskra and Nakra valleys of northwest Georgia.

Currently, there is no GAP for ADB-funded energy sector projects. However, as highlighted in ADB Gender and Energy Tool Kit, ${ }^{175}$ the multiple gender concerns include the following:

\section{Access and Affordability}

The traditional roles of men and women affect energy consumption and use of natural resources, making a gender analysis of Georgia's context for rural and urban areas vital (footnote 175). Households in regional towns and villages still often rely on wood for heating and cooking. Lack of access to a domestic gas supply means that women (or men ${ }^{176}$ ) are obliged to spend long and exhausting hours cutting wood and lighting fires, rather than in more productive livelihood activities, family welfare, or education. The provision of domestic gas and electricity supplies would dramatically improve the quality of life for many families, but this must be affordable. Energy insecurity and high costs pose serious challenges in the access to energy, especially for poor women. Requirements for connection or user fees without affordable options will neglect the needs of households with female heads and other vulnerable groups.

174 ADB. 2017d. Completion Report: Sustainable Energy. Georgia Resident Mission: Tbilisi.

175 ADB. 2012. Gender Energy Tool Kit: Going Beyond the Meter. Manila. https:/www.adb.org/sites/default/files/ institutional-document/33650/files/gender-toolkit-energy.pdf.

176 Time use studies in Georgia suggest that men spend considerably more time than women gathering fuel for heating and cooking. Footnote 164. 


\section{Promoting Women's Voices in Energy Planning and Implementation}

Women are often primary users of energy, but their decision-making power in the household and communities is usually restricted, reducing their voice in determining spending levels and type of service of clean and renewable energy. Promoting women's voices at these levels through consultation and other methods is vital, as is increasing women's political representation and involvement in energy sector planning. It is important to hear from women what types of energy they prefer, what times they would like to have access to energy if a 24-hour supply is not available, and how they would like to pay for the service. ${ }^{177}$

\section{Equal Opportunities for Employment in Energy}

The ADB-funded initiatives provided employment opportunities in target areas (footnote 174), but efforts are needed to ensure these are extended to women. The energy sector has the potential to offer significant jobs and skills training for both women and men, including in the development, sales, and installation and maintenance of renewable energy sources, such as solar panels.

\section{Safety}

Energy sources that are not clean often affect women and children most acutely. Biomass, such as wood, is the main fuel source for cooking and heating in many poor households in Georgia. Smoke emissions and indoor air pollution from the burning of solid biomass in unventilated spaces can lead to increased diseases and morbidity among poor women and children (footnote 175), so it is vital to ensure clean, affordable energy sources are readily available, and to raise public awareness on the importance of clean energy.

\section{Entry Points for Mainstreaming Gender in the Energy Sector}

Support technical assistance grants that can pave the way for mainstreaming gender in the energy sector. As experience shows, even though many gender concerns are related to energy, it is difficult to mainstream gender into energy projects. Innovative approaches are needed to create entry points for integrating gender in these projects. One possibility is to design a TA to help identify gender issues in the project areas, and to integrate gender actions in the project design. ADB can also design grants linked to energy projects, aimed at empowering women to take advantage of opportunities opened by more reliable power supply. Projects are planned for power transmission network rehabilitation in Georgia, which may include rehabilitation of substations, new household power connections, and provision of more reliable energy sources to the citizens. To help women maximize these interventions' benefits, ADB can provide them with training on establishing energy-based enterprises, becoming technicians in renewable energy such as hydropower or solar energy, or on other skills for employment in energy-related jobs. Lessons can be learned from initiatives in other countries, such as the solar panel technician training for women in Pakistan, aimed to complement energy projects in the country by empowering women to access sustainable energy sources. ${ }^{178}$

Integration of gender analysis and institutionalization of the collection of sexdisaggregated data within the project management systems. Integration of gender analysis in the energy sector is key for identifying different needs of women and men in the sector. During project design, collection of sex-disaggregated data and gender-specific information

177 Interview with the program manager for Gender Equality Projects, UNDP on 21 November 2017, Tbilisi.

178 ADB. 2017e. Sustainable Solutions for Women's Empowerment-Pilot Project: Solar Panel Technician Training for Women in Pakistan. Pakistan: ACTED. Unpublished report. 
can inform the design of project interventions and setting of targets. It is also useful for monitoring project activities and impacts during project implementation. To enable the collection of this data, it is also important for energy agencies and utilities to maintain sex-disaggregated databases of potential and existing customers to capture differences in energy use and needs, payment, and other service-related issues; and to identify personnel's needs and issues.

Promote women's employment and enterprise development in the energy sector. Energy is one of the key sectors for ADB's future operations in Georgia. ADB could consider developing pilot programs to support women entrepreneurs in the energy sector to learn new technologies and start up MSMEs. Initiatives could also include targets for employment of women in the energy sector, not only as meter readers and in customer care, but also as technicians and managers. At the same time, sustaining women's participation in the sector is possible by encouraging female students to take on energy-related technical courses or offering them free courses.

ADB's gender tool kit on energy can provide guidance in mainstreaming gender in the energy sector. The gender tool kit on energy (footnote 175) was published in 2012, but the guidelines are still relevant and useful in addressing gender considerations in energy projects. The tool kit provides detailed discussions on why gender matters in the energy sector; the guiding elements of gender-responsive energy services; key actions in the different ADB project cycles, including identifying gender issues in the initial poverty and social analysis, and conducting a detailed gender analysis during the project design phase; and suggested questions for gender analysis. It also provides suggestions for gender entry points in designing projects in energy subsectors. A summary of the suggested gender outputs is provided in Box 10.

\section{Finance and Public Sector Management}

ADB supported the Government of Georgia's MOF and MOLHSA through the \$250 million Improving Domestic Resource Mobilization for Inclusive Growth Program (IDRMIG), which ran in 2014-2016. ${ }^{179}$ The project objectives were as follows:

1. Reduce debt and improve fiscal risk management, with a focus on reducing fiscal risk related to macroeconomic shocks, financial system stability, debt sustainability, contingent liabilities, and risks arising from state-owned enterprise operations.

2. Enable robust revenue and public expenditure management, through improved tax systems and increased in-house audit capacity.

3. Enhance the generation of domestic savings, with a focus on creating better pension systems, especially for women. Key elements are increasing the value of Universal Pensions in line with inflation, establishing a sustainable private pensions savings system to supplement the universal pension, ${ }^{180}$ and raising public awareness of the benefits of voluntary and mandatory occupational savings.

179 ADB. 2017a. Completion Report: Georgia: Improving Domestic Resources Mobilization for Inclusive Growth Program (IDRMIGP). Tbilisi. In addition, ADB provided related TA for capital market development, pension reforms, public-private partnerships, and public debt management.

180 This measure is designed to enable the long-term sustainability of the pension system, while maintaining a minimum pension as protection against extreme poverty. Noncontributory social pensions, or general social assistance funded by the local, regional, or national government that provides a regular payment with the 


\section{Box 10: Gender Entry Points for Project Designs in Energy Subsectors}

The ADB gender tool kit on energy provides possible gender-inclusive design features and activities that may be included in ADB-supported energy projects. A summary of the genderspecific outputs, under which the design features and activities are discussed, are outlined below:

\section{Policy and Institutional Capacity Development}

- Public consultation on energy policy, with participation by the poor and women.

- $\quad$ Gender-responsive approaches adopted in energy policy or strategy.

- Institutional capacity of energy agencies and utilities built to provide gender-responsive services.

\section{Power Generation, Transmission, and Distribution in Conventional Energy}

- $\quad$ Energy access expanded for poor households.

- $\quad$ Energy-based women's enterprises established and operating.

- Employment for women generated in the energy sector.

- Gender-sensitive user education programs conducted.

- $\quad$ Energy service delivery improved to poor and low-income households.

- Women's involvement as service providers in the energy sector increased.

- Women's participation in local public-private partnership initiatives increased.

- $\quad$ Gender-responsive corporate social responsibility conducted.

\section{Rural Electrification}

- $\quad$ Energy access by rural poor women and men increased and expanded.

- Women's participation in decentralized, community-managed distribution models enhanced.

- Women's energy-based rural entrepreneurship at the cottage and village levels developed.

- $\quad$ Service delivery capacity transferred to rural poor women.

\section{Renewable Energy}

- Access of the poor, rural women and men to renewable energy systems and technologies improved.

- Women trained and employed as service providers in renewable energy systems and technologies.

- $\quad$ Gender mainstreamed in climate mitigation financing schemes.

- Targeted investments provided to maximize gender-equality results of renewable energy.

\section{Energy Sector Development, Energy Efficiency, and Energy Trade}

- $\quad$ Energy efficiency at the household level increased with women as active change agents.

- Poor and vulnerable communities benefited from sustainable energy-efficiency enhancement measures.

- $\quad$ Poor households benefited from energy trade between countries. 


\section{Support the mobilization of private resources for investment through capital market development and enterprise support, including MSMEs.}

Under objective 4, ADB funding was oriented to building the capacity of existing and potential entrepreneurs in business, and to improve their access to funding for MSMEs. Two newly established government agencies received funding as part of the policy-based loan from ADB for enterprise support: the Entrepreneurship Development Agency (EDA) and the Georgia Innovation and Technology Agency (GITA), both under the auspices of MOESD. GITA provides business-related services such as innovation centers and technology parks, and commercial grants for MSMEs. EDA provides beneficiaries with collateral insurance-up to $50 \%$ of the loan amount-and cofinances the annual interest rate of commercial loans for the first 2 years. ${ }^{181}$

A GAP was prepared and successfully implemented for IDRMIG, in line with the project's overall goal to contribute to improved living conditions and employment opportunities for citizens, particularly women (footnote 179).

Key gender issues and concerns for the finance and PSM projects are as follows:

\section{Access and Inclusion}

Gender inequities in pension provision are common in many countries because of women's typically lower income and extended periods of leave from work for maternity. A key performance indicator for the GAP was the inclusion of measures to ensure both women and men are not negatively impacted by pension reforms. The current universal pension favors women because of their longevity and entry into retirement at 60, compared to men at 65 . This was retained and will supplement a private pension scheme into which contributions can be paid up to the age of 70. Although women's income from private pensions may be lower than those of men on average for the reasons outlined above, it is assumed combined pensions will eventually lead to higher living standards for elderly women and men (footnote 179).

Gender responsiveness is an intrinsic aspect of ADB-funded projects for MSME development under the IDRMIG. The GAP set numerical targets for the allocation of funding and training opportunities for female entrepreneurs. This led to positive outcomes for women's economic empowerment (Box 11).

As the case study in Box 11 illustrates, support in the form of accessible, small, and micro bank loans and grants, and tailored business training has proven to be very successful in promoting female entrepreneurship and should be an integral part of any MSME-focused projects. The risk is without such measures, women are less likely to benefit from grant schemes than men. This is because women are often disadvantaged at the start-up stage of businesses due to their

principal aim of providing relief against poverty. ADB and the World Bank classifies this type of pension as Zero Pillar. J. Gadbury and L. Schou-Zibell. 2011. Pensions and Pension Reform in Georgia, ADB Central and West Asia Working Paper. Manila: ADB.

181 Since 2014, a key area for financial support has been MSME development in rural areas, initially in the Western region. Initiatives include a commercial granting scheme, with available grants from GEL5,000 to GEL15,000 $(\$ 1,824-\$ 5,473)$ and technical assistance in the form of training and individual consultations for a year after funds are received. EDA Georgia. 2016. Annual Report. Tbilisi. http://enterprisegeorgia.gov.ge/files/document/1938313 d7f039122cb076f052ed0aef7.pdf. The scheme has been very successful. During the first stage in 2015, there were 7,600 applicants. This number doubled in the second stage when people saw evidence of neighbors and relatives whose businesses benefited from the grants. In 2017, 20,029 applications were received. 


\section{Box 11: Supporting Female Entrepreneurs through a Targeted Approach}

Given the proven economic empowerment benefits of supporting female-headed micro, small, and medium-sized enterprises, gender-responsiveness is an intrinsic aspect of ADB-funded projects in this area, under the Improving Domestic Resource Mobilization for Inclusive Growth Program. The Gender Action Plan required the Entrepreneurship Development Agency (EDA) and the Georgia Innovation and Technology Agency (GITA) to allocate up to $40 \%$ of grants and loans to female entrepreneurs. This amounted to GEL2 million (around \$754.7 million) in 2016 for the EDA alone. The agencies were also required to support innovation and to provide training for existing and potential female entrepreneurs.

There have been clear women's economic empowerment outcomes from the resulting genderresponsive measures. For example, the EDA aimed to create a "level playing field" for those applying for grants. Efforts were made to communicate widely about the schemes through public outreach programs. Both women and men were encouraged to submit their application forms and business ideas, which a committee assesses for feasibility. Short-listed candidates received training, through which they gained the skills to translate these ideas into business plans that included a financial analysis. The plans then went into another competitive process before being selected and funded. The rationale behind this design was to ensure all female and male applicants are equally prepared with the knowledge to draft an effective business plan.

Between 2015 and 2016, 40\% of the EDA's 4,876 total beneficiaries were female entrepreneurs. ${ }^{2}$ Examples of new and existing funded female-owned businesses include an enamel jewelry and souvenir workshop, a bakery, a sewing workshop, a food processing plant, and various cafes and small hotels.

Emerging stories demonstrate the positive impacts for women, their families, and their communities. For example, a Muslim woman living in a mountainous region in the northern part of Georgia borrowed GEL15,000 (around \$5,660) to set up the first guesthouse in the region. Her success inspired other women, who set up similar businesses in the area. In Kakheti, a grant was used to set up a female-only café, which responds to a local need in an area where cultural norms prevent women and men from mixing in public places. ${ }^{b}$

a DA Georgia.2016. Annual Report. Tbilisi.

b Interview with the head of Enterprise, EDA on 14 November 2017, Tbilisi.

Sources: EDA Georgia. 2016. Annual Report. Tbilisi.; Interview with the head of Enterprise, EDA on 14 November 2017, Tbilisi.

lack of access to capital and business training. Those who already have businesses often find it difficult to scale up beyond the microlevel, due to limited financial assets and other factors, such as poor market linkages compared to many men. ${ }^{182}$

Setting gender targets for funding entrepreneurs through financial institutions is an excellent first step to promoting women in business, but they need to be part of a long-term strategy that fosters gender-equitable access. Even when gender quotas are in place, the conditions for commercial grants and loans need to respond to the different situations of women and men. For example, current recipients of the EDA's commercial grants are required to contribute

182 ADB. 2014a. Gender Tool Kit: Micro, Small, and Medium-Sized Enterprise Finance and Development. Manila. 
$20 \%$ of the overall investment. This automatically excludes many poorer Georgian women, who do not own assets such as property or land that they could use to generate the required $20 \%$ capital. Added to these existing constraints, imminent plans to increase the scale of the EDA's grants from GEL15,000 to GEL50,000 $(\$ 5,466-\$ 18,222)$ will orient them more to small and medium businesses rather than the microenterprises women are more likely to own. ${ }^{183}$

Since 2007, ADB's Private Sector Operations has been active in Georgia's finance sector by providing loans to some of the country's largest commercial banks to increase lending to MSMEs. To improve outreach to the regions outside the capital, in 2015, ADB provided a loan and a TA grant to TBC Bank, Finca Bank Georgia, and Credo Microfinance Organization through the Financial Inclusion for Micro and Small Business Growth in Georgia project (classified as having some gender elements). The approved project is aimed at helping the beneficiary banks expand capacity for financing MSMEs and increase their outreach to rural areas, expand advisory services to MSMEs, and increase financial literacy in remote villages. ${ }^{184}$ The loan includes gender entry points on output level to target women through all the service and products offered to MSMEs under the project, including access to financial services and financial literacy and/or capacity development. It is expected that under the project's support, Credo will service at least 114,000 women; Finca Bank Georgia will service at least 36,000 women; and of TBC's trainees (through TBC Academy, one of the innovative models of increasing skills and financial literacy for MSMEs), 1,000 will be women (footnote 184). The focus is to provide services to rural customers and, with this, support diversification into rural areas and secondary towns, and improve access to investment capital for MSMEs and farms.

\section{Entry Points for Mainstreaming Gender in Finance and Public Sector Management}

Support gender mainstreaming initiatives of relevant government agencies. Systematic processes for mainstreaming gender should be introduced in the MOF, MOESD, MOLHSA, GITA, EDA, and other relevant implementing and partners' agencies so gender dimensions are viewed as integral to project success rather than purely a donor requirement. The appropriate policies should be institutionalized to promote a sustainable gender-responsive approach that goes beyond a donor requirement.

Appoint gender specialists or GFPs in relevant agencies. Gender-responsive planning, implementation, and monitoring and evaluation will be better ensured if there is a dedicated person to oversee this. The appointment of gender specialists will facilitate the advancement of gender equality goals in key ministries and agencies. In agencies executing or implementing ADB-supported projects, the appointment of GFPs to focus on the implementation and reporting of gender actions will ensure these are successfully implemented. ADB can provide support to build the capacity of these GFPs in line with the gender policy and other requirements.

183 UN Women 2013. Accessibility of Microfinance Institution Services for Women: Existing Barriers and Opportunities. Tbilisi: UN Women.

184 ADB. 2015b. Report and Recommendation of the President: Financial Inclusion for Micro and Small Business Growth (Georgia) Proposed Loans and Technical Assistance Credo Microfinance Organization, FINCA Bank Georgia and TBC Bank. Manila. 
Design interventions to promote women's entrepreneurship. Support in the form of accessible, small and micro bank loans and grants and tailored business training has been very successful in promoting female entrepreneurship. These should be an integral part of any future ADB or government plans aimed at MSME development. Gender quotas should be promoted as an integral aspect of all MSME business grant and loan schemes to offset male biases. Provisions to increase outreach to poorer and/or ethnic minority women should be put in place.

Increase women's access to finance. Increasing women's access to finance is extensively targeted under the private sector operations in Georgia by setting specific targets for inclusion of women in services and products in the project. The ongoing private sector loan to Finca, Credo, and TBC Bank, for instance, is expected to benefit thousands of women. MFIs, banks, and state financing agencies supporting entrepreneurship, such as the EDA and GITA should continue creating enabling conditions for women to access loans and grants, and to transition out of micro into small and medium-sized enterprises, scale up their businesses, and access markets. Measures should include facilitating access to start-up loans, small and micro loans and grants, and offering business training to potential and existing female grantees.

Produce knowledge products on women's MSMEs. There are many gateways to integrating gender in finance and PSM projects, but it is crucial to fully understand the various options before taking action. Research should be funded and conducted to generate robust evidence on the specific challenges many women face in establishing MSMEs, to guide policy makers (such as MOESD), planners, and project officers in designing more gender-responsive projects and policies. Producing success stories of women entrepreneurs and promoting networking among women in business can demonstrate the valuable contribution they are making, and encourage more women to follow their example.

Government ministries need to ensure efforts to promote women's economic empowerment are not restricted to MSMEs. Initiatives are also needed to ensure women are fully integrated in the mainstream economy through paid employment. This will require the introduction of mandatory compliance with international labor law, and the GE and NonDiscrimination Laws for private and public sector actors, to counter gender discrimination.

Project planners can draw lessons from ADB's tool kit on gender and MSMEs. The gender tool kit on MSMEs (footnote 182) provides useful guidance in designing gender-responsive projects on finance and MSMEs. As with the other tool kits, it includes a detailed discussion on why gender matters in MSMEs. It provides useful guidance in identifying social and gender issues during the concept stage and undertaking gender analysis during the design stage. Finally, it offers entry points that the project team can consider in mainstreaming gender in MSME finance projects. 


\section{Conclusion}

Over the past 2 decades, Georgia made significant progress in gender equality. Advancing women and gender equality is crucial for inclusive growth as Georgia continues to strive to improve socioeconomic development outcomes, and continued efforts are needed to promote equal economic, social, and political participation of women and men. As an integral part of this process, it is important that women's role and contribution to the development of the country and well-being of the society are recognized within Georgia particularly by the Government of Georgia, and other public sector and private sector actors.

To promote enhanced gender equality outcomes, it is vital to ensure women of different groups can exercise their rights, have access to policies meeting their needs, and have an active voice in decision-making at all levels. Although the GE Law and other mechanisms and structures are in place, more efforts are needed to effectively mainstream gender in different sectors. This will also help create more gender awareness and ensure key sectors are aligned to the diverse needs and priorities of the local population and demands of development. To guarantee women's economic participation, the country needs to develop more measures to narrow the gender gap in formal employment and wages, overcome gender stereotypes in education and occupations, and support women's access to finance and business development services. The creation of mechanisms to promote women in political decision-making and improve social protection and health care for all groups is also critical. At the same time, women must be recognized as an important pillar of Georgia's socioeconomic development.

ADB has a strategically important positioning in Georgia and should, therefore, continue to use its leverage to contribute to the wider advancement of women and gender equality. Enhancing women's involvement in the infrastructure sector and in urban development and energy can help significantly improve the participation and consideration of the needs of the diverse groups of people who should benefit from development interventions. Approaches such as promoting women in MSMEs, enabling women to enter highly paid formal sector employment, and adopting gender-sensitive policies and programs can largely facilitate women's economic empowerment and advancement. Georgia is at an important stage of defining its development agenda, and institutionalizing gender equality at different levels of governance is essential for achieving inclusive socioeconomic approaches and outcomes. Georgia's ambition to become a regional hub provides a critical foundation for ADB to show leadership in mainstreaming gender across a wide range of sectors, policies, and programs. 


\section{Summary of Recommendations and Entry Points for Gender Mainstreaming in Key Sectors}

\section{Transport (Including Urban Transport)}

- Ensure that women's needs, issues, and preferences are taken into account during project planning and implementation.

- Promote sex-disaggregated data collection in project monitoring mechanisms and in data collections systems of executing agencies and implementing agencies.

- Integrate concrete measures to address social risks associated with transport projects.

- Explore opportunities for increasing women's employment and economic empowerment in the transport sector.

- Support awareness-raising and capacity-building activities for the government and sector partners.

- Adopt contextually relevant good practices and recommendations from ADB's transport initiatives and tool kits.

- Support TA projects that can potentially open entry points for mainstreaming gender in the transport sector.

\section{Water and Other Urban Services}

- Ensure inclusion of all groups of the population, including women, during consultations and stakeholder meetings.

- Increase women's access to training and employment opportunities in the sector.

- Continue women-targeted awareness campaigns on efficient water use, better sanitation practices, and customer rights.

- Support the efforts of executing and implementing agencies in strengthening their sex-disaggregated data collections and analysis systems.

- Support initiatives to build gender mainstreaming capacity of the executing agency.

- Support the development of guidelines and provide capacity building on gendersensitive urban planning.

\section{Energy}

- Promote the integration of gender analysis and institutionalize the collection of sexdisaggregated data within project management systems.

- Increase women's voice in decision-making in the energy sector.

- Promote women's employment and enterprise development in the energy sector.

- Support TA grants that can pave the way for mainstreaming gender in the energy sector.

- ADB's gender tool kit on energy can provide guidance in mainstreaming gender in the energy sector. 


\section{Finance}

- Support gender mainstreaming initiatives of relevant government agencies.

- Appoint gender specialists or GFPs in relevant agencies.

- Design interventions to promote women's entrepreneurship.

- Increase women's access to finance through the EDA, GITA, MFIs, and banks. In particular, strengthen rural women's access to finance, training, and business development services.

- Produce knowledge products on women's MSMEs, including policies, research, and success stories to promote women's entrepreneurship and access to employment.

- Project planners can draw lessons from ADB's tool kit on gender and MSMEs.

\section{Knowledge and Skill Building}

- Gender analysis in the demands of the labor market can be informative to meet the gaps in education and skill development.

- Promote a gender-balanced pool of students for the fields of study in high demand in the country.

- Support the creation of platforms for women to be involved in knowledge sharing at the regional level.

- Establish better links with academia and civil society for more accountability, cooperation, and visibility of ADB.

- Support the collection and analysis of sex-disaggregated data in various sectors and fields.

- Build knowledge for gender analysis in various ADB sectors. 


\section{References}

ADB. 2017a. Completion Report: Improving Domestic Resource Mobilization for Inclusive Growth Program (Georgia). Tbilisi: Georgia Resident Mission.

ADB. 2017b. Country Operations Business Plan Georgia:2018-2020. Manila.

ADB. 2017c. Completion Report: Completed Projects in WSS Sectors under USIIP Funding. Georgia Resident Mission: Tbilisi. Unpublished report.

ADB. 2017d. Completion Report: Sustainable Energy. Georgia Resident Mission: Tbilisi.

Unpublished report.

ADB. 2016a. Key Indicators for Asia and the Pacific. https://www.adb.org/sites/default/files/ publication/357006/geo.pdf.

ADB. 2016b. Project Administration Manual, Georgia: Secondary Roads Improvement Project.

ADB. 2016c. Georgia: Livable Urban Areas: Integrated Urban Plans for Balanced Regional Development, Technical Assistance Report. Manila.

ADB. 2015a. A Safe Public Transportation System for Women and Girls. Policy Brief. Manila.

ADB. 2015b. Report and Recommendation of the President: Financial Inclusion for Micro and Small Business Growth (Georgia) Proposed Loans and Technical Assistance Credo Microfinance Organization, FINCA Bank Georgia and TBC Bank. Manila.

ADB. 2014a. Gender Tool Kit on Micro, Small and Medium-Sized Enterprise Finance and Development. Manila.

ADB. 2014b. Georgia Country Partnership Strategy 2014-2018. Tbilisi: Georgia Resident Mission. https://www.adb.org/documents/georgia-country-partnershipstrategy-2014-2018.

ADB. 2014c. Georgia Transport Sector Assessment, Strategy and Road Map. Manila.

ADB. 2013a. Gender and Transport Tool Kit: Maximizing the Benefits of Mobility for All. Manila.

ADB. 2013b. Gender Equality and Women's Empowerment Operational Plan, 2013-2020:

Moving the Agenda Forward in Asia and the Pacific. Manila.

ADB. 2012. Gender Energy Tool Kit: Going Beyond the Meter. Manila.

ADB. 2010a. Sustainable Transport Initiative-Operational Plan. Manila. https://www.adb .org/documents/sustainable-transport-initiative-operational-plan.

ADB. 2010b. Report and Recommendation of the President to the Board of Directors: Proposed Multitranche Financing Facility to Georgia for the Sustainable Urban Transport Investment Program. Manila.

ADB. 2003. Gender and Development: Framework, Policies, and Strategy. Manila. 
ADB. 2006. Gender Checklist: Water Supply and Sanitation. Manila.

I. Bakhtadze. 2012. Key Features of Georgian Women Entrepreneurs Recent Success: Why it is Important for Georgia to Share US Experience. Paper for 7th Silk Road International Conference "Challenges and Opportunities of Sustainable Economic Development in Eurasian Countries.” 24 May 2012-26 May 2012. Tbilisi.

M. Barkaia. 2018. "The Country of the Happiest Women”?: Ideology and Gender in Soviet Georgia. In M. Barkaia and A. Waterson, eds. Gender in Georgia: Feminist Perspectives on Culture, Nation and History in the South Caucasus. New York: Berghahn Books.

Z. Burt et al. 2016. Towards Gender Equality through Sanitation Access. Discussion Paper No. 12. UN Women. New York.

Caucasus Research Resource Center. 2014. NDI: Women's Political Participation in Georgia. Fact sheet. Tbilisi.

CEDAW Committee. 2014. Alternative Report to the United Nations Committee on the Elimination of Discrimination against Women (CEDAW), Concerning Women's Rights and Gender Issues in Georgia. Tbilisi.

J. Charita and M. Tokmazishvili. 2009. Gender Dimensions of the Financial Policy of Georgia. Tbilisi: UNDP/SIDA.

C. Chkheidze. 2018. Women's Political Representation in Post-Soviet Georgia. In M. Barkaia and A. Waterson, eds. Gender in Georgia: Feminist Perspectives on Culture, Nation and History in the South Caucasus. New York: Berghahn Books.

M. Chitashvili et al. 2010. National Research on Domestic Violence against Women in Georgia. Fountain: Tbilisi.

M. Das Gupta. 2015. "Missing Girls" in the South Caucasus Countries: Trends, Possible Causes, and Policy Options. Policy Research Working Paper 7236. Washington, DC: World Bank.

E. Duban. 2010. Gender Assessment, USAID/Georgia. Tbilisi: USAID. http://pdf.usaid.gov/ pdf_docs/Pnads884.pdf.

N. Dudwick. 2015. "Missing Women" in the South Caucasus: Local Perceptions and Proposed Solutions. Report 94705. Washington, DC: World Bank.

EDA Georgia. 2016. Annual Report.

European Centre for Minority Development in Georgia. 2013. European Needs Assessment of Ethnic Minority Women in Georgia. Tbilisi.

EU Special Advisor on Constitutional and Legal Reform and Human Rights in Georgia. 2013. Georgia in Transition, Report on the Human Rights Dimension: Background, Steps Taken and Remaining Challenges: Assessment and Recommendations by Thomas Hammarberg. Tbilisi: EU/PDO.

J. Gadbury and L. Schou-Zibell. 2011. Pensions and Pension Reform in Georgia. ADB Central and West Asia Working Paper. Manila: ADB.

Gender Equality Council of Georgia and UNDP. January 2018. Georgia: Barriers and Recommendations (1 and 2). Tbilisi: Parliament of Georgia. 
Georgia-Beijing + 20. 2014. National Review of the Implementation of the Beijing Declaration and Platform for Action.

T. Goltz. 2009. Georgia Diary: A Chronicle of War and Chaos in the Post-Soviet Caucasus. London, UK: Routledge.

Government of Georgia. 2014. Socio-Economic Strategy of Georgia “Georgia 2020.” https:// www.adb.org/sites/default/files/linked-documents/cps-geo-2014-2018-sd-01.pdf.

C. Guilmoto and S. Tafuro. 2017. Sex Ratio at Birth in Georgia: An Overview Based on the 2014 General Population Census Data. Tbilisi: UNFPA and Geostat.

C. Guilmoto. 2015. Gender-Biased Sex Selection in Georgia: Context, Evidence and Implications. Tbilisi: UNFPA, UNDP, and UN Women.

N. Gvianishvili. 2018. Being Transgender in Georgia. In M. Barkaia and A. Waterson, eds. Gender in Georgia: Feminist Perspectives on Culture, Nation and History in the South Caucasus. New York: Berghahn Books.

N. Gvianishvili. 2012. Transgender Persons in Georgia. In Situation of LGBT Persons in Georgia. Tbilisi: Women's Initiatives Supporting Group.

Government of Georgia. 2018. Prime Minister Presents Education Reform Vision at Ikalto Monastery Complex. http://gov.ge/print.php?gg=1\&sec_id=497\&info_ $\mathrm{id}=67853$ \&lang_id=ENG.

Inter-Parliamentary Union. 2017 Women in Politics. https:/www.ipu.org/resources/ publications/infographics/2017-03/women-in-politics-2017.

Inter Parliamentary Union. 2016. Women in Parliament in 2016: This Year in Review. http://archive.ipu.org/pdf/publications/WIP2016-e.pdf.

Japaridze, E. et al. 2016. Implementation of Gender Policy in Georgia: 2016. Progress Report on National Action Plan of 2014-2016 for the Implementation of Gender Equality Policy in Georgia. http://www.parliament.ge/en/ajax/downloadFile/72000/Gender Equality_NAP_report_2016_ENG_Edited_Final_July_2017.

Japaridze, W. et al. 2013. Gender Attitudes and Perceptions among Young People in Georgia. Tbilisi: Gender Centre for Social Studies Gender Equality Programme.

Javakhishvili, N. and N. Buthsashvili. 2018. Domestic Violence in Georgia: State and Community Responses, 2006-2015. In M. Barkaia and A. Waterson, eds. 2018. Gender in Georgia: Feminist Perspectives on Culture, Nation and History in the South Caucasus. New York: Berghahn Books.

I. Khomeriki et al. 2012. Gender Equality Issues in Studying Social Sciences: Gender Analysis of Textbooks. Tbilisi: Centre for Civil Integration and Inter-Ethnic Relations.

N. Kuprashvili. 2010. Georgia Combating Violence in the Home. Tbilisi: Institute for War \& Peace.

C. Moser. 1993. Gender Planning and Development: Theory, Practice and Training. London, UK: Routledge.

National Statistical Office of Georgia. 2016. Gender Statistics. http://www.geostat.ge/cms/ site_images/_files/english/Gender\%20Statistics.pdf. 
National Statistical Office of Georgia. 2017. Men and Women in Georgia: Statistical Publication. http://www.geostat.ge/cms/site_images/_files/english/health/ W\&M\%20in\%20ENG_2017.pdf

National Statistical Office of Georgia. 2017. Employment and Unemployment: Economic Status by Sex. Tbilisi.

National Center for Disease Control and Health. 2012. Reproductive Health Survey, Georgia 2010: Final Report. Tbilisi: NCDC.

A. Nussberger. 2013. South Ossieta. Oxford Public International Law. Oxford, England.

V. Papava. 2013. Reforming of the Post-Soviet Georgia's Economy in 1991-2011. Tbilisi: Centre for Applied Economic Studies.

V. Papava. 2006. The Political Economy of the Rose Revolution, In Orbis 50 (4). Elsevier.

A. Petersen. 2008. The 1992-3 Georgia-Abhazia War: A Forgotten Conflict. In Caucasian Review of International Affairs Vol. 2 (4). pp. 9-21.

R. Pkhakadze and T. Jamaspishvili. 2007. Domestic Violence, a Burning Issue in Georgia. In Gender and Development 15 (1).

Public Defenders Office of Georgia (PDOG). 2015. Violence against Women and Domestic Violence in Georgia, Special Report. Tbilisi: PDOG.

PDOG. 2016. Women's Rights and Gender Equality. Tbilisi.

PDOG. 2017. Special Report on the Rights of Women and Children in Conflict-Affected Region: Review of 2014-2016. Tbilisi.

H. Reeves and S. Baden. 2000. Gender and Development: Concepts and Definitions. Brighton, UK: Institute of Development Studies.

A. Rekhviashvili. 2018. Tracing the LGBT Movement in the Republic of Georgia: Stories of Activists. In M. Barkaia and A. Waterson, eds. Gender in Georgia: Feminist Perspectives on Culture, Nation and History in the South Caucasus. New York: Berghahn Books.

T. Sabedahvili. 2011. The Identification and Regulation of Domestic Violence in Georgia (1991-2006). PhD dissertation. Budapest: Central European University.

T. Sabedashvili. 2018. The Domestic Violence Challenge to Soviet Women's Empowerment Policies. In M. Barkaia and A. Waterson, eds. Gender in Georgia: Feminist Perspectives on Culture, Nation and History in the South Caucasus. New York: Berghahn Books.

E. R. Scott. 2007. Georgia's Anti-Corruption Revolution. In L. Shelly et al. Organized Crime and Corruption in Georgia. New York: Routledge.

R. Shahrashoub and C. Miller. 1995. From WID to GAD: Conceptual Shifts in the Women and Development Discourse. United Nations Research Institute Occasional Paper Series. United Nations Research Institute for Social Development.

L. Shelly et al. 2007. Organized Crime and Corruption in Georgia. New York: Routledge.

N. Sumbadze. 2018. Gender Equality: Still a Disputed Value in Georgian Society. In M. Barkaia. and A. Waterson, eds. Gender in Georgia: Feminist Perspectives on Culture, Nation and History in the South Caucasus. New York: Berghahn Books. 
N. Sumbadze. 2008. Gender and Society Georgia. Tbilisi: SIDA/UNDP.

L. Tsuladze. 2010. Behind the Scenes: Qualitative Research Results. In M. Chitashvili et al., eds. National Research on Domestic Violence in Georgia. Tbilisi: Fountain.

UN Women. 2013. Accessibility of Microfinance Institution Services for Women: Existing Barriers and Opportunities. Tbilisi: UN Women.

UN Women. 2014. Study on Needs and Priorities of IDPs and Conflict-Affected Women and Girls. Tbilisi.

UN Women. 2016a. No One Left Behind: Lessons Learned from the Grassroots Mobilisation of Women in Georgia. Tbilisi.

UN Women. 2016b. Gender Assessment of Agriculture and Local Development Systems. Tbilisi.

UN Women and National Statistical Office. 2017. National Study on Violence against Women: Summary Report. Tblisi.

Women's Information Center. 2014. CEDAW Shadow Report (Alternative Report to CEDAW Concerning Women's Rights and Gender Issues in Georgia). Tbilisi: WIC.

World Economic Forum. 2016. The Global Gender Gap Report. http://www3.weforum.org/ docs/GGGR16/WEF_Global_Gender_Gap_Report_2016.pdf.

World Bank Group. 2017. Gender-Based Violence in Georgia: Links among Conflict, Economic Opportunities, and Services. Washington, DC: World Bank.

World Bank Group. 2016. Georgia Country Gender Assessment, Poverty and Equity Global Practice. http://documents.worldbank.org/curated/en/733891487232457573/ pdf/112838-WP-P157626-Georgia-CGA-2016-final-PUBLIC.pdf.

World Bank. 2011. World Development Report 2012: Gender and Development. Washington, DC: World Bank.

World Bank. 2015. Gender at a Glance: Georgia. http://documents.worldbank.org/curated/ en/404201467993235447/pdf/100410-BRI-GAAG-GEO-041315-PUBLICBox393223B-ADD-SERIES-Europe-and-Central-Asia-ECA-gender-at-a-glance.pdf.

C. Zampas et al. 2018. Human Rights in the Context of Sexual and Reproductive Health and Well-Being in Georgia: Country Assessment. Tbilisi: PDOG. 


\section{APPENDIX \\ List of Key Informants}

\section{Implementing Agencies and Government Departments}

Otar Antia, head of Enterprise Development Department, Enterprise Development Agency

Georgia (Enterprise Georgia)

Nona Chichinadze, gender specialist, Municipal Development Fund

Sopo Japaridze, assistant to the Prime Minister on Human Rights and Gender Equality Issues

Tinatin Lebanidze, head of International Procurement and Donor Relations Department, United Water Supply Company of Georgia

Luka Mosashvili, ADB projects officer, Department of Roads

Tisnami Sabanadze, head of Economic Policy and Analysis Department, Ministry of Economy and Sustainable Development

Zaza Simonia, deputy chairman, Roads Department of Georgia, Ministry of Regional

Development and Infrastructure

Tea Sonishvili, gender focal point, Ministry of Economy and Sustainable Development

Dimitri Tskitishvili, member of Parliament and chair of Gender Equality Council

Ann Tsurtsumia-Zurabishvili, Gender Equality Council coordinator

\section{Multilateral Agencies and Nongovernment Organizations}

Mariam Bandeladze, component manager, United Nations Population Fund

Sophia Georgieva, World Bank

Teona Kupunia, program manager, National Democratic Institute

Ann Inasaridze, Caucasus Environmental NGO Network

Khatuna Madurashvili, senior manager, Regional GBV Program Middle East, North Africa, and Caucasus, Care

Marka Meshveliani, program manager for Gender Equality Projects, United Nations

Development Programme

Elene (Maya) Rusetskaia, director, Women's Information Fund

Tamar Sabedashvili, National Program Office, UN Women

Marina Tabukashvili, general director, Taso Foundation 


\section{$A D B$}

Yesim Elhan-Kayalar, Georgia country director

Michel Van der Auwera, unit head, Project Administration Unit

Georgi Kiziria, senior project officer for Transport, Energy, and Private Sector

Tea Papuashvili, associate project analyst

Ketevan Chkheidze, gender specialist and consultant

Mookiah Thiruchelvam, urban development specialists, Urban Development and Water Division

\section{Focus Group Discussions}

Water Supply Company's staff and female customers in Poti

Municipal Development Fund

Roads Department of Georgia 


\section{Georgia Country Gender Assessment}

This publication provides a gender analysis of socioeconomic areas and issues in Georgia and relevant operations of the Asian Development Bank. Georgia has advanced its gender equality agenda but progress is still needed to achieve some key gender equality outcomes. Georgia continues to fare poorly on key global indicators of economic status and political voice. Violence against women also remains a pervasive issue in the country, affecting one in seven women. Some gender-responsive practices were identified, but significant gaps and missed opportunities for women's empowerment and inclusion were also identified. Recommendations include the need for capacity-building on gender mainstreaming, increased human and financial resources, and an improved evidence base.

\section{About the Asian Development Bank}

ADB is committed to achieving a prosperous, inclusive, resilient, and sustainable Asia and the Pacific, while sustaining its efforts to eradicate extreme poverty. Established in 1966, it is owned by 67 members48 from the region. Its main instruments for helping its developing member countries are policy dialogue, loans, equity investments, guarantees, grants, and technical assistance.

$\mathrm{ADB}$

\section{ASIAN DEVELOPMENT BANK}

6 ADB Avenue, Mandaluyong City 1550 Metro Manila, Philippines

www.adb.org 